'REAL TIME' EARLY WARNING INDICATORS FOR COSTLY ASSET PRICE BOOM/BUST CYCLES

\title{
A ROLE FOR GLOBAL LIQUIDITY
}

by Lucia Alessi

and Carsten Detken 


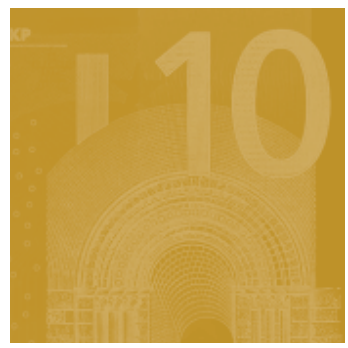

\title{
WORKING PAPER SERIES
}

NO 1039 / MARCH 2009

\author{
'REAL TIME' EARLY WARNING \\ INDICATORS FOR COSTLY ASSET \\ PRICE BOOM/BUST CYCLES
}

A ROLE FOR GLOBAL LIQUIDITY I

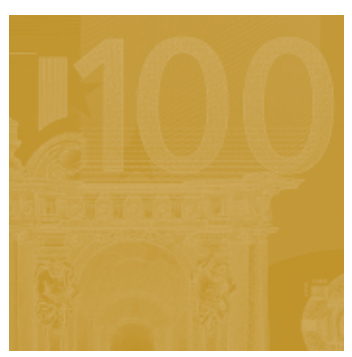

by Lucia Alessi ${ }^{2}$

and Carsten Detken ${ }^{3}$

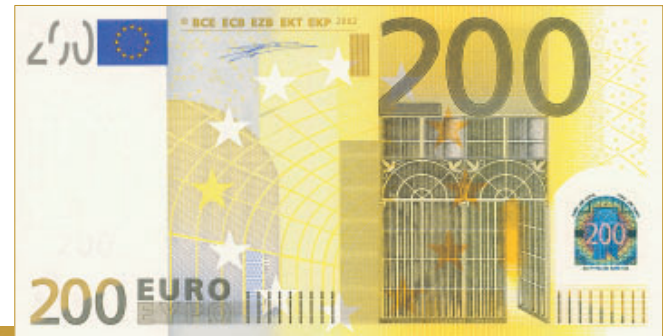

In 2009 all ECB

This paper can be downloaded without charge from http://www.ecb.europa.eu or from the Social Science Research Network electronic library at http://ssrn.com/abstract_id=1361492.

I Both authors thank participants at the EABCN and CREI Conference on Business Cycle Developments, Financial Fragility, Housing and Commodity Prices in Barcelona, 2 I-23 November 2008 and in particular Benoît Mojon, as well as an anonymous referee of the WP series for very helpful comments. All remaining errors are our own. The views expressed in this paper are those of the authors and do not necessarily reflect those of the European Central Bank.

2 Directorate General Statistics, European Central Bank, Kaiserstrasse 29, D-603II Frankfurt am Main, Germany; e-mail: lucia.alessi@ecb.europa.eu; the paper has been written while being a consultant in the Directorate General Research. 3 Directorate General Research, European Central Bank, Kaiserstrasse 29, D-603II Frankfurt am Main, 
(C) European Central Bank, 2009

Address

Kaiserstrasse 29

60311 Frankfurt am Main, Germany

Postal address

Postfach 160319

60066 Frankfurt am Main, Germany

Telephone

+496913440

Website

http://www.ecb.europa.eu

\section{Fax}

+496913446000

All rights reserved.

Any reproduction publication and reprint in the form of a different publication, whether printed or produced electronically, in whole or in part, is permitted only with the explicit written authorisation of the ECB or the author(s).

The views expressed in this paper do not necessarily reflect those of the European Central Bank

The statement of purpose for the ECB Working Paper Series is available from the ECB website, http://www.ecb.europa. eu/pub/scientific/wps/date/html/index. en.html

ISSN 1725-2806 (online) 


\section{CONTENTS}

Abstract

Non-technical summary

1 Introduction

2 'Real time' signalling approach and risk aversion

3 Identication of asset price booms

4 Data and indicators

5 Results

6 Predicting the recent boom/bust episode

7 Conclusions

References

Annex

European Central Bank Working Paper Series 


\begin{abstract}
We test the performance of a host of real and financial variables as early warning indicators for costly aggregate asset price boom/bust cycles, using data for 18 OECD countries between 1970 and 2007.

A signalling approach is used to predict asset price booms that have relatively serious real economy consequences. We use a loss function to rank the tested indicators given policy makers' relative preferences with respect to missed crises and false alarms. The paper analyzes the suitability of various indicators as well as the relative performance of financial versus real, global versus domestic and money versus credit based liquidity indicators.

We find that global measures of liquidity are among the best performing indicators and display forecasting records, which provide useful information for policy makers interested in timely reactions to growing financial imbalances, as long as aversion against type I and type II errors is not too unbalanced. Furthermore, we explore out-of-sample whether the most recent wave of asset price booms (2005-2007) would be predicted to be followed by a serious economic downturn.
\end{abstract}

Keywords: Early Warning Indicators, Signalling Approach, Leaning Against the Wind, Asset Price Booms and Busts, Global Liquidity.

JEL Classification E37 · E44 E E51. 


\section{Non-technical summary}

The recent financial turmoil has intensified the debate on whether central banks should use policy rates in the build-up to financial imbalances in order to ward against booming asset price developments. The objective would be to dampen the degree of real and financial overheating both through the standard transmission mechanism and by forcefully signalling to the public the central bank's view about growing financial imbalances. As a result, the central bank might more effectively maintain financial and price stability in the medium to long run. So far, one of the main counter-arguments to implement 'leaning against the wind' monetary and/or macro-prudential policies has been that the data do not provide a reliable signal to act in real time. This is particularly important as it is impossible to identify an asset price bubble with certainty and many booms simply burst without creating larger problems for the real economy. Thus policy-makers would need reliable indicators which identify harmful boom/bust cycles with sufficient lead time.

We report some evidence based on the signalling approach developed by Kaminsky, Lizondo and Reinhart [1998] which is often used to predict foreign exchange and banking crises. A warning signal is issued when an indicator exceeds a certain threshold, e.g. a particular percentile of its distribution.

We first define aggregate asset price booms (based on a price index consisting of weighted real private property, commercial property and equity prices) across 18 OECD countries using quarterly data between 1970 and 2007. Asset price booms are identified for each country and a high-cost boom is defined as a boom that is followed by a three-year period, in which overall real GDP growth was at least three percentage points lower than potential growth.

We test a set of five real variables and 13 financial variables, and up to six different transformations of these variables - overall 89 indicators - to ascertain their suitability as early warning indicators for high-cost asset price boom/bust cycles within a six-quarter forecasting horizon.

We extend the performance evaluation of warning indicators by deriving a measure of use- 
fulness for the policy maker, which depends on her relative aversion against missed crises as opposed to false alarms. Furthermore, in this paper the performance of the indicators is based on signals as they would have been obtained in the period they refer to.

The results reveal that over the average of all countries and in the case of many preference parameters the global M1 gap and the global private credit gap are the best early warning indicators. Interestingly, the best indicators are global variables, which can be explained by the fact that asset price boom/bust cycles are largely international phenomena. The best indicator for a policy maker who is only slightly more averse against false alarms than missed crises, is the global private credit gap. In terms of the absolute performance using the optimal $70 \%$ percentile across countries predicted on average $95 \%$ of high-cost booms by issuing a signal in at least one of the six preceding quarters. The share of correct signals as a percentage of periods in which a high-cost boom actually developed within the following six quarters is $82 \%$. The share of false alarms as a percentage of periods in which no high-cost boom followed is $32 \%$ and the average lead time for the first warning signal is 5.5 quarters.

The performance of the liquidity indicators can be further improved by defining a signal to be issued only when two indicators simultaneously exceed their respective thresholds, which, in particular, reduces the proportion of false alarms.

Finally, we are interested in confirming whether the asset price booms, which started in the mid-2000s, are predicted to be high-cost booms. In order to do so, we counted the warning signals issued by the two best indicators in the 11 quarters between the first quarter of 2005 and the third quarter of 2007. With respect to the global private credit gap, the optimal $70 \%$ threshold was breached in seven quarters, thus showing a clear and persistent warning signal. Global M1, however, provided no signal at its optimal 90\% threshold.

The results show that it is possible to identify early warning indicators for individual countries and also groups of countries which perform reasonably well. Nevertheless, as recent events show, indicators that have historically performed nearly equally well can provide different messages. Signals obtained should thus be interpreted carefully and should only be regarded as one of several inputs in the information set of decision-makers. 


\section{Introduction}

The recent financial crisis has intensified the debate whether changes in regulatory policies and monetary policy should be actively used in the building up phase of financial imbalances in order to contain asset price booms and bubbles. With respect to monetary policy, the pertinent question is whether central banks should 'lean against the wind' of a sustained and swift upward movement in asset prices, which is considered unsustainable and bears the risk of a possibly abrupt future correction. An asset price bust can have serious negative consequences for the real economy and in case of financial instability it will complicate the central bank's task to maintain price stability. Indeed, in such a situation uncertainty about the prevailing transmission mechanism would increase and in the worst case transmission could get seriously impaired.

It is worth highlighting three major knowledge gaps with respect to the current debate on 'leaning against the wind' policies.

First, it is not exactly clear through which channel tightening monetary policy in times of excessively low risk aversion would be successful in dampening an asset price boom. Recently though more and more empirical evidence as well as theoretical arguments have been produced directly or indirectly supporting the 'leaning against the wind' proposition. There is growing empirical evidence on the existence of a risk-taking channel. ${ }^{1}$ Banks seem to take on more risk in times of persistently low interest rates even after controlling for the cyclical net worth of borrowers and the endogeneity of monetary policy. ${ }^{2}$ Furthermore, it has been shown that small increases of the policy rate could possibly break herding behavior of private investors, if the policy move is interpreted as a credible signal of the central bank's information/analysis on the state of the economy. ${ }^{3}$ Another potentially important channel in favor of a 'leaning against the wind' policy is the increased symmetry in central banks' responses with respect to boom and bust periods, which would reduce moral hazard. ${ }^{4}$

\footnotetext{
${ }^{1}$ While Rajan [2005] introduced the channel, Borio and Zhu [2007] coined the term.

${ }^{2}$ See Jiménez et al. [2007].

${ }^{3}$ See Loisel et al. [2008]. Hoerova et al. [2008] explore a similar channel.

${ }^{4}$ See Diamond and Rajan [2008].
} 
Second, it has not yet been convincingly shown that asset price boom and bust cycles are under all conditions bad for the long run growth path of the economy. There is some evidence that the increase in collateral value during asset price booms alleviates financing constraints as long as the boom lasts, which could more than compensate for the recession during the bust phase. This evidence though has only been provided for middle income countries and is unlikely to hold for countries with well developed financial markets. ${ }^{5}$ But the general issue how much financial instability should be accepted in order to best exploit the long run growth potential remains an open question. The answer is likely to be country and time dependent.

Third, there is some scepticism in the academic and central banking community whether asset price bubbles can be identified in real time in order to allow policy makers to react. ${ }^{6}$ On the other hand, it might not be necessary to come to a firm conclusion whether particular asset price movements are fundamentally justified or not in the first place. ${ }^{7}$ Adalid and Detken [2007] pursue such an agnostic approach and derive in sample characteristics of costly asset price booms, where booms are simply defined as unusually swift and persistent asset price increases compared to trend. ${ }^{8}$ This paper provides new evidence that early warning indicators exist which signal costly asset price developments in 'real time' and with sufficient lead to react.

This paper provides no further arguments with respect to the debate to which degree monetary policy or regulatory and supervisory measures are suited to address growing financial imbalances - most likely they will have to complement each other in the sense that monetary policy will be the backup-solution to lacking or inefficient regulatory and supervisory action. But in both cases, reliable and timely warning signals are a necessary requirement for any policy aiming at tightening the screws during pre-boom and early boom periods.

The timeliness of the topic of early warning indicators with respect to asset price cycles is also revealed by the ongoing discussions for a new international monetary and financial

\footnotetext{
${ }^{5}$ See Rancière et al. [2008].

${ }^{6}$ Kohn [2008] mentions this as one of the key challenges casting doubt on the feasibility of 'leaning against the wind'.

${ }^{7}$ See Adrian and Shin [2008a].

${ }^{8}$ Borio and Lowe [2002], [2004] and Borio and Drehmann [2008] provide evidence that detrended asset prices can serve as indicators for banking crises.
} 
architecture. The informal meeting of European Heads of State or Government on 7 November, 2008 in Brussels concluded that "an early warning system must be established to identify upstream increases in risks or the formation of bubbles in the valuation of different economic assets".

More precisely, this paper aims at answering four questions. First, do we have indicators, which when used in the simplest early warning indicator (signalling) approach, provide useful information to decision makers in a timely manner? We attempt to answer this question using historical data but in an as realistic as possible 'real-time' experiment. Second, are financial or real indicators more useful in predicting costly asset price cycles? Third, considering the information content in financial variables, are global or domestic indicators better suited to provide early warning signals? And fourth, do money or credit based liquidity indicators show a superior performance in predicting costly asset price boom/bust cycles?

With respect to deciding on what is an acceptable performance for an indicator we go beyond the standard way of searching for indicators with noise to signal ratios below 1, but take into account the preferences of policy makers, i.e. their relative aversion with respect to type I and type II errors. ${ }^{9}$ Our approach results in a much tougher criterion to assess the usefulness of the indicators.

Section 2 introduces the signalling approach as in Kaminsky et al. [1998] and applied to banking crises in Borio and Lowe [2002],[2004] and Borio and Drehmann [2008] but adds some further elements of 'real time' evaluation and an alternative measure evaluating the usefulness of indicators.

In Section 3 we outline the method to define the events to be predicted, which are costly aggregate asset price booms. The asset price index consists of weighted real private property, commercial property, and equity prices for 18 OECD countries using quarterly data between 1970 and 2007 provided by the Bank for International Settlements.

\footnotetext{
${ }^{9}$ Bussière and Fratzscher [2008] to our knowledge is the only study taking a similar loss function based approach.
} 
Section 4 describes the data set, i.e. 18 real and financial variables and the transformations we apply to derive overall 89 indicators, which we evaluate with respect to their forecasting performance. In particular, we include variables which have previously been found to explain real effects following asset price boom/bust cycles. ${ }^{10}$

Section 5 presents the results of the forecast evaluation and addresses the four questions raised above. We also investigate to which degree joint indicators improve the performance over single indicators as in Borio and Lowe [2002].

Section 6 uses the best indicators to analyze out-of-sample whether the most recent wave of asset price booms in the 2005-2007 period had been predicted to be high cost, as they cannot yet be classified as high or low cost on the basis of post boom GDP data. ${ }^{11}$

Section 7 concludes. The results reveal that over the average of all countries and for a wide range of preference parameters the global private credit gap and the global M1 gap are the best early warning indicators. ${ }^{12}$ The forecast performance is such that the approach should provide value added to policy makers contemplating leaning against growing financial imbalances either by means of monetary or macro-prudential policies - as long as their preferences are relatively balanced between missed crises and false alarms. With respect to the latest boom wave around 2005-2007, the global private credit gap has been sending persistent warning signals while the global money (M1) gap has not.

\section{2 'Real Time' Signalling Approach and Risk Aversion}

We use the signalling approach as described in Kaminsky et al. [1998] and Kaminsky and Reinhart [1999], which has frequently been employed to predict foreign exchange and banking crises, but to our knowledge not for predicting asset price boom/bust episodes. While most banking crises are preceded by asset price cycles, not all asset price cycles lead to banking crises. The definition of a banking crisis is also less straight-forward as it might appear at first

\footnotetext{
${ }^{10}$ See Adalid and Detken [2007].

${ }^{11}$ Borio and Drehmann [2008] evaluate the performance of their indicators with respect to the 2007/09 banking crisis and show how it depends on the definition of banking crisis.

${ }^{12}$ Global gaps refer to detrended ratios to GDP with country weights derived from PPP adjusted GDP shares.
} 
sight. For example, one could argue whether a banking crisis should be characterized by the failure of at least one bank or already by the provision of central bank emergency liquidity assistance and/or a government bail-out or the provision of government guarantees for at least one bank. Some banking crises have large, some low GDP costs, but most importantly there are relatively few banking crises around. The advantage of studying asset price cycles is that there is a sufficient number of them and one can also explore the characteristics of the group of relatively more costly compared to the less costly cycles.

The signalling approach is one of the two threshold approaches using a binary explanatory variable. The other approach is the discrete-choice (probit/logit) model. ${ }^{13}$ In the signalling approach a warning signal is issued when an indicator exceeds a threshold, here defined by a particular percentile of an indicator's own distribution. This approach assumes an extreme non-linear relationship between the indicator and the event to be predicted.

Each quarter of the evaluation sample for each indicator falls into one of the following quadrants of the below matrix.

\begin{tabular}{||c||c|c||}
\hline \hline & $\begin{array}{c}\text { Costly Boom/Bust Cycle } \\
\text { (within 6 quarters) }\end{array}$ & $\begin{array}{c}\text { No Costly Boom/Bust Cycle } \\
\text { (within 6 quarters) }\end{array}$ \\
\hline \hline Signal issued & $A$ & $B$ \\
\hline No signal issued & $C$ & $D$ \\
\hline \hline
\end{tabular}

$A$ is the number of quarters in which an indicator provides a correct signal, $B$ the number of quarters in which a wrong signal is issued. Correspondingly, $C$ is the number of quarters the indicator does not issue a signal despite a costly boom/bust cycle starting within the following six quarters. $D$ is the number of quarters in which the indicator does not provide any warning signal, and rightly so.

$A /(A+C)$ is the number of good signals as a ratio to all quarters in which a costly boom/bust cycle followed within six quarters. $B /(B+D)$ represents the share of bad signals

\footnotetext{
${ }^{13}$ See Chui and Gai [2005] for a survey and Edison [2003] for relevant discussions.
} 
as a ratio of all quarters in which no such booms followed. $B /(B+D)$ can be considered the share of type II errors (event not occurring but signal issued, as share of $B+D$ ) or simply the share of false alarms. Correspondingly $C /(A+C)$ is labeled the share of type I errors (event occurring but no signal issued, as share of $A+C$ ) or simply the share of missed costly boom/bust cycles.

Kaminsky et al. [1998] and the literature following their seminal contribution assess the usefulness of an indicator by computing the adjusted noise to signal ratio (aNtS) defined as $[B /(B+D)] /[A /(A+C)]$. A useful indicator is supposed to have an aNtS of less than 1. A value of 1 would result if an indicator provides purely random signals.

The criterium of aNtS $<1$ though is only a necessary condition for an indicators' usefulness in practice, as a) the resulting type I and type II errors might be unacceptable to policy makers given their preferences and b) the gain associated with receiving signals from an indicator as compared to ignoring it, which also depends on preferences, might be irrelevant.

We define a loss function for the policy maker, a central banker in this case, to analyze the usefulness and to rank indicators. ${ }^{14}$ The loss function is defined as

$$
L=\theta \frac{C}{A+C}+(1-\theta) \frac{B}{B+D}
$$

$\theta$ is the parameter revealing the policy maker's relative risk aversion between type I and type II errors. The loss can be easily interpreted. It is the preference weighted sum of type I and type II errors. A $\theta$ lower than 0.5 reveals that the central banker is less averse towards missing a signal for a costly asset price boom/bust cycle than towards receiving a false alarm. ${ }^{15}$

\footnotetext{
${ }^{14}$ Bussière and Fratzscher [2008] introduce the loss function approach to the early warning indicator literature. Their loss function differs from ours as it assumes that policy makers receive disutility from missing crisis $(C)$ and receiving a signal $(A+B)$ irrespective whether the signal is correct or wrong.

${ }^{15}$ We believe a $\theta$ smaller than 0.5 is a realistic description of central bankers' loss functions, although the recent financial crisis might have increased the average $\theta$. If asset price booms are not discovered as such in a timely manner or the monetary policy strategy does not foresee reacting to asset price developments beyond the impact of asset prices on consumer price inflation at traditional forecast horizons, there always remains the possibility to smooth the bust phase by means of a very accommodative monetary policy stance and by providing liquidity (to the market or individual banks). On the other hand, a central banker would certainly have to cope with serious public pressure when being found out to have spoiled the party while relying on a false alarm. Furthermore, even if the indicator performed well and provided a correct signal and the central banker successfully 'leaned against the wind', he might be criticized for too tight monetary policy as the counterfactual is unavailable.
} 
The usefulness of an indicator can then be defined as

$$
\min [\theta ; 1-\theta]-L
$$

A central banker can always realize a loss of $\min [\theta ; 1-\theta]$ by disregarding the indicator. If $\theta$ is smaller than 0.5 , the benchmark is obtained by ignoring the indicator, which amounts to never having any signals issued so that $A=B=0$. The resulting loss according to eq. (1) is $\theta$. If $\theta$ exceeds 0.5 , the benchmark for the central bank is assuming there is always a costly boom developing, i.e. assuming a signal is always issued so that $C=D=0$. The resulting loss is $1-\theta$. An indicator is then useful to the extent that it produces a loss lower than $\min [\theta ; 1-\theta]$ for a given $\theta$.

Another difference to the standard literature using the signalling approach is that the performance of the indicators reported here is based on a 'real time' analysis. Indeed, at each point in time we set the thresholds for the indicators on the basis of past observations. Trends are calculated recursively only using available data up to each point in time. Therefore we obtain signals as they would have been obtained in the period they refer to. There is though one notable exception and one caveat. The percentiles of the distribution, beyond which a warning signal is issued, are optimized ex-post for each indicator using all relevant boom/bust cycles in the evaluation sample between 1979 and 2002. Unfortunately, a strictly real time approach, i.e. choosing the optimal percentile of the distribution at each point in time, is not feasible. Indeed, we would need to have, at each point in time, at least one past costly asset price boom/bust cycle, in order to evaluate the indicator's performance. In our approach, the specific indicator thresholds for each quarter are derived by applying the fixed optimal percentile to the distribution of the data available up to each specific point in time. Thresholds for each indicator are thus time and country dependent. The caveat is that we use the most recent vintage of data and not a true real time data set with unrevised data. Nevertheless, we use conservative lags to proxy for standard publication lags and thus real time data availability. Publication lags are particularly important for housing prices and vary across countries, as will be discussed in Section 4 . 


\section{Identification of Asset Price Booms}

We start by mechanically defining asset price boom episodes for 18 OECD countries ${ }^{16}$ between 1970:Q1 and 2007:Q4. The real aggregate asset price indices have been provided by the Bank for International Settlements and are weighted averages of equity prices, residential and commercial real estate prices, and are deflated with the national consumption deflators. ${ }^{17}$ An aggregate asset price boom is defined as a period of at least three consecutive quarters, in which the real value of the index exceeds the recursive trend plus 1.75 times the recursive standard deviation of the series. The recursive trend is calculated with a very slowly adjusting HodrickPrescott filter $(\lambda=100000)$ taking into account only data up to the respective quarter. ${ }^{18}$ The value of 1.75 is the one preferred by Mendoza and Terrones [2008] in identifying credit booms. 1.75 also provides results which are relatively comparable to the boom identification reported in Adalid and Detken [2007]. ${ }^{19}$

We then differentiate between aggregate asset price booms, which have little consequences for the real economy and those that have significant effects. The definition of a high-cost boom (HCB) is chosen in a way to reasonably split our sample of 45 booms, for which we have three years of post-boom GDP data, into two groups so that the low-cost booms (LCB) can function as control group. ${ }^{20}$ We define a high-cost boom as a boom, which is followed by a three year period in which overall real GDP growth has been at least three percentage points lower than potential growth. The choice of 3 percentage points over three years lower than potential is

\footnotetext{
${ }^{16}$ The countries are Australia, Belgium, Canada, Switzerland, Germany, Denmark, Spain, Finland, France, the United Kingdom, Ireland, Japan, Netherlands, Norway, New Zealand, Sweden, the United States.

${ }^{17}$ We use aggregate instead of individual asset class price indices as we are also interested in growing financial imbalances which could potentially be addressed by means of timely adjustments to the monetary policy stance. As the interest rate is a relatively blunt tool affecting the whole range of asset prices, it is more likely to be used in episodes when a boom is identified in an aggregate index.

${ }^{18}$ A similar method has previously been used in Gourinchas et al. [2001] and Borio and Lowe [2002]. Also in Detken and Smets [2004] and Adalid and Detken [2007] the price index needs to exceed 10\% of its slowly adjusting recursive trend in order for a quarter to qualify as potential boom quarter. In this paper instead, we identify booms using country specific information with respect to the volatility of asset prices, which should give a better picture of what can be considered unusually swift asset price developments for each country. See also Mendoza and Terrones [2008] for a discussion of alternative methods.

${ }^{19}$ The examples in Mendoza and Terrones [2008], their Figures 4 and 5, show that the main difference in this class of boom identification methods derives from the choice of country specific standard deviations versus fixed percentage thresholds to compute deviations from trends, rather than the choice of $\lambda$ to compute the recursive trend. Nevertheless, we also derived all results of the paper when defining booms by a fixed larger than 10 percentage point deviation from trend without major qualitative changes.

${ }^{20} 15$ of the identified booms cannot be classified because three years of post boom GDP data are not (yet) available.
} 
close to the median of post boom losses, which is 3.5 p.p.. In this way we divide our sample of 45 classifiable (out of 60 identified) booms into 29 high-cost and 16 low-cost booms. Figure 1 shows the identified boom periods. High-cost boom quarters are depicted in black, low-cost booms are grey and framed periods are unclassified booms. The quarters marked by xxx in Figure 1 are periods in which the asset price index breaches the boom threshold. ${ }^{21}$ This reveals that in some cases we classified two boom episodes which closely followed each other as one boom and thus bridged a few periods of asset prices below the trend plus 1.75 standard deviations. Otherwise the post boom period of the earlier boom would have overlapped with the boom period of the later boom. ${ }^{22}$ Furthermore, in two cases we artificially ended the boom periods (Finland and Sweden in 2000Q3) after the aggregate asset price gaps had been falling by more than 35 percentage points compared to their respective peaks. It is reassuring that all banking crises with significant GDP costs as identified by Honohan and Laeven [2005], i.e. Finland 1991-1994 (-21\% of GDP), Italy 1990-1995 (-22\% of GDP) and Sweden 1991-1994 (-11\% of GDP), are following high-cost booms according to our identification scheme.

Figure 2 provides a different perspective on the boom classification results. It shows the number of countries experiencing aggregate asset price booms at each point in time. There have been basically three major waves of asset price booms since the 1980s. In terms of the number of countries affected, the first wave peaked in 1989, the second in 2000 and the third in early 2007. While the first wave of cycles were all high-cost booms, only about $60 \%$ of the second wave has been classified as such. Concerning the third wave the verdict is still open.

\footnotetext{
${ }^{21}$ There is one exception to the high/low-cost classification scheme, which is the boom identified for Japan between 1987 and 1989. According to our definition it would be a low cost boom with aggregate GDP growth 1.7 percentage points below potential over the following three years. But as this boom triggered the 'lost decade' with losses of $48 \%$ of GDP occurring after our reference period, we nevertheless classified this boom as high cost.

${ }^{22}$ The longest bridged period is 6 quarters, see Figure 1.
} 


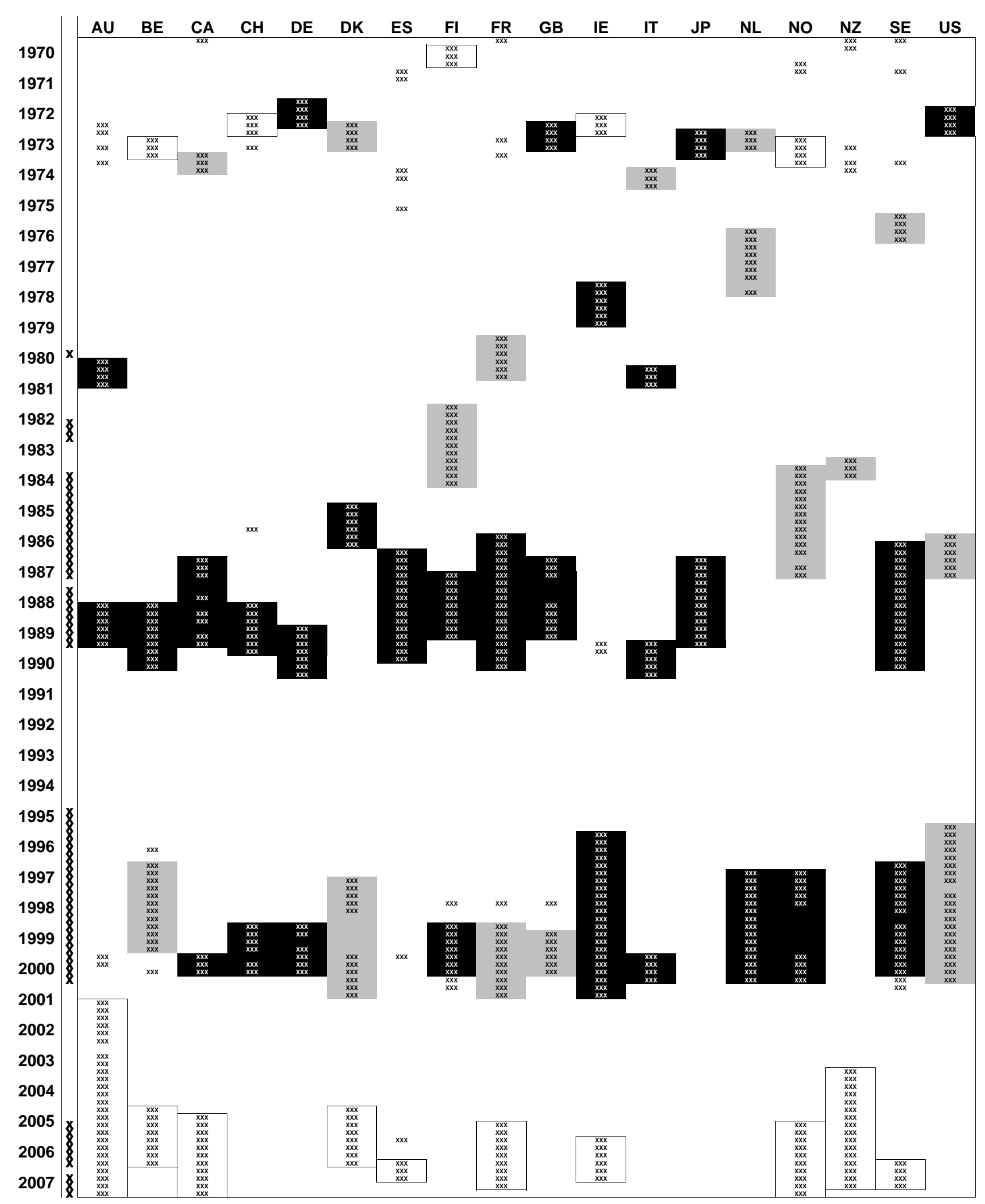

Figure 1: Identified boom periods. In those periods highlighted with $\mathbf{x x x}$ the real value of the index exceeds the recursive trend plus 1.75 times its recursive standard deviation. Grey indicates low-cost booms, black indicates high-cost booms while the others are non classified booms. The first column indicates with $\mathbf{X}$ those quarters in which the detrended Global Private Credit to GDP ratio (GlobPC-HP) issues warning signals (with threshold at the $70^{\text {th }}$ percentile). 


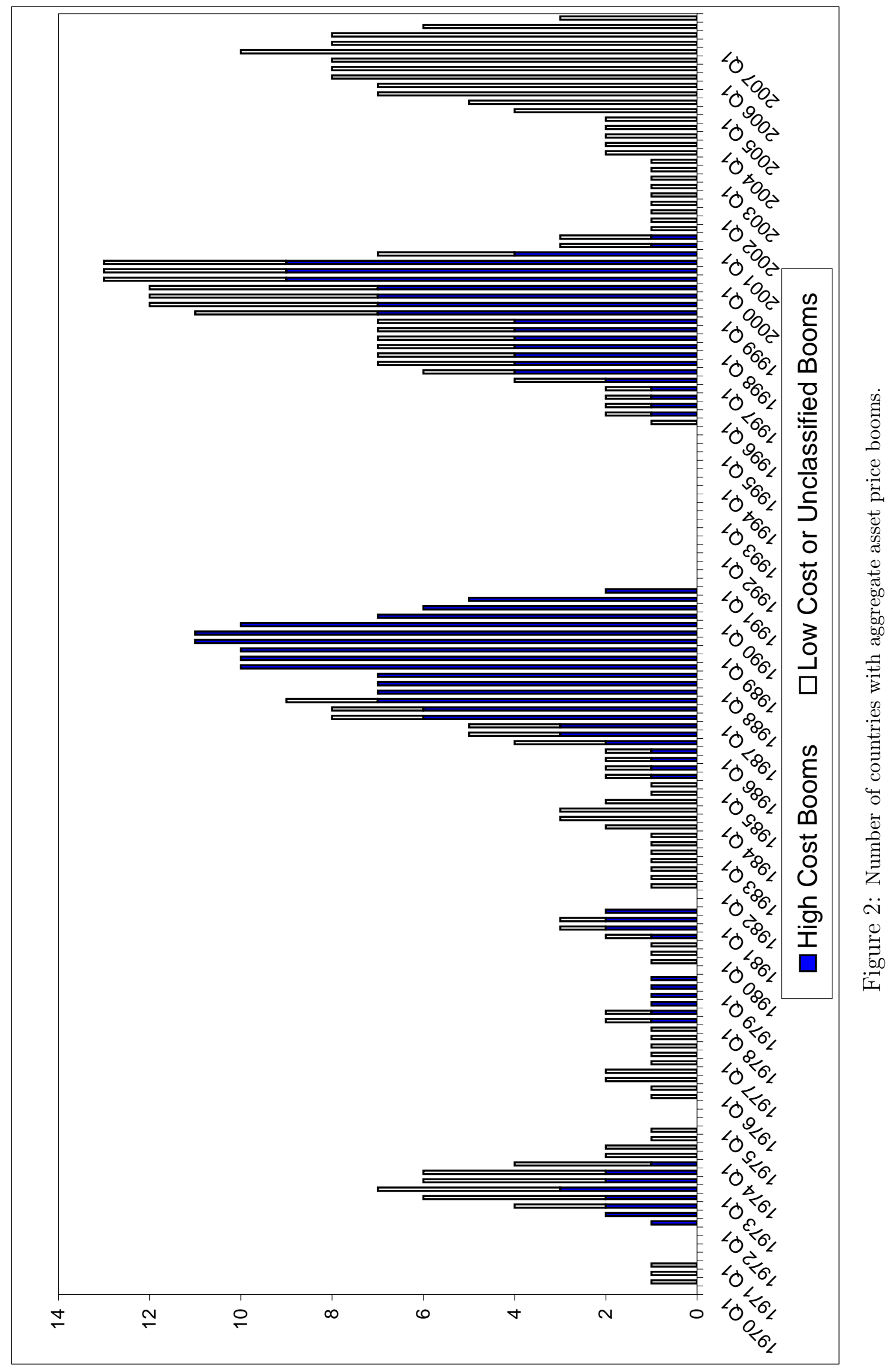




\section{Data and Indicators}

We test a set of 18 real and financial variables, and up to 6 different transformations of these variables - overall 89 indicators - on their suitability as early warning indicators for high-cost asset price boom/bust cycles within a 6 quarter forecasting horizon. Variables related to the real side of the economy are GDP, consumption, investment and housing investment (all in real terms). Financial variables are consumer price deflated equity, housing and aggregate asset prices, the term spread, real effective exchange rates, real and nominal 3-months interest rates and 10 year bond yields, real M1, real M3, real private credit and real domestic credit. Furthermore we correct real money and credit growth rates from endogenous business cycle and asset price components by means of recursive VAR models. ${ }^{23}$ In addition, we also evaluate consumer price inflation. Furthermore, we test GDP (at PPP) weighted averages of the 18 countries of seven financial variables (private credit, M1, and M3 all as ratios to GDP, nominal short rates, and the VAR shocks for M1, M3 and private credit growth), which we label global financial variables. The legend in the Annex provides the information necessary to read the tables in the following sections.

We compute several transformations of the variables in order to check for their forecasting performance. Variables are used (if applicable) as year on year growth rates (yoy), six quarter cumulated growth rates (cum), deviations ('gaps') from a recursive slowly adjusting HP trend (detr and $H P^{24}$ ), deviations from a slowly adjusting HP trend of the ratio to GDP (toGDPdetr and toGDP-HP) and levels (lev). For housing prices we use seasonally adjusted as well as non-seasonally adjusted data, taking into account the established seasonal patterns. ${ }^{25}$ All other variables, except aggregate asset prices, equity prices, exchange rates and interest rates are seasonally adjusted.

In order to proxy for data availability at the time decisions have to be taken, we generally

\footnotetext{
${ }^{23}$ See Adalid and Detken [2007], for a description of the methodology to derive these shocks. Here though we estimate the VARs recursively to mimic real time data availability and use six quarter moving averages of the derived shocks.

${ }^{24}$ The time series for detr and $H P$ are the same. The difference is that in order to derive the threshold at each point in time when applying the optimal percentile, past values are treated differently. For detr variables, the optimal percentile is applied to the series of recursively detrended variables without updating the trend for past periods. For $H P$ variables the optimal percentile is applied to past detrended series obtained when updating the trend at each point in time, so that also the history of the indicator changes as time elapses.

${ }^{25}$ See Ngai and Tenreyro [2008].
} 
assume a publication lag of 1 quarter. This means that an indicator is calculated for each quarter with variables lagged by one quarter. This might bias the results against financial variables, as in reality the latter often have a much shorter publication lag if any at all, so that at least a reasonable approximation for the current quarter would usually be available. Housing price indices are different though. For some countries, private residential housing prices are available only annually or biannually and publication lags vary significantly. Given the country specific information we collected, the following lags are applied in the analysis: most countries housing and aggregate asset price indices are applied with a one quarter lag, except France, Italy, Japan and Denmark for which we use two quarters and Germany which is lagged four quarters.

Comparing our set-up with the series of papers by Borio and coauthors, the following main differences should be highlighted. For the same set of countries, we are predicting costly asset price cycles and not banking crises, so that compared to Borio and Lowe [2004] and Borio and Drehmann [2008] we evaluate 24 (plus a control group of additional 10) instead of 15 and 13 events, respectively. A distinction is also relevant with respect to the analyzed lead time, which is set up to 6 quarters in our case and varies between 1 and 5 years for the BIS papers. This makes sense noting that booms tend to precede banking crises. Also notice that only Borio and Lowe [2004] also use quarterly data (1974-1999) like in this paper, while otherwise annual data are employed. Only Borio and Drehmann [2008] also use property prices. More generally, the main differences are the loss function criterium introduced in section 2 to rank indicators, the broader set of reported indicators which also include global variables and the choice to define thresholds in terms of percentiles rather than absolute values.

Details about our data sources can be found in the Annex.

\section{Results}

In order to compare the forecasting performance for high-cost boom episodes within a six quarter horizon for our 89 indicators we proceed as follows. In a first step we optimize the percentile to calculate the thresholds for each indicator for each individual country by 
minimizing the loss function (1) by means of a grid search for the best percentile in the range of $[0.05-0.95]$ in steps of 0.05 . We compute a ranking of the 89 indicators for different values of $\theta(0.2,0.3,0.4,0.5,0.6$ and 0.8$)$. Note that the optimal percentile is derived ex-post by using all available high-cost booms per country, but the threshold varies in time as the percentile is applied to quarterly updated distributions of the indicator as time passes. This time variation of the threshold is taken into account during the optimization of the percentile. The evaluation period is 1979:Q1 to 2002:Q1. We begin the evaluation only in 1979 as we need some starting window in order to compute reasonable initial trends and to estimate the initial VARs. Furthermore, we cannot evaluate yet the last boom wave, as we do not have three years of post boom GDP data. There are thus 24 high cost booms (and 10 low-cost booms) left in the evaluation window.

When we compute the resulting figures for A, B, C and D of the matrix shown in Section 2, we exclude boom periods as of the fourth consecutive quarter from the evaluation, as by then a warning signal is not really useful anymore and it might not be advisable to mix early warning signals with signals during an established boom episode.

In the tables presented in this paper indicators are ranked by their usefulness for the policy maker as defined above in eq. (2). In some tables we will follow Kaminsky et al. [1998] and also present a few other standard evaluation measures like the aNtS ratio and its two components $A /(A+C)$ and $B /(B+D)$. The booms column reveals the percent of booms which is predicted in one of the six quarters preceding the boom or during the first three quarters of the boom. The probability of the event conditional on a signal being issued is $A /(A+B)$. The diffprob column shows the difference between the conditional (on a signal being issued) and unconditional probabilities of the event, i.e. $A /(A+B)-(A+C) /(A+B+C+D)$. The larger this probability difference the better the indicator, but it must at least be positive for an indicator to be potentially valuable. We also report the average lead time of an indicator in the $A L T$ column, which is the average number of leading quarters by which an indicator has been signalling an event for the first time. And finally, we report the persistence of the signal, which is nothing else than the inverse of the aNtS ratio, labelled pers. This number 
can be interpreted as the factor by which a signal is issued more persistently in times of growing imbalances (i.e. costly boom/bust cycle starting within 6 quarters) compared to tranquil times. A persistence value larger than 1 is a necessary condition for an indicator to be useful.

Instead of reporting country by country results, we show averages for two groups of countries. The first is the simple average over the 18 countries and the second a GDP weighted average of the eight euro area countries in our sample by using optimal country specific thresholds for each indicator. Annex Tables 1 and 2 show the results for all 89 indicators for $\theta=0.4$ for both groups of countries. For the average over all countries (Annex Table 1) the best indicators are cumulated real consumption growth over 6 quarters, the nominal long term interest rate gap ${ }^{26}$ and the real equity price gap, all producing preference weighted errors (i.e. the loss, not shown) of about $22-23 \%$. With a $\theta$ of 0.4 , the usefulness for the policy maker is $0.18-0.17$. The interpretation is that on average over the 18 countries the preference weighted errors can be reduced by $17-18 \%$ compared to the loss resulting if the indicator would be disregarded. The standard evaluation measures look very reasonable, with the aNtS around 0.3 and an average lead time of about 5.7 quarters. The best indicators for the euro area average (Annex Table 2) are the global private credit gap (detr and HP), the nominal long term interest rate gap and the M1/GDP ratio gap with similar properties as for the overall average, i.e. losses of $22 \%$ and aNtS around 0.26 . One major difference between the results for all countries and for (weighted) euro area countries is that while for the former there are both real (in particular consumption and investment) as well as financial indicators among the best performing ones, financial variables dominate for the euro area average.

In order to derive optimal percentiles and thresholds for the euro area, the above results on average performance with country specific percentiles might not be particularly useful though. An indicator may be good for one country and perform very badly for another. As optimal domestic percentiles vary, it is not clear which percentile one would have to select for the euro area. In case one would take the average or weighted average percentile, the previously

\footnotetext{
${ }^{26}$ Interest rates are entered with a negative sign. This means that rates above e.g. the $85 \%$ quantile are the $15 \%$ lowest interest rates.
} 
reported performance measures are no indication at all for a possible euro area performance. We therefore repeat the exercise of optimizing the percentiles, per indicator, for all the different values of $\theta$ by imposing that the percentile has to be the same for all countries or alternatively for all euro area countries in the sample. The common percentile chosen is the one which minimizes the aggregate loss over all countries or the weighted aggregate loss for the euro area countries. We also average the evaluation statistics derived with the common $\theta$. Results obtained by forcing the same percentile to be applied across countries should provide more useful information for selecting the optimal percentile for aggregate euro area data in the future. Whether it is more advisable to rely on the larger sample of 18 but more diverse countries or rather on the (weighted) average of 8 euro area countries is debatable, which is why we present again results for both groups of countries. Using euro area data directly is not advisable at the current stage, as we might be left with only 1 or 2 episodes (2 only if we would use aggregated national data to proxy for the euro area before 1999) in our evaluation window, see Figure 2.

Annex Tables 3-5 show the full set of results for three different $\theta(0.2,0.4$ and 0.6$)$ obtained with a common percentile. Annex Tables 6-8 present the result for the weighted average of euro area countries. The optimal percentile as well as the coefficient of variation of the country specific optimal percentiles are also mentioned in these tables. The cross-country variation in optimal percentiles is valuable information with respect to the problems associated with choosing a common percentile for the euro area.

Figure 3 visualizes one particular example (global M1 gap (detr), constrained euro area percentile) of how the optimal trade-off of policy makers depends on relative preferences. Policy makers' preferences, i.e. the aversion to missing a boom/bust cycle relative to receiving false alarms as measured by $\theta$, is depicted on the X-axis. Type I errors (missed high-cost boom as percentage of periods in which a high-cost boom followed within 6 quarters, $C /(A+C))$ and type II errors (false alarms as percentage of periods in which no high-cost boom followed 


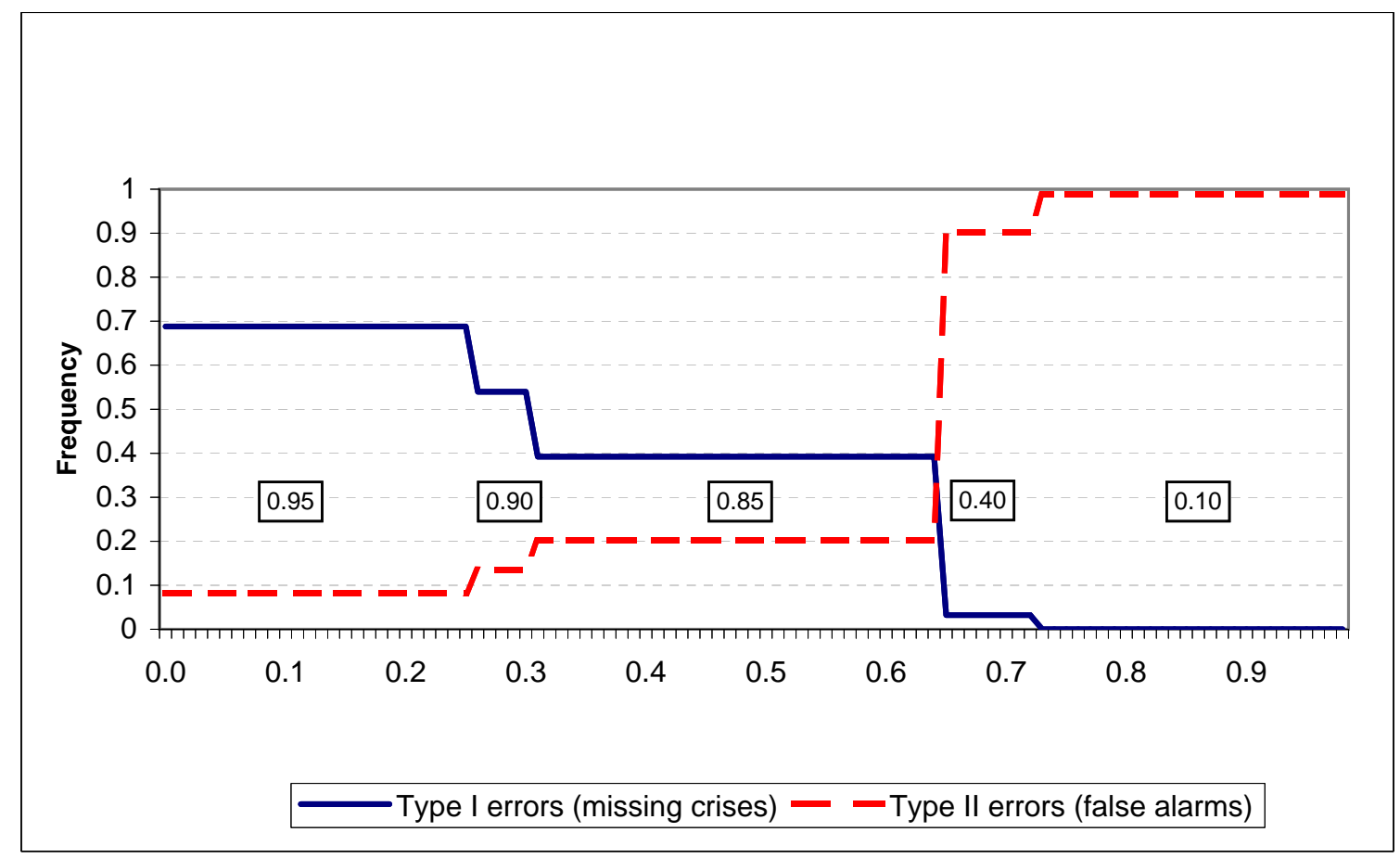

Figure 3: The central banker's trade-off between missing crises and false alarms (and optimal thresholds) for the Global M1 Gap. X-axis: $\theta$.

within 6 quarters, $B /(B+D))$ are depicted on the Y-axis. ${ }^{27}$ The boxes between the two error lines show the percentile minimizing the loss function for the indicator (globM1-detr). The optimal percentile of the distribution of the M1 gap - which when exceeded triggers a warning signal - declines in discontinuous steps with rising $\theta$. Correspondingly, type I errors fall and type II errors increase. Another way to use the information provided in Figure 3 is to choose the threshold, which would produce acceptable type I and II errors for the decision maker. In this particular example, it seems that a percentile of $85 \%$ looks like a reasonable choice. The (time varying) thresholds associated with a $85 \%$ percentile did not allow issuing a warning signal in $40 \%$ of quarters followed by a costly boom/bust cycle and provided false alarms in $20 \%$ of quarters not followed by a costly boom/bust cycle.

Tables 1 and 2 summarize the most important information for the best 5 indicators for different $\theta$, imposing the same optimized percentiles for all countries both for the 18 countries and the sub group of 8 euro area countries, respectively.

\footnotetext{
${ }^{27}$ Please note there is no reason that type I and type II errors should add up to 1.
} 


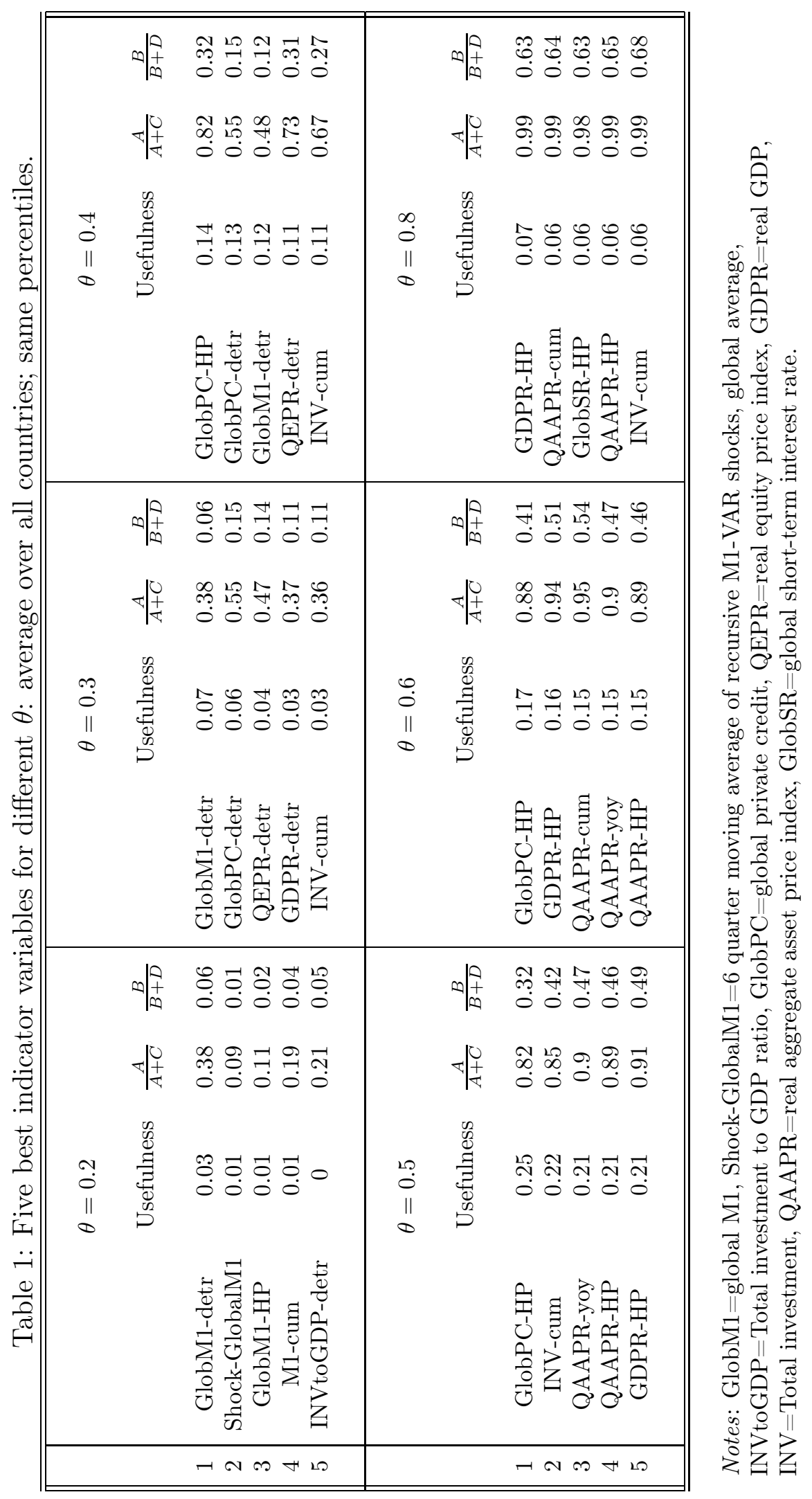




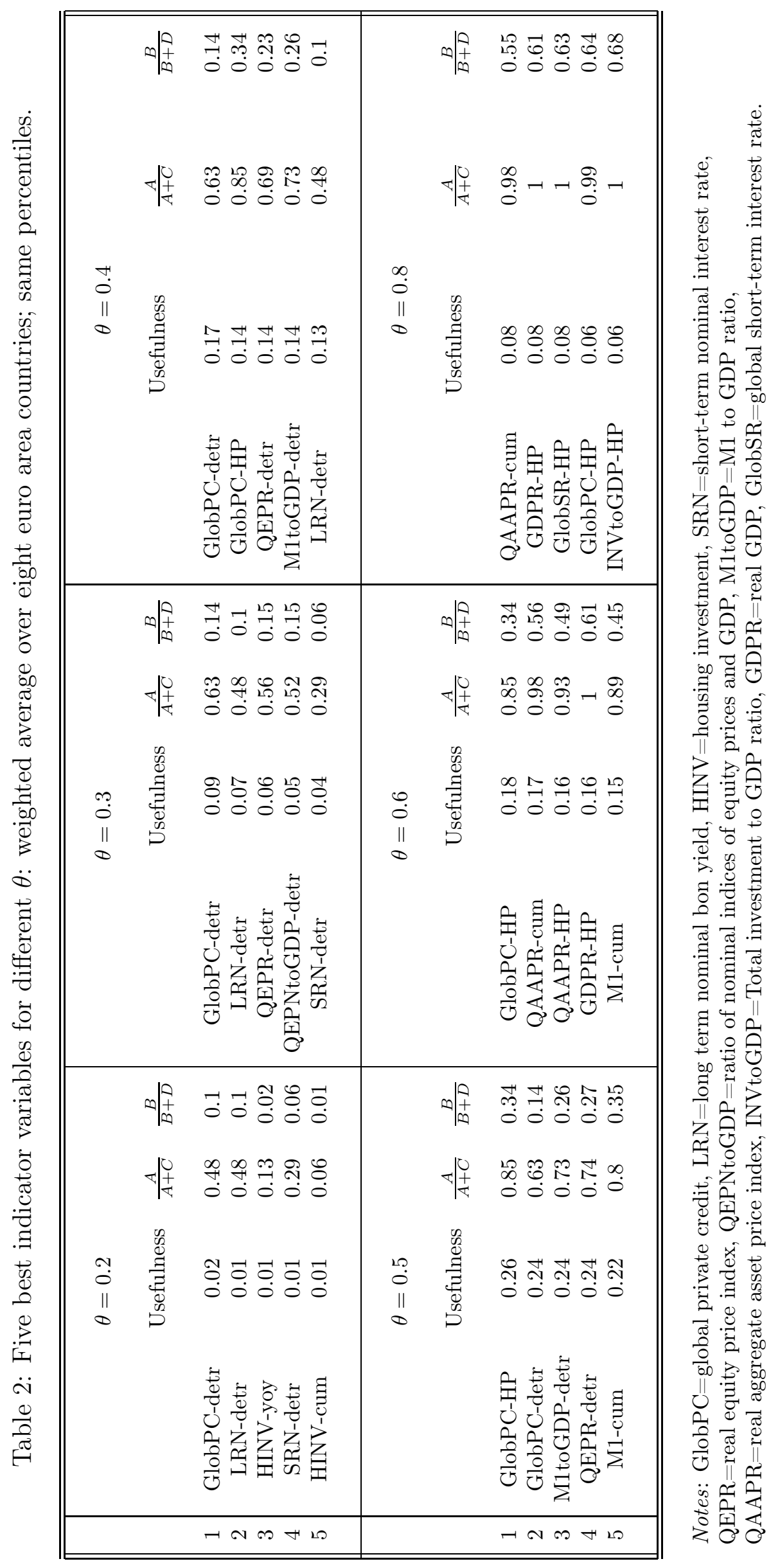


Tables 1 and 2 can be used to answer the questions we are interested in, though the tables in the Annex provide many more details with respect to the average lead time, the persistence of the signals, the aNtS, and the number of booms predicted for different $\theta$.

Constructing early warning indicators in this simple way (i.e using a single indicator in a signalling model) seems to provide useful information to predict costly asset price booms in case of relatively balanced preferences of the policy maker. For example, Table 1 reveals that taking the average over all countries with a balanced risk aversion between type I and type II errors $(\theta=0.5)$, using the global private credit gap, defined as the PPP-GDP weighted average of detrended private credit to GDP ratios, would reduce the preference weighted errors, i.e. the loss, by 25 percentage points compared to a situation in which the policymaker would ignore the indicator. The private credit gap would signal a costly asset price boom in $82 \%$ of quarters which are actually followed by a costly boom within 6 quarters. The private credit gap would issue a false alarm in $32 \%$ of cases in which no costly boom follows. The optimal percentile to derive the threshold is $70 \%$ while it varies across countries between $40 \%$ and $85 \%$ (65-85\% for euro area countries), which results in a relatively low coefficient of variation of 0.17 (0.10 for $\theta=0.4$, see Annex Table 4). The average lead time is 5.5 quarters. Most importantly, $95 \%$ of booms are signalled in at least one of the 6 preceding quarters (or one of the three first boom quarters), and the difference in the conditional and unconditional probability of a boom following a signal is $16 \%$ (28\% with the alternative detrending method (detr instead of $H P))^{28}$

Tables 1 and 2 also reveal that the usefulness of the approach chosen here is not breathtaking when policy makers have a clear preference for either type I or type II errors. Overall losses are lowest for very low and very high $\theta$, but the gain in computing an early warning indicator in comparison to disregarding it, is only marginal for $\theta$ equal to $0.2,0.3$ and 0.8 . In the case of rather unbalanced preferences, the aversion to one or the other type of errors is so high that it is hard to beat the benchmark, which is disregarding the indicator. This is the case despite the fact that - as Annex Tables 3 and 6 show - aNtS are excellent by the standards of the literature, i.e. much closer to zero than to one (e.g. as low as 0.12 for $\theta=0.2$ ).

\footnotetext{
${ }^{28}$ The crosses in the very left column of Figure 1 show as an example the exact periods in which $G l o b P C$ - $H P$ provides warning signals, i.e. the periods in which the indicator breaches the $70^{\text {th }}$ percentile threshold.
} 
An additional argument suggesting that the mentioned indicators are useful can be derived when the 10 low-cost booms in our evaluation period are used as control group. Annex Tables 9 and 10 show the performance of the 89 indicators in predicting low-cost instead of high-cost booms, here for $\theta$ equal to 0.4 . The best five indicators for the overall average as well as the best three indicators for the euro area average are transformations of the real aggregate asset price index which is used to define the boom episodes. It is not surprising that the aggregate asset prices themselves are at some threshold able to predict a boom. The interesting point is that with respect to low-cost booms, there is no other variable which contains more information, in contrast to the high-cost boom exercises. ${ }^{29}$ This seems to suggest that there is genuine information in e.g. private credit gaps to predict costly asset price boom episodes.

With respect to the question whether real or financial variables contain more information to predict costly asset price boom/bust cycles, Tables 1 and 2 suggest that financial indicators perform better. The results for all 18 countries (Table 1) show that it is only cumulated real investment growth, for $\theta=0.2$ also the investment ratio gap and for $\theta$ equal to 0.6 and 0.8 also the real GDP gap which make it into the top five. Global private credit gaps and for the three lower $\theta$ also the global M1 gap dominate. For the euro area countries (Table 2), the dominance of financial variables is even more evident. This is perhaps surprising, as the ECB's monetary policy strategy implicitly includes some element of leaning against the wind of asset price cycles due to its second pillar, the monetary analysis. As there is evidence that asset price boom/bust cycles are associated with money and credit cycles ${ }^{30}$ one could expect the observable leading indicator properties of money and credit aggregates to be reduced over time to the extent that leaning against the wind is effectively pursued. In any case, this would bias our results against finding a good forecast performance for financial variables for euro area countries. ${ }^{31}$

\footnotetext{
${ }^{29} \mathrm{An}$ interesting observation, which is compatible with the previous argument, is that the higher $\theta$ the more prominent the aggregate asset price index appears in the ranking of indicators, which is also visible in Tables 1 and 2. This shows that the more averse the policy maker is against missing a boom, the more difficult it is for any other indicator to provide relatively more useful warning signals than the asset price index itself.

${ }^{30}$ Adalid and Detken [2007] and Goodhart and Hofmann [2008].

${ }^{31}$ Borio and Lowe [2004] find no evidence for leaning against the wind type of behavior in Australia, Germany,
} 
Concerning the question whether the more useful financial variables are global or domestic variables, the verdict is very clear for the results of the 18 countries. Global credit and global money are the best indicators. For the euro area countries, detrended domestic long and short term nominal interest rates, as well as domestic inverse M1-velocity gaps and cumulated M1 growth rates are often nearly as useful as the global private credit gaps. But overall, global liquidity measures, especially but not only based on credit, seem to be the best indicators. This result is certainly linked to the strong international correlation of asset price booms as depicted in Figure 2. ${ }^{32}$ Nevertheless, even if one believes that what matters for asset price booms is global liquidity, the dominance of global measures for domestic booms is not obvious, at least for the indicators based on broad monetary aggregates. One could expect that global liquidity will affect domestic asset prices once foreign capital is invested in a particular country. In this case global liquidity would usually show up in domestic monetary aggregates in case the foreign investment is settled through the banking system. This is not the case for (domestic) credit based indicators, which is why Adalid and Detken [2007] suggest that foreign capital flows driving a wedge between money and credit aggregates might have been one reason to explain their result that M3 based liquidity shocks are more relevant for asset price booms than credit based measures. Indeed Annex Tables 3-8, where we show the full set of results for all countries and the euro area weighted averages for three selected values of $\theta$, respectively, do not reveal any dominance of global M3 versus domestic M3 indicators. To the contrary, the only somehow useful M3 based measures (same percentile for all countries with $\theta=0.4$, Annex Table 4), are domestic M3 measures (M3-cum and M3-yoy).

There remains the question whether money or credit based liquidity measures perform better. Borio and Lowe [2004] argue that credit is the better indicator for banking crises. Adalid

Japan and the US using Taylor rules as a benchmark for a neutral policy stance. Adalid and Detken [2007] show that on average over 22 high-cost boom episodes across 18 OECD countries, Taylor rule gaps indicate a loosening of monetary policy in pre-high-cost and during high-cost boom periods. As the samples of both studies correspond with our evaluation window, the absence of leaning against the wind behavior might explain the benign statistics of our financial indicators.

${ }^{32}$ See also Ciccarelli and Mojon [2008] who find evidence for a large global component in domestic consumer price inflation. 
and Detken [2007] present evidence that M3 growth corrected for endogenous components is a more robust determinant of post asset price boom recessions. Adrian and Shin [2008b] argue that money could be the better indicator of growing financial imbalances as it might be a more comprehensive measure of banks balance sheets. ${ }^{33}$ The results in this paper suggest that the differences between money (M1) and private credit are not very large, but that the global credit gap is overall the best early warning indicator. The fact that M1 performs better than M3 requires further investigation with respect to the underlying reason for the indicator property of money. M1 focuses on the monetary policy stance while M3 would suggest the role of money as a summary statistic of banks' balance sheets.

Finally, we also tested whether joint indicators can further improve the usefulness of the signalling approach. Joint indicators imply that a warning signal is issued only when both indicators exceed their respective optimal thresholds. ${ }^{34}$ The matrix grid search is performed and all percentile combinations of two joint indicators each in the range [0.05-0.95] with 0.05 steps were tested in order to find the combination minimizing the loss function for six different values of $\theta$. As this is computationally more expensive, we did not run all combinations of our 89 indicators. We focused on the two best indicators, the global private credit gap and the global M1 gap, and combined them with 16 indicators we were relatively more interested in and/or which were among the best indicators in the single indicator analysis. ${ }^{35}$

Tables 3 and 4 present the results for the average over all countries and the weighted average of euro area countries, respectively, requiring all countries to adopt the same percentiles per indicator for $\theta=0.4$.

When comparing Table 3 with Annex Table 4 and Table 4 with Annex Table 7 a few patterns emerge. The usefulness of joint indicators only slightly improves over the single best indicator, by 1 percentage point for all countries and by 2 percentage points for the euro

\footnotetext{
${ }^{33}$ Adrian and Shin [2008a] instead argue that most likely neither money nor private credit are good indicators as one should focus on investment banks' balance sheets and disregard traditional Monetary and Financial Institutions (MFI) balance sheets.

${ }^{34}$ See Borio and Lowe [2002].

${ }^{35}$ The indicators combined with globPC-detr and globM1-detr are $Q A A P R-H P, Q A A P R-y o y, Q R P R$-HP, QEPR-detr, LRN-detr, LRR-HP, SRN-detr, globSR-HP, shock-globalPC, shock-globalM3, REX-HP, GDPR$H P, I N V$-yoy, HINV-yoy, CONS-cum, CPI-yoy; see legend in the Annex.
} 


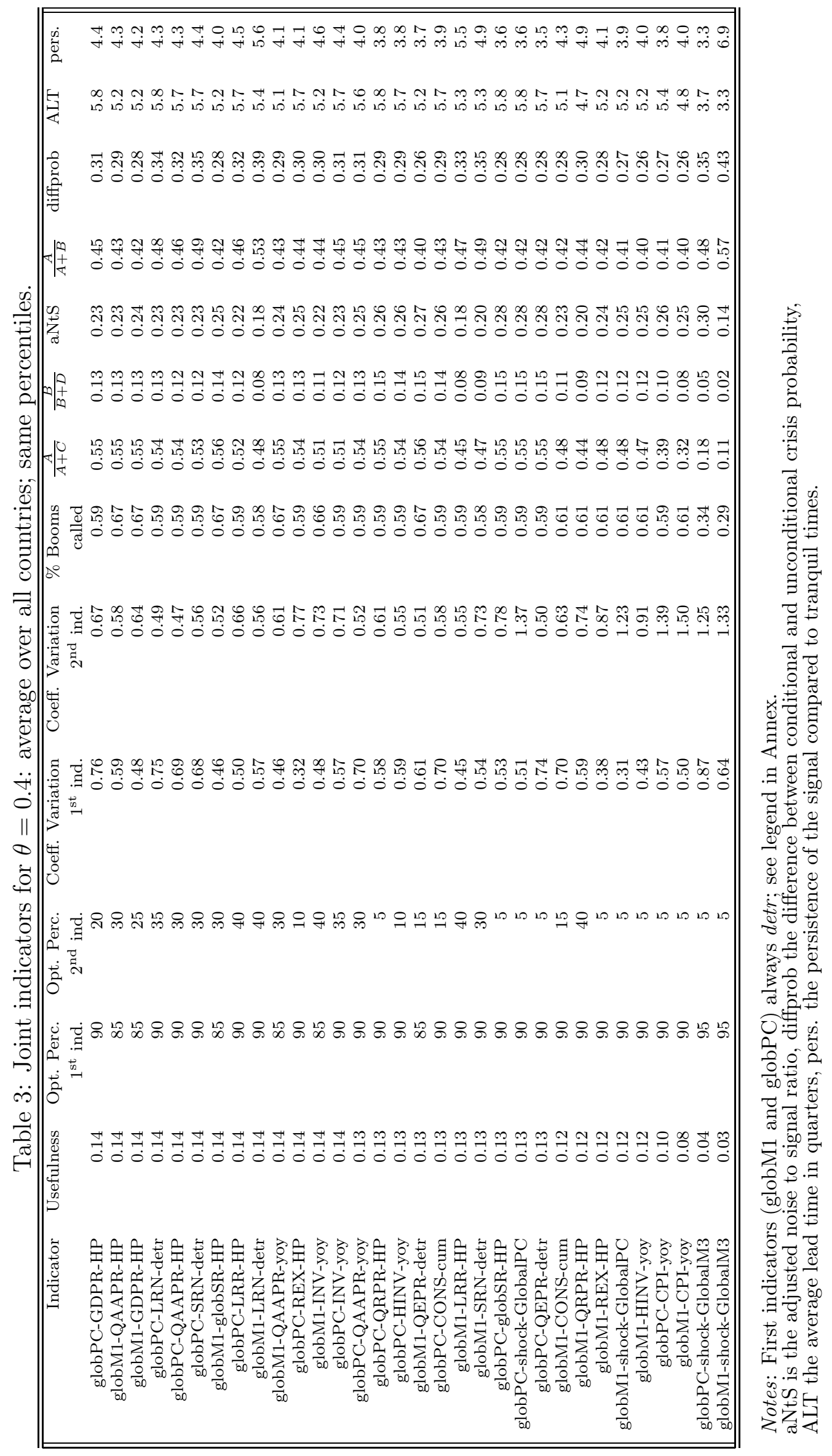




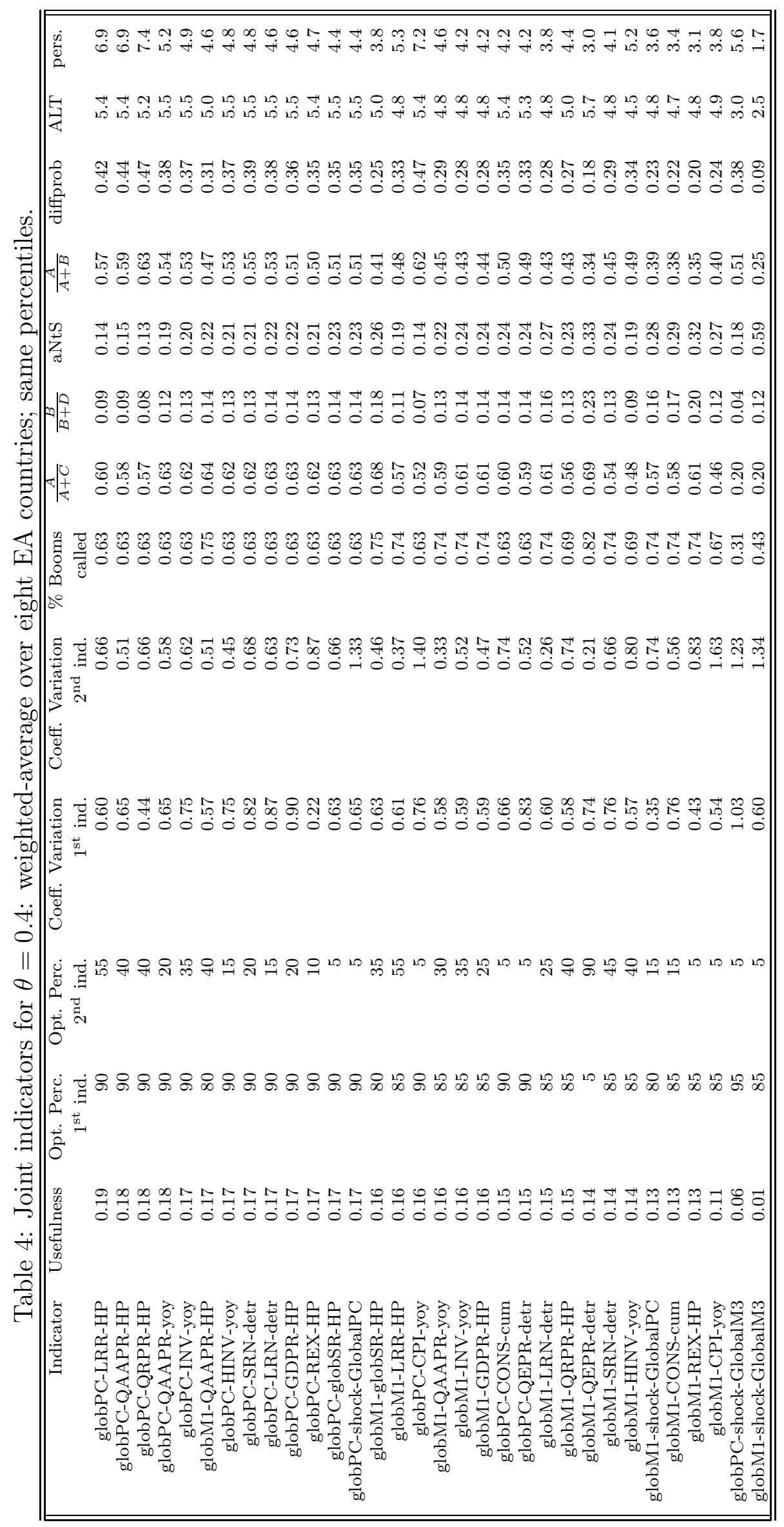

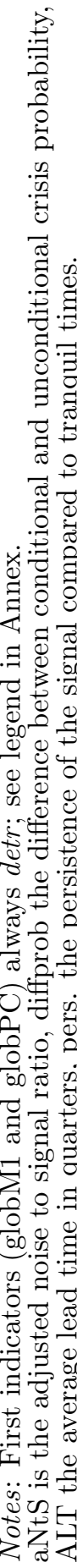


area countries, which is not too impressive. The coefficients of variation across the group of countries increase strongly in the joint indicator exercises, possibly signalling that the optimal thresholds from the joint indicator exercise are less robust and less easily applied to the euro area as a whole. Improvements of the aNtS are more sizable (reductions up to 50\%), which is achieved by eliminating a large number of false alarms. Thus the overall best indicator (at $\theta=0.4$ ) for the euro area weighted average (Table 4) would set a simultaneous 90 percentile threshold for the global private credit gap and a 55 percentile threshold for detrended real long-term bond yields (i.e. a detrended real bond yield only slightly lower than the median). $60 \%$ of periods in which a costly boom followed within six quarters has been correctly signalled. False alarms are issued in only $9 \%$ of periods not followed by a costly boom. The aNtS is 0.14 and the average lead time 5.4 quarters (see Table 4, first indicator row).

\section{Predicting the Recent Boom/Bust Episode}

Finally, we are interested to see whether the asset price booms which started in the mid 2000s are predicted to be high-cost booms by our best indicators. In order to do so, we first counted the warning signals in the 11 quarters between the first quarter of 2005 and the third quarter of 2007 (the start of the financial turmoil) for three of the best indicators. With respect to the global private credit gap, the picture is mixed (see Table 5).

Table 5: Number of quarters where warning signals were issued in 2005Q1-2007Q3, i.e. 11-quarter-period $(\theta=0.3)$.

\begin{tabular}{||ccc||}
\hline \hline Indicator & $\begin{array}{c}\text { Optimal } \\
\text { threshold }\end{array}$ & $\begin{array}{c}\text { Number of } \\
\text { signals }\end{array}$ \\
globPC-detr & 90 (all) & 0 \\
& 90 (EA) & 0 \\
globPC-HP & 70 (all) & 7 \\
& 85 (EA) & 3 \\
globM1-detr & 90 (all) & 0 \\
& 95 (EA) & 0 \\
\hline \hline
\end{tabular}

The outcome depends on the way the threshold is derived, in particular whether the per- 
centile to derive the threshold at each point in time is applied to past recursively derived gaps (-detr) or at each point in time to an updated past gap distribution (-HP). The latter method is associated with an optimal $70 \%$ threshold for all countries and the threshold has been breached in 7 of the 11 quarters. For the euro area countries the optimal -HP threshold is at the 85 percentile and 3 quarters provide a warning signal. Using globPC-detr as well as the global M1 gap instead provided no warning signals at the optimal 90 or respectively 95 percentile thresholds, which is likely to constitute type I errors. This shows how the result can depend on the method to derive the thresholds, as well as whether money or credit are used as indicators (despite the fact that both performed well historically). From a global perspective, the tightening of monetary policies during the second half of the 2000s has clearly been visible in developments of M1 during our evaluation window, while credit growth had still been strong enough to exceed the $70^{\text {th }}$ percentile.

In Table 6 we report again the three global indicators shown in Table 5, but which are here applied to the country specific booms identified in the late 2000s. We also checked the three best indicators for predicting high-cost booms derived country by country and evaluated whether they would have predicted a high-cost boom in the 6 quarters preceding the boom and the first three boom quarters. The time window for which the number of warning signals is reported is mentioned for each country in Table 6 . In case no boom has been identified for a particular country in the second half of this decade, we evaluate the signals for the last 9 quarters of our sample. In the lower part of Table 6, the country specific indicators as well as the optimal thresholds are shown beside the number of quarters in which warning signals are issued.

Apart from Belgium and New Zealand, the global private credit gap $(-H P)$ issued at least one warning signal for all countries, while the global M1 gap did not. The results for the country specific indicators certainly provide a very mixed picture. These results are similar to Borio and Drehmann [2008] who find that the performance of their best indicator, i.e. a joint domestic private credit and property price gap, in the recent episode depends on the definition of a banking crisis. According to a restrictive definition of a crisis the indicator picks two out 


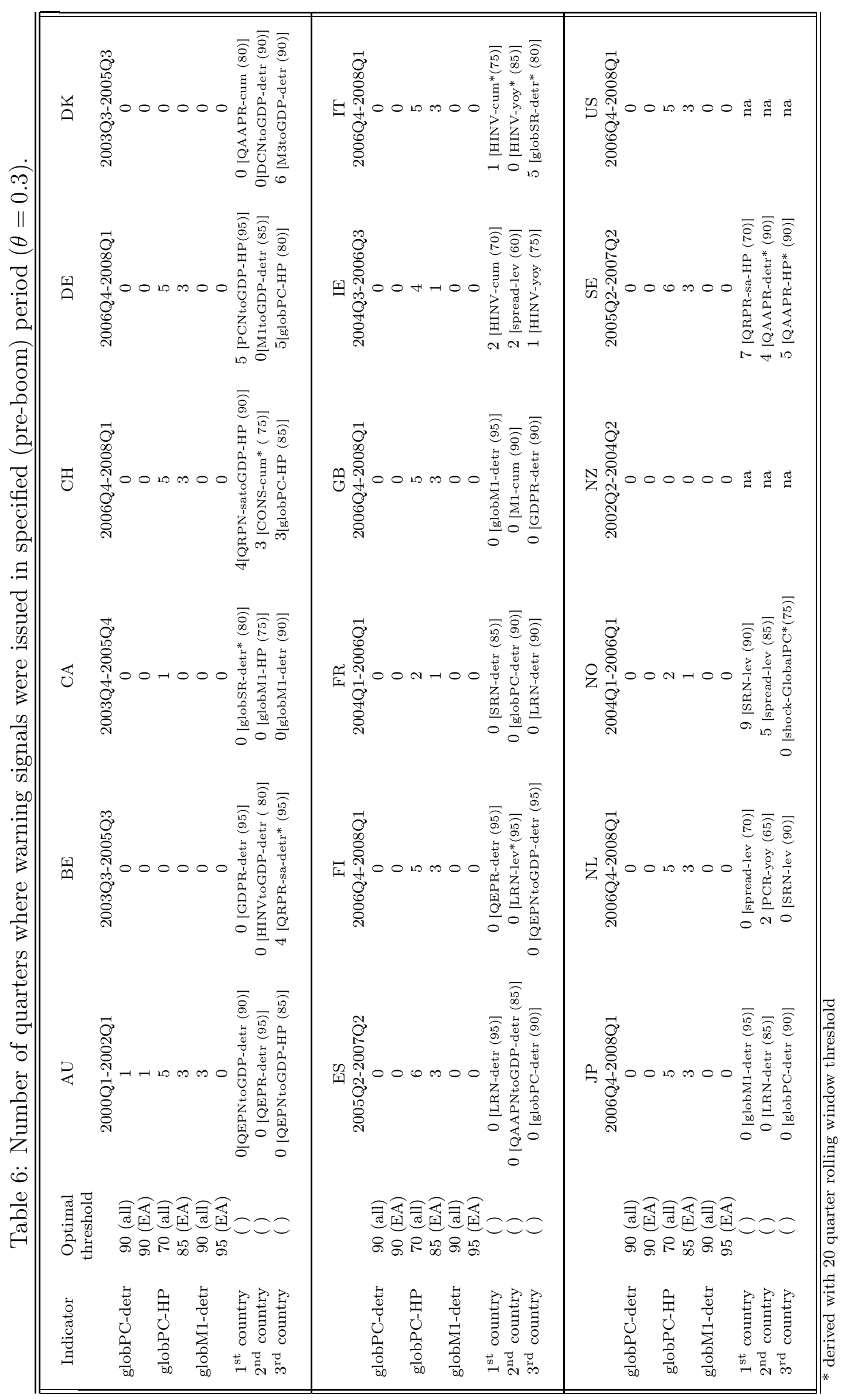


of three countries in crisis. With a less restrictive definition, it issues a warning signal in 9 out of 14 countries with banking crises.

\section{Conclusions}

We analyze the performance of a signalling approach to predict high cost aggregate asset price booms for 18 OECD countries since the 1970s. We deviate from the standard early warning indicator literature by simulating a 'real time' exercise and by focusing on the usefulness of indicators from a policy maker's perspective.

The results show that some indicators perform very well on average over our two country groups (all 18 and 8 euro area countries, respectively) with regard to standard evaluation criteria like the adjusted noise to signal ratio. ${ }^{36}$ The usefulness of the indicators for a policy maker though crucially depends on her relative preferences with respect to missed crises and false alarms. In case of relatively balanced preferences, the best indicator reduces the preference weighted sum of type I and type II errors by as much as 25 percentage points compared to a situation in which the indicator is ignored.

In our opinion central bankers on average tend to have a stronger preference for missing crises than to act on noisy signals for various reasons. The recent financial crisis may have changed this to some degree. Preferences becoming more balanced might explain the growing interest in early warning systems with respect to financial imbalances.

The best indicator for a policy maker who is only slightly more averse against false alarms than missed crises, is the global private credit gap. In terms of the absolute performance using the optimal $70 \%$ percentile across countries predicted on average $95 \%$ of high-cost booms by issuing a signal in at least one of the six preceding quarters. The share of correct signals as a percentage of periods in which a high-cost boom actually developed within the following

\footnotetext{
${ }^{36}$ These results confirm the findings in Borio and Lowe [2002], [2004] and Borio and Drehmann [2008] for banking crises.
} 
six quarters is $82 \%$. The share of false alarms as a percentage of periods in which no highcost boom followed is $32 \%$ and the average lead time for the first warning signal is 5.5 quarters.

Considering joint indicators is one way of significantly reducing the noisiness of signals (by close to $50 \%$ ), without though noticeably improving the overall gain with respect to preference weighted errors. Furthermore, the optimal threshold percentiles of joint indicators reveal a much stronger cross-country variation than single indicators, which raises issues for extracting optimal percentiles for the euro area by analyzing historical data for individual countries.

With respect to the other three questions mentioned upfront, the results of this paper would suggest that financial variables contain more information for predicting costly asset price booms than the real indicators we tested, that global financial indicators perform better than domestic ones and that global credit outperforms global money, though often by a very small margin.

The good performance of global financial indicators certainly reflects the large international simultaneity of the identified asset price cycles. This underlines the legitimacy of at least reflecting on stability oriented macro and macro-prudential policies from an international perspective.

Nevertheless, as the exercise of predicting the most recent boom wave shows, historically nearly equally well performing indicators can provide different messages. Signals obtained by any of the suggested indicators should thus be interpreted very carefully and should only be considered one of several inputs to the information set of decision makers. In particular, reliance on any single or joint indictor is certainly not advisable at this stage. One way to proceed might be to consider weighted composite indicators as in Kaminsky et al. [1998] and Edison [2003].

Nevertheless the evidence presented in this paper - in our view - shows that the often claimed unavailability of timely warning indicators is unlikely to be a major hindrance for 
'leaning against the wind' type of policies, if the latter would be deemed desirable by policy makers.

In terms of future research, results suggested here should be cross-checked and qualified by discrete choice models in particular to better explore the degree of non-linearity and the codependence between variables to derive an operational early warning indicator system for costly asset price boom/bust cycles. Furthermore, other balance sheet items of (other) financial intermediaries should be analyzed with respect to their information content. 


\section{References}

R. Adalid and C. Detken. Liquidity shocks and asset price boom/bust cycles. Working Paper Series 732, European Central Bank, February 2007.

T. Adrian and H. S. Shin. Financial intermediaries, financial stability and monetary policy. Working Paper Series 346, Federal Reserve Bank of New York, September 2008a.

T. Adrian and H. S. Shin. Money, liquidity and financial cycles. In A. Beyer and L. Reichlin, editors, The Role of Money - Money and Monetary Policy in the Twenty-First Century, pages 299-309. European Central Bank, 2008b.

C. Borio and M. Drehmann. Towards and operational framework for financial stability: "fuzzy" measurement and its consequences. Paper prepared for 12th annual conference of Banco de Chile on financial stability, monetary policy and central banking, Santiago, 6-7 November, 2008.

C. Borio and P. Lowe. Asset prices, financial and monetary stability: Exploring the nexus. Working Paper 114, BIS, 2002.

C. Borio and P. Lowe. Securing sustainable price stability: should credit come back from the wilderness? Working Paper 157, BIS, 2004.

C. Borio and H. Zhu. Capital regulation, risk-taking and monetary policy: A missing link in the tranmsission mechanism? Keynote presentation at the ECB conference on the implications of changes in banking and financing on the monetary policy transmission, Frankfurt, 29-30 November, 2007.

M. Bussière and M. Fratzscher. Low probability, high impact: Policy making and extreme events. Journal of Policy Modeling, 30(1):111-121, 2008.

M. Chui and P. Gai. Private Sector Involvement and International Financial Crises. Oxford University Press, 2005.

M. Ciccarelli and B. Mojon. Global inflation. Working Paper Series WP-08-05, Federal Reserve Bank of Chicago, 2008.

C. Detken and F. Smets. Asset price booms and monetary policy. Working Paper Series 364, European Central Bank, May 2004. 
D. Diamond and R. Rajan. Illiquidity and interest rate policy. Working paper, University of Chicago, October 2008. (Unpublished).

H. Edison. Do indicators of financial crises work? An evaluation of an early warning system. International Journal of Finance \& Economics, 8(1):11-53, 2003.

C. Goodhart and B. Hofmann. House prices, money, credit and the macroeconomy. Working Paper Series 888, European Central Bank, April 2008.

P.-O. Gourinchas, R. Valdes, and O. Landerretche. Lending booms: Latin America and the world. Economía, 1(2):47-99, 2001.

M. Hoerova, C. Monnet, and T. Temzelides. Information and monetary policy. Working paper, European Central Bank, 2008. (Mimeo).

P. Honohan and L. Laeven. Systemic financial distress: Containment and resolution. Cambridge University Press, 2005.

G. Jiménez, S. Ongena, J.-L. Peydró-Alcalde, and J. Saurina. Hazardous times for monetary policy: What do twenty-three million bank loans say about the effects of monetary policy on credit risk? CEPR Discussion Papers 6514, C.E.P.R. Discussion Papers, October 2007.

G. Kaminsky and C. Reinhart. The twin crises: The causes of banking and balance-of-payments problems. American Economic Review, 89(3):473-500, 1999.

G. Kaminsky, S. Lizondo, and C. Reinhart. Leading indicators of currency crisis. Staff Paper 1, IMF, 1998.

D. Kohn. Monetary policy and asset prices revisited. Speech at the Cato Institute's 26th Annual Monetary Policy Conference, Washington, D.C.. Available at www.federalreserve.gov/newsevents/speech/kohn20081119a.htm, 2008.

O. Loisel, A. Pommeret, and F. Portier. Illiquidity and interest rate policy. Working paper, 2008. (Unpublished).

E. Mendoza and M. Terrones. An anatomy of credit booms: Evidence from macro aggregates and micro data. Working Paper 14049, NBER, May 2008. 
R. Ngai and S. Tenreyro. Hot and cold seasons in the housing markets. Working paper, London School of Economics, September 2008. (Unpublished).

R. Rajan. Has financial development made the world riskier? NBER Working Paper 11728, 2005.

R. Rancière, A. Tornell, and F. Westermann. Systemic crises and growth. The Quarterly Journal of Economics, 123(1):359-406, 2008. 
ANNEX 


\section{Legend}

In the tables in the main text as well as this Annex we use the following notation:

Transformations:

detr and $H P=$ deviations from slowly adjusting, recursive Hodrick-Prescott filter trend with a $\lambda$ of 100000 instead of the usual 1600 for quarterly data. The difference between detr and HP only concerns the derivation of the threshold as explained in the main text;

yoy=year on year growth rates;

cum $=$ six quarter cumulated growth rates;

$l e v=$ level.

Variables:

$G D P R=$ real GDP;

$C O N S=$ private final consumption expenditure;

$I N V=$ gross total fixed capital formation;

$H I N V=$ private residential fixed capital formation;

$Q A A P R=$ real aggregate asset price index;

$Q E P R=$ real equity price index;

$Q R P R=$ real residential property price index;

$L R N=$ long-term bond yield, nominal;

$L R R=$ long-term bond yield, real;

$S R N=$ short-term interest rate, nominal;

$S R R=$ short-term interest rate, real;

spread $=$ long-term bond yield minus short-term interest rate;

$R E X=$ real effective exchange rate index; $M 1$ and $M 3=$ respective monetary aggregates; for AU, CA, UK, JP, NO, NZ, SE and the US M3 refers to a broad aggregate M2 or M3;

$P C R=$ real private credit;

$D C R=$ real domestic credit;

$P C N t_{0} G D P$ and $D C N t_{0} G D P=$ respective ratios of nominal variables.

shock $/]=$ six lagged quarters moving average of standard macro VAR including asset prices and money and alternatively credit ordered last (see Adalid and Detken [2007]), estimated recursively.

glob or Global in the notation of variables refers to PPP-GDP weighted averages of the series from all 18 countries. Global credit and monetary aggregates are all nominal ratios to GDP.

All data except asset prices are seasonally adjusted. For $Q R P R$ we also use a seasonally adjusted series $(-s a)$.

The main data source is OECD Economic Outlook and Main Economic Indicators. Domestic and private credit are from the IMF's International Financial Statistics, lines 32 and 32D, respectively. The latter two series have been corrected for structural breaks as described in Adalid and Detken [2007]. Asset price indices have been kindly provided by the BIS. Narrow monetary aggregates are from the BIS and ECB sources. 


\begin{tabular}{|c|c|c|c|c|c|c|c|c|}
\hline Indicators & usefulness & $\begin{array}{r}\% \text { booms } \\
\text { called }\end{array}$ & $\frac{A}{A+C}$ & $\frac{B}{B+D}$ & aNtS & $\frac{A}{A+B}$ & diffprob & ALT \\
\hline CONS-cum & 0.18 & 0.85 & 0.77 & 0.22 & 0.28 & 0.38 & 0.24 & 5.6 \\
\hline LRN-detr & 0.17 & 0.86 & 0.80 & 0.24 & 0.30 & 0.42 & 0.28 & 5.8 \\
\hline QEPR-detr & 0.17 & 0.96 & 0.88 & 0.30 & 0.34 & 0.38 & 0.24 & 5.9 \\
\hline globPC-HP & 0.17 & 0.89 & 0.78 & 0.24 & 0.30 & 0.38 & 0.24 & 5.7 \\
\hline CONS-yoy & 0.16 & 0.93 & 0.78 & 0.26 & 0.33 & 0.33 & 0.19 & 5.5 \\
\hline INV-cum & 0.16 & 0.95 & 0.69 & 0.20 & 0.29 & 0.39 & 0.25 & 4.9 \\
\hline M1-cum & 0.15 & 0.79 & 0.70 & 0.21 & 0.30 & 0.37 & 0.23 & 5.7 \\
\hline GDPR-detr & 0.15 & 0.89 & 0.73 & 0.24 & 0.33 & 0.37 & 0.23 & 5.2 \\
\hline globPC-detr & 0.15 & 0.75 & 0.73 & 0.24 & 0.33 & 0.45 & 0.30 & 6.0 \\
\hline globM1-detr & 0.15 & 0.66 & 0.59 & 0.15 & 0.25 & 0.45 & 0.31 & 5.6 \\
\hline PCR-yoy & 0.14 & 0.73 & 0.62 & 0.17 & 0.28 & 0.45 & 0.31 & 5.4 \\
\hline QEPNtoGDP-detr & 0.14 & 0.88 & 0.81 & 0.30 & 0.37 & 0.36 & 0.22 & 5.9 \\
\hline QAAPR-HP & 0.14 & 0.87 & 0.76 & 0.26 & 0.35 & 0.35 & 0.21 & 5.3 \\
\hline PCR-cum & 0.14 & 0.74 & 0.68 & 0.21 & 0.31 & 0.38 & 0.24 & 5.6 \\
\hline QAAPR-yoy & 0.14 & 1.00 & 0.81 & 0.30 & 0.37 & 0.32 & 0.18 & 5.4 \\
\hline GDPR-HP & 0.14 & 0.98 & 0.87 & 0.34 & 0.39 & 0.29 & 0.15 & 5.8 \\
\hline INVtoGDP-HP & 0.14 & 0.86 & 0.73 & 0.25 & 0.35 & 0.32 & 0.18 & 5.4 \\
\hline INV-yoy & 0.14 & 0.90 & 0.66 & 0.21 & 0.31 & 0.34 & 0.20 & 5.1 \\
\hline QAAPR-cum & 0.14 & 0.93 & 0.77 & 0.28 & 0.36 & 0.35 & 0.21 & 5.0 \\
\hline INVtoGDP-detr & 0.14 & 0.72 & 0.65 & 0.20 & 0.31 & 0.37 & 0.23 & 5.8 \\
\hline QAAPNtoGDP-detr & 0.14 & 0.83 & 0.73 & 0.26 & 0.35 & 0.32 & 0.18 & 5.4 \\
\hline M1-yoy & 0.14 & 0.75 & 0.61 & 0.18 & 0.30 & 0.39 & 0.25 & 5.4 \\
\hline QAAPR-detr & 0.13 & 1.00 & 0.86 & 0.35 & 0.41 & 0.32 & 0.18 & 5.5 \\
\hline HINV-yoy & 0.13 & 0.84 & 0.57 & 0.16 & 0.28 & 0.41 & 0.27 & 4.6 \\
\hline M3-cum & 0.13 & 0.72 & 0.61 & 0.19 & 0.31 & 0.37 & 0.24 & 5.3 \\
\hline SRN-detr & 0.13 & 0.91 & 0.73 & 0.27 & 0.37 & 0.35 & 0.21 & 5.5 \\
\hline HINV-cum & 0.13 & 0.67 & 0.48 & 0.10 & 0.22 & 0.40 & 0.26 & 4.8 \\
\hline QRPR-sa-HP & 0.13 & 0.80 & 0.70 & 0.25 & 0.36 & 0.32 & 0.17 & 5.4 \\
\hline QRPR-HP & 0.13 & 0.79 & 0.69 & 0.25 & 0.36 & 0.32 & 0.18 & 5.3 \\
\hline QAAPNtoGDP-HP & 0.12 & 0.88 & 0.71 & 0.26 & 0.37 & 0.35 & 0.20 & 5.3 \\
\hline M3-yoy & 0.12 & 0.74 & 0.53 & 0.15 & 0.28 & 0.41 & 0.28 & 4.6 \\
\hline HINVtoGDP-detr & 0.12 & 0.53 & 0.43 & 0.09 & 0.20 & 0.31 & 0.17 & 5.0 \\
\hline HINVtoGDP-HP & 0.12 & 0.67 & 0.50 & 0.14 & 0.27 & 0.41 & 0.26 & 4.5 \\
\hline DCR-yoy & 0.11 & 0.78 & 0.63 & 0.23 & 0.37 & 0.35 & 0.21 & 5.2 \\
\hline QEPR-HP & 0.11 & 0.86 & 0.61 & 0.23 & 0.37 & 0.32 & 0.18 & 5.3 \\
\hline DCR-cum & 0.11 & 0.65 & 0.59 & 0.22 & 0.36 & 0.23 & 0.09 & 5.6 \\
\hline globM1-HP & 0.11 & 0.65 & 0.52 & 0.17 & 0.32 & 0.34 & 0.20 & 5.5 \\
\hline QEPR-cum & 0.11 & 0.88 & 0.66 & 0.26 & 0.40 & 0.33 & 0.19 & 5.1 \\
\hline shock-PC & 0.11 & 0.74 & 0.53 & 0.18 & 0.33 & 0.37 & 0.22 & 5.4 \\
\hline QEPR-yoy & 0.11 & 0.94 & 0.71 & 0.30 & 0.42 & 0.34 & 0.20 & 5.4 \\
\hline M1toGDP-detr & 0.10 & 0.77 & 0.68 & 0.28 & 0.41 & 0.31 & 0.17 & 5.6 \\
\hline PCNtoGDP-HP & 0.10 & 0.72 & 0.61 & 0.23 & 0.38 & 0.33 & 0.19 & 5.3 \\
\hline globM3-detr & 0.10 & 0.60 & 0.57 & 0.21 & 0.38 & 0.23 & 0.09 & 5.9 \\
\hline QRPN-satoGDP-HP & 0.10 & 0.67 & 0.62 & 0.25 & 0.41 & 0.31 & 0.16 & 5.4 \\
\hline QRPR-sa-cum & 0.09 & 0.78 & 0.72 & 0.32 & 0.45 & 0.25 & 0.11 & 5.3 \\
\hline QRPR-sa-yoy & 0.09 & 0.85 & 0.70 & 0.31 & 0.44 & 0.27 & 0.13 & 5.0 \\
\hline QRPNtoGDP-HP & 0.09 & 0.64 & 0.58 & 0.23 & 0.39 & 0.34 & 0.19 & 5.3 \\
\hline PCNtoGDP-detr & 0.09 & 0.71 & 0.65 & 0.28 & 0.43 & 0.29 & 0.14 & 5.8 \\
\hline QRPR-yoy & 0.09 & 0.83 & 0.70 & 0.31 & 0.45 & 0.27 & 0.13 & 5.1 \\
\hline shock-M1 & 0.09 & 0.57 & 0.39 & 0.11 & 0.27 & 0.34 & 0.21 & 5.1 \\
\hline SRN-lev & 0.09 & 0.86 & 0.80 & 0.39 & 0.48 & 0.30 & 0.16 & 5.7 \\
\hline QEPNtoGDP-HP & 0.09 & 0.78 & 0.60 & 0.26 & 0.43 & 0.28 & 0.14 & 5.4 \\
\hline globSR-HP & 0.08 & 0.94 & 0.89 & 0.45 & 0.51 & 0.24 & 0.10 & 5.9 \\
\hline QRPR-cum & 0.08 & 0.77 & 0.69 & 0.32 & 0.46 & 0.23 & 0.09 & 5.6 \\
\hline M1toGDP-HP & 0.08 & 0.72 & 0.57 & 0.25 & 0.43 & 0.31 & 0.17 & 5.8 \\
\hline SRR-detr & 0.08 & 0.91 & 0.76 & 0.37 & 0.49 & 0.26 & 0.11 & 5.5 \\
\hline DCNtoGDP-detr & 0.08 & 0.76 & 0.66 & 0.31 & 0.47 & 0.28 & 0.14 & 5.7 \\
\hline LRR-HP & 0.07 & 0.77 & 0.63 & 0.30 & 0.48 & 0.30 & 0.16 & 5.7 \\
\hline REX-HP & 0.07 & 0.62 & 0.44 & 0.17 & 0.40 & 0.29 & 0.15 & 5.1 \\
\hline shock-GlobalPC & 0.07 & 0.71 & 0.46 & 0.19 & 0.42 & 0.24 & 0.10 & 5.3 \\
\hline LRR-detr & 0.07 & 0.85 & 0.69 & 0.34 & 0.50 & 0.23 & 0.09 & 5.5 \\
\hline LRN-HP & 0.07 & 0.68 & 0.60 & 0.28 & 0.48 & 0.25 & 0.11 & 5.9 \\
\hline shock-GlobalM1 & 0.07 & 0.56 & 0.38 & 0.14 & 0.37 & 0.26 & 0.12 & 5.2 \\
\hline SRR-lev & 0.07 & 0.34 & 0.30 & 0.09 & 0.29 & 0.41 & 0.24 & 5.6 \\
\hline LRN-lev & 0.06 & 0.85 & 0.80 & 0.43 & 0.53 & 0.24 & 0.10 & 5.8 \\
\hline spread-lev & 0.06 & 0.56 & 0.49 & 0.22 & 0.45 & 0.32 & 0.17 & 5.4 \\
\hline QRPR-sa-detr & 0.06 & 0.76 & 0.71 & 0.37 & 0.52 & 0.25 & 0.11 & 5.3 \\
\hline QRPR-detr & 0.06 & 0.76 & 0.71 & 0.37 & 0.53 & 0.25 & 0.11 & 5.3 \\
\hline shock-M3 & 0.06 & 0.56 & 0.43 & 0.19 & 0.44 & 0.27 & 0.12 & 5.5 \\
\hline globM3-HP & 0.05 & 0.79 & 0.66 & 0.35 & 0.53 & 0.24 & 0.10 & 5.4 \\
\hline shock-GlobalM3 & 0.05 & 0.38 & 0.28 & 0.10 & 0.37 & 0.34 & 0.18 & 5.4 \\
\hline REX-cum & 0.05 & 0.54 & 0.33 & 0.14 & 0.42 & 0.23 & 0.09 & 4.8 \\
\hline LRR-lev & 0.05 & 0.32 & 0.30 & 0.12 & 0.40 & 0.27 & 0.12 & 5.7 \\
\hline DCNtoGDP-HP & 0.05 & 0.55 & 0.40 & 0.19 & 0.47 & 0.20 & 0.05 & 5.3 \\
\hline QRPN-satoGDP-detr & 0.04 & 0.63 & 0.57 & 0.31 & 0.55 & 0.22 & 0.08 & 4.8 \\
\hline globSR-detr & 0.04 & 0.43 & 0.37 & 0.18 & 0.49 & 0.21 & 0.07 & 5.6 \\
\hline SRN-HP & 0.04 & 0.58 & 0.41 & 0.21 & 0.51 & 0.18 & 0.05 & 5.2 \\
\hline M3toGDP-detr & 0.04 & 0.59 & 0.51 & 0.27 & 0.54 & 0.22 & 0.07 & 4.9 \\
\hline REX-detr & 0.04 & 0.66 & 0.51 & 0.28 & 0.55 & 0.26 & 0.12 & 5.1 \\
\hline QRPNtoGDP-detr & 0.04 & 0.63 & 0.59 & 0.33 & 0.57 & 0.21 & 0.06 & 5.0 \\
\hline REX-yoy & 0.03 & 0.54 & 0.38 & 0.20 & 0.52 & 0.21 & 0.07 & 5.5 \\
\hline SRR-HP & 0.03 & 0.50 & 0.34 & 0.17 & 0.51 & 0.18 & 0.03 & 5.5 \\
\hline M3toGDP-HP & 0.03 & 0.34 & 0.28 & 0.14 & 0.49 & 0.16 & 0.02 & 5.9 \\
\hline -spread-lev & 0.02 & 0.44 & 0.31 & 0.18 & 0.57 & 0.13 & 0.00 & 5.0 \\
\hline CONStoGDP-detr & 0.02 & 0.23 & 0.17 & 0.08 & 0.50 & 0.15 & 0.01 & 5.3 \\
\hline globSR-lev & 0.02 & 0.25 & 0.23 & 0.13 & 0.55 & 0.10 & -0.04 & 5.7 \\
\hline CPI-yoy & 0.01 & 0.21 & 0.18 & 0.10 & 0.55 & 0.26 & 0.10 & 5.5 \\
\hline CPI-cum & 0.01 & 0.15 & 0.12 & 0.06 & 0.53 & 0.19 & 0.03 & 4.9 \\
\hline CONStoGDP-HP & 0.01 & 0.35 & 0.16 & 0.10 & 0.60 & 0.17 & 0.02 & 4.1 \\
\hline
\end{tabular}

Table 1: $\theta=0.4$, average results over all countries, High-Cost Booms. 


\begin{tabular}{|c|c|c|c|c|c|c|c|c|}
\hline Indicators & usefulness & $\begin{array}{r}\% \text { booms } \\
\text { called }\end{array}$ & $\frac{A}{A+C}$ & $\frac{B}{B+D}$ & aNtS & $\frac{A}{A+B}$ & diffprob & ALT \\
\hline globPC-detr & 0.18 & 0.69 & 0.67 & 0.15 & 0.22 & 0.55 & 0.39 & 5.8 \\
\hline globPC-HP & 0.18 & 0.92 & 0.84 & 0.26 & 0.31 & 0.39 & 0.23 & 5.7 \\
\hline LRN-detr & 0.18 & 0.83 & 0.73 & 0.19 & 0.26 & 0.49 & 0.33 & 5.3 \\
\hline M1toGDP-detr & 0.17 & 0.85 & 0.78 & 0.24 & 0.30 & 0.37 & 0.21 & 5.7 \\
\hline QEPR-detr & 0.17 & 0.84 & 0.76 & 0.22 & 0.29 & 0.39 & 0.23 & 5.9 \\
\hline SRN-detr & 0.16 & 0.70 & 0.58 & 0.12 & 0.21 & 0.37 & 0.27 & 4.2 \\
\hline M1-cum & 0.16 & 0.92 & 0.75 & 0.24 & 0.32 & 0.41 & 0.25 & 5.6 \\
\hline QEPNtoGDP-detr & 0.15 & 0.75 & 0.71 & 0.22 & 0.31 & 0.38 & 0.22 & 5.8 \\
\hline INVtoGDP-HP & 0.14 & 1.00 & 0.84 & 0.33 & 0.39 & 0.33 & 0.18 & 5.4 \\
\hline INV-cum & 0.14 & 0.99 & 0.73 & 0.26 & 0.35 & 0.38 & 0.22 & 5.0 \\
\hline INV-yoy & 0.14 & 1.00 & 0.75 & 0.27 & 0.36 & 0.34 & 0.19 & 5.0 \\
\hline globM1-detr & 0.14 & 0.74 & 0.61 & 0.17 & 0.29 & 0.38 & 0.23 & 4.8 \\
\hline M1-yoy & 0.13 & 0.85 & 0.72 & 0.26 & 0.36 & 0.37 & 0.21 & 5.6 \\
\hline QAAPR-yoy & 0.13 & 1.00 & 0.88 & 0.36 & 0.41 & 0.32 & 0.16 & 5.9 \\
\hline QAAPR-cum & 0.13 & 1.00 & 0.87 & 0.36 & 0.41 & 0.31 & 0.15 & 5.7 \\
\hline QEPR-cum & 0.13 & 0.83 & 0.66 & 0.23 & 0.34 & 0.38 & 0.22 & 5.5 \\
\hline QAAPNtoGDP-HP & 0.13 & 1.00 & 0.68 & 0.24 & 0.36 & 0.34 & 0.19 & 5.3 \\
\hline QEPR-yoy & 0.13 & 0.95 & 0.67 & 0.24 & 0.36 & 0.36 & 0.20 & 5.0 \\
\hline QAAPR-HP & 0.12 & 0.99 & 0.81 & 0.33 & 0.41 & 0.30 & 0.14 & 5.8 \\
\hline LRR-HP & 0.12 & 0.85 & 0.76 & 0.31 & 0.40 & 0.35 & 0.19 & 5.4 \\
\hline CONS-yoy & 0.12 & 0.95 & 0.68 & 0.25 & 0.37 & 0.31 & 0.16 & 4.6 \\
\hline globSR-HP & 0.11 & 1.00 & 0.93 & 0.43 & 0.46 & 0.31 & 0.15 & 5.9 \\
\hline HINV-yoy & 0.11 & 0.59 & 0.38 & 0.06 & 0.17 & 0.44 & 0.30 & 4.0 \\
\hline PCR-cum & 0.11 & 0.63 & 0.48 & 0.14 & 0.28 & 0.35 & 0.21 & 3.9 \\
\hline SRN-lev & 0.11 & 0.87 & 0.79 & 0.35 & 0.44 & 0.36 & 0.21 & 6.0 \\
\hline LRN-HP & 0.11 & 0.49 & 0.45 & 0.12 & 0.26 & 0.24 & 0.14 & 4.0 \\
\hline GDPR-HP & 0.10 & 1.00 & 0.90 & 0.43 & 0.48 & 0.28 & 0.12 & 5.8 \\
\hline CONS-cum & 0.10 & 0.68 & 0.51 & 0.17 & 0.33 & 0.29 & 0.15 & 4.1 \\
\hline PCR-yoy & 0.10 & 0.58 & 0.45 & 0.13 & 0.29 & 0.40 & 0.26 & 3.4 \\
\hline shock-GlobalPC & 0.10 & 0.93 & 0.63 & 0.26 & 0.40 & 0.31 & 0.16 & 5.3 \\
\hline M1toGDP-HP & 0.10 & 0.85 & 0.76 & 0.34 & 0.45 & 0.35 & 0.20 & 5.8 \\
\hline QEPR-HP & 0.10 & 0.79 & 0.59 & 0.23 & 0.40 & 0.32 & 0.16 & 5.4 \\
\hline shock-M1 & 0.09 & 0.55 & 0.40 & 0.11 & 0.27 & 0.31 & 0.16 & 3.4 \\
\hline HINV-cum & 0.09 & 0.58 & 0.32 & 0.06 & 0.18 & 0.36 & 0.22 & 3.1 \\
\hline QAAPNtoGDP-detr & 0.09 & 0.79 & 0.74 & 0.34 & 0.46 & 0.27 & 0.11 & 4.6 \\
\hline M3-cum & 0.09 & 0.73 & 0.69 & 0.32 & 0.46 & 0.20 & 0.09 & 4.4 \\
\hline globM3-detr & 0.09 & 0.56 & 0.50 & 0.19 & 0.39 & 0.20 & 0.05 & 4.3 \\
\hline GDPR-detr & 0.08 & 0.59 & 0.44 & 0.16 & 0.36 & 0.34 & 0.18 & 3.5 \\
\hline QEPNtoGDP-HP & 0.08 & 0.79 & 0.67 & 0.32 & 0.47 & 0.29 & 0.13 & 5.9 \\
\hline REX-HP & 0.08 & 0.55 & 0.35 & 0.10 & 0.29 & 0.24 & 0.14 & 3.1 \\
\hline QAAPR-detr & 0.08 & 1.00 & 0.86 & 0.44 & 0.52 & 0.32 & 0.17 & 5.5 \\
\hline SRN-HP & 0.08 & 0.46 & 0.37 & 0.12 & 0.33 & 0.14 & 0.03 & 2.8 \\
\hline SRR-detr & 0.08 & 0.95 & 0.65 & 0.31 & 0.47 & 0.30 & 0.14 & 5.6 \\
\hline globSR-detr & 0.07 & 0.59 & 0.43 & 0.17 & 0.39 & 0.26 & 0.10 & 2.7 \\
\hline shock-PC & 0.07 & 0.63 & 0.50 & 0.22 & 0.43 & 0.25 & 0.13 & 3.3 \\
\hline globM1-HP & 0.07 & 0.49 & 0.39 & 0.15 & 0.37 & 0.22 & 0.06 & 3.0 \\
\hline INVtoGDP-detr & 0.07 & 0.43 & 0.39 & 0.15 & 0.38 & 0.29 & 0.13 & 4.2 \\
\hline PCNtoGDP-detr & 0.06 & 0.57 & 0.52 & 0.24 & 0.47 & 0.26 & 0.10 & 5.0 \\
\hline HINVtoGDP-HP & 0.06 & 0.46 & 0.29 & 0.09 & 0.32 & 0.34 & 0.21 & 2.6 \\
\hline REX-cum & 0.06 & 0.51 & 0.30 & 0.10 & 0.33 & 0.23 & 0.08 & 2.9 \\
\hline DCR-yoy & 0.06 & 0.94 & 0.79 & 0.43 & 0.54 & 0.26 & 0.11 & 5.7 \\
\hline QRPR-sa-HP & 0.06 & 0.68 & 0.55 & 0.27 & 0.49 & 0.18 & 0.02 & 3.6 \\
\hline PCNtoGDP-HP & 0.06 & 0.79 & 0.73 & 0.39 & 0.53 & 0.29 & 0.13 & 4.8 \\
\hline SRR-lev & 0.06 & 0.32 & 0.22 & 0.05 & 0.22 & 0.45 & 0.33 & 3.3 \\
\hline SRR-HP & 0.06 & 0.62 & 0.42 & 0.19 & 0.44 & 0.20 & 0.05 & 3.6 \\
\hline globM3-HP & 0.05 & 0.70 & 0.58 & 0.30 & 0.51 & 0.34 & 0.18 & 4.9 \\
\hline QRPR-HP & 0.05 & 0.69 & 0.54 & 0.27 & 0.50 & 0.18 & 0.02 & 3.6 \\
\hline DCNtoGDP-detr & 0.05 & 0.65 & 0.60 & 0.31 & 0.52 & 0.19 & 0.03 & 4.8 \\
\hline DCR-cum & 0.05 & 0.51 & 0.46 & 0.22 & 0.48 & 0.12 & -0.04 & 2.9 \\
\hline LRN-lev & 0.05 & 0.72 & 0.71 & 0.39 & 0.55 & 0.29 & 0.14 & 6.0 \\
\hline M3-yoy & 0.05 & 0.59 & 0.43 & 0.20 & 0.47 & 0.19 & 0.08 & 3.3 \\
\hline spread-lev & 0.05 & 0.62 & 0.43 & 0.21 & 0.48 & 0.30 & 0.16 & 4.1 \\
\hline shock-GlobalM3 & 0.05 & 0.44 & 0.31 & 0.13 & 0.41 & 0.23 & 0.11 & 3.1 \\
\hline REX-yoy & 0.04 & 0.47 & 0.41 & 0.21 & 0.50 & 0.15 & 0.00 & 3.5 \\
\hline globSR-lev & 0.04 & 0.49 & 0.42 & 0.21 & 0.51 & 0.17 & 0.01 & 3.0 \\
\hline LRR-detr & 0.04 & 0.78 & 0.57 & 0.32 & 0.56 & 0.23 & 0.07 & 3.9 \\
\hline QRPN-satoGDP-HP & 0.04 & 0.67 & 0.57 & 0.32 & 0.56 & 0.17 & 0.01 & 3.8 \\
\hline CONStoGDP-detr & 0.04 & 0.34 & 0.23 & 0.10 & 0.41 & 0.27 & 0.12 & 3.0 \\
\hline HINVtoGDP-detr & 0.04 & 0.28 & 0.14 & 0.03 & 0.24 & 0.21 & 0.05 & 1.7 \\
\hline QRPNtoGDP-HP & 0.04 & 0.66 & 0.57 & 0.32 & 0.56 & 0.16 & 0.00 & 3.8 \\
\hline shock-GlobalM1 & 0.03 & 0.46 & 0.27 & 0.12 & 0.46 & 0.17 & 0.02 & 3.5 \\
\hline LRR-lev & 0.03 & 0.37 & 0.31 & 0.15 & 0.49 & 0.19 & 0.08 & 3.3 \\
\hline REX-detr & 0.03 & 0.70 & 0.41 & 0.22 & 0.54 & 0.32 & 0.17 & 4.9 \\
\hline CONStoGDP-HP & 0.03 & 0.46 & 0.15 & 0.05 & 0.32 & 0.31 & 0.16 & 2.7 \\
\hline shock-M3 & 0.03 & 0.42 & 0.20 & 0.08 & 0.42 & 0.25 & 0.14 & 2.7 \\
\hline QRPR-sa-yoy & 0.03 & 0.70 & 0.57 & 0.33 & 0.59 & 0.16 & 0.01 & 3.8 \\
\hline QRPR-yoy & 0.03 & 0.66 & 0.55 & 0.33 & 0.59 & 0.16 & 0.01 & 3.9 \\
\hline CPI-yoy & 0.02 & 0.15 & 0.13 & 0.06 & 0.43 & 0.20 & 0.14 & 1.3 \\
\hline CPI-cum & 0.01 & 0.13 & 0.10 & 0.04 & 0.44 & 0.16 & 0.10 & 1.0 \\
\hline QRPR-sa-cum & 0.01 & 0.48 & 0.41 & 0.26 & 0.64 & 0.13 & -0.03 & 2.6 \\
\hline M3toGDP-HP & 0.00 & 0.56 & 0.41 & 0.27 & 0.65 & 0.14 & -0.02 & 3.3 \\
\hline QRPR-cum & 0.00 & 0.48 & 0.41 & 0.27 & 0.67 & 0.12 & -0.03 & 2.7 \\
\hline DCNtoGDP-HP & -0.01 & 0.65 & 0.41 & 0.28 & 0.69 & 0.17 & 0.02 & 3.8 \\
\hline -spread-lev & -0.01 & 0.16 & 0.06 & 0.05 & 0.94 & 0.02 & -0.03 & 0.4 \\
\hline QRPR-sa-detr & -0.02 & 0.48 & 0.43 & 0.31 & 0.73 & 0.12 & -0.04 & 2.7 \\
\hline QRPN-satoGDP-detr & -0.02 & 0.25 & 0.25 & 0.20 & 0.78 & 0.05 & -0.10 & 1.5 \\
\hline QRPR-detr & -0.02 & 0.48 & 0.44 & 0.33 & 0.73 & 0.12 & -0.04 & 2.8 \\
\hline QRPNtoGDP-detr & -0.02 & 0.25 & 0.25 & 0.20 & 0.80 & 0.05 & -0.10 & 1.5 \\
\hline M3toGDP-detr & -0.02 & 0.53 & 0.38 & 0.29 & 0.77 & 0.13 & -0.03 & 3.1 \\
\hline
\end{tabular}

Table 2: $\theta=0.4$, weighted-average results over EA countries, High-Cost Booms. 


\begin{tabular}{|c|c|c|c|c|c|c|c|c|}
\hline Indicators & usefulness & $\begin{array}{r}\text { Opt. } \\
\text { Percen. }\end{array}$ & $\begin{array}{r}\text { Coeff. } \\
\text { Variation }\end{array}$ & $\begin{array}{r}\% \text { booms } \\
\text { called }\end{array}$ & $\frac{A}{A+C}$ & $\frac{B}{B+D}$ & aNtSs & $\frac{A}{A+B}$ \\
\hline globM1-detr & 0.03 & 95 & 0.03 & 0.51 & 0.38 & 0.06 & 0.17 & 0.52 \\
\hline shock-GlobalM1 & 0.01 & 95 & 0.07 & 0.24 & 0.09 & 0.01 & 0.12 & 0.57 \\
\hline globM1-HP & 0.01 & 95 & 0.04 & 0.29 & 0.11 & 0.02 & 0.14 & 0.57 \\
\hline M1-cum & 0.01 & 95 & 0.10 & 0.33 & 0.19 & 0.04 & 0.19 & 0.36 \\
\hline INVtoGDP-detr & 0.00 & 95 & 0.11 & 0.40 & 0.21 & 0.05 & 0.23 & 0.40 \\
\hline INV-cum & 0.00 & 95 & 0.12 & 0.53 & 0.18 & 0.04 & 0.24 & 0.40 \\
\hline HINVtoGDP-detr & 0.00 & 95 & 0.06 & 0.32 & 0.16 & 0.04 & 0.24 & 0.30 \\
\hline shock-M1 & 0.00 & 95 & 0.12 & 0.16 & 0.06 & 0.01 & 0.23 & 0.35 \\
\hline HINV-yoy & 0.00 & 90 & 0.08 & 0.52 & 0.16 & 0.04 & 0.25 & 0.43 \\
\hline shock-GlobalM3 & 0.00 & 90 & 0.04 & 0.00 & 0.00 & 0.00 & & \\
\hline SRR-lev & 0.00 & 95 & 0.17 & 0.00 & 0.00 & 0.00 & & 0.00 \\
\hline globPC-detr & 0.00 & 95 & 0.03 & 0.59 & 0.44 & 0.11 & 0.25 & 0.48 \\
\hline CONS-yoy & 0.00 & 95 & 0.14 & 0.09 & 0.02 & 0.01 & 0.34 & 0.50 \\
\hline HINV-cum & 0.00 & 90 & 0.14 & 0.35 & 0.13 & 0.03 & 0.27 & 0.39 \\
\hline M3-cum & 0.00 & 85 & 0.10 & 0.41 & 0.25 & 0.06 & 0.26 & 0.35 \\
\hline M3-yoy & 0.00 & 95 & 0.11 & 0.27 & 0.08 & 0.02 & 0.28 & 0.50 \\
\hline globPC-HP & 0.00 & 95 & 0.07 & 0.15 & 0.05 & 0.02 & 0.31 & 0.42 \\
\hline M1-yoy & 0.00 & 95 & 0.10 & 0.25 & 0.14 & 0.04 & 0.28 & 0.35 \\
\hline CONS-cum & 0.00 & 95 & 0.18 & 0.02 & 0.01 & 0.01 & 0.70 & 0.20 \\
\hline HINVtoGDP-HP & 0.00 & 95 & 0.10 & 0.14 & 0.04 & 0.02 & 0.39 & 0.36 \\
\hline PCR-yoy & -0.01 & 95 & 0.15 & 0.25 & 0.09 & 0.03 & 0.34 & 0.42 \\
\hline INVtoGDP-HP & -0.01 & 95 & 0.08 & 0.13 & 0.09 & 0.03 & 0.34 & 0.18 \\
\hline LRR-lev & -0.01 & 95 & 0.09 & 0.00 & 0.00 & 0.01 & & 0.00 \\
\hline INV-yoy & -0.01 & 95 & 0.11 & 0.35 & 0.11 & 0.04 & 0.33 & 0.33 \\
\hline shock-GlobalPC & -0.01 & 95 & 0.10 & 0.17 & 0.05 & 0.02 & 0.45 & 0.22 \\
\hline CPI-yoy & -0.01 & 95 & 0.19 & 0.00 & 0.00 & 0.01 & & 0.00 \\
\hline CPI-cum & -0.01 & 95 & 0.17 & 0.00 & 0.00 & 0.01 & & 0.00 \\
\hline QRPNtoGDP-HP & -0.01 & 95 & 0.07 & 0.11 & 0.04 & 0.02 & 0.54 & 0.38 \\
\hline PCR-cum & -0.01 & 95 & 0.12 & 0.22 & 0.07 & 0.03 & 0.42 & 0.29 \\
\hline QRPR-yoy & -0.01 & 95 & 0.07 & 0.08 & 0.04 & 0.02 & 0.62 & 0.19 \\
\hline DCR-cum & -0.01 & 95 & 0.19 & 0.16 & 0.07 & 0.03 & 0.45 & 0.19 \\
\hline QRPR-HP & -0.01 & 95 & 0.09 & 0.15 & 0.07 & 0.03 & 0.44 & 0.31 \\
\hline QRPN-satoGDP-HP & -0.01 & 95 & 0.07 & 0.11 & 0.04 & 0.02 & 0.57 & 0.28 \\
\hline SRR-HP & -0.01 & 95 & 0.06 & 0.04 & 0.02 & 0.02 & 1.15 & 0.08 \\
\hline DCR-yoy & -0.01 & 95 & 0.13 & 0.13 & 0.05 & 0.03 & 0.51 & 0.13 \\
\hline LRR-HP & -0.01 & 95 & 0.06 & 0.06 & 0.03 & 0.02 & 0.77 & 0.16 \\
\hline QRPR-sa-yoy & -0.01 & 95 & 0.06 & 0.08 & 0.04 & 0.02 & 0.65 & 0.17 \\
\hline QAAPR-cum & -0.01 & 95 & 0.07 & 0.38 & 0.14 & 0.05 & 0.36 & 0.39 \\
\hline QRPR-sa-HP & -0.01 & 95 & 0.07 & 0.11 & 0.04 & 0.03 & 0.61 & 0.31 \\
\hline shock-M3 & -0.01 & 95 & 0.09 & 0.05 & 0.02 & 0.02 & 1.11 & 0.20 \\
\hline shock-PC & -0.01 & 95 & 0.18 & 0.06 & 0.04 & 0.03 & 0.68 & 0.11 \\
\hline QAAPR-yoy & -0.01 & 95 & 0.08 & 0.32 & 0.13 & 0.05 & 0.39 & 0.28 \\
\hline GDPR-detr & -0.01 & 95 & 0.09 & 0.65 & 0.37 & 0.11 & 0.30 & 0.35 \\
\hline QRPR-sa-cum & -0.01 & 95 & 0.07 & 0.09 & 0.04 & 0.03 & 0.71 & 0.25 \\
\hline globSR-HP & -0.02 & 90 & 0.05 & 0.05 & 0.01 & 0.02 & 1.78 & 0.13 \\
\hline QEPR-detr & -0.02 & 95 & 0.10 & 0.71 & 0.47 & 0.14 & 0.29 & 0.35 \\
\hline QRPR-cum & -0.02 & 95 & 0.07 & 0.07 & 0.02 & 0.03 & 1.36 & 0.22 \\
\hline QEPR-HP & -0.02 & 95 & 0.04 & 0.42 & 0.18 & 0.07 & 0.39 & 0.34 \\
\hline QEPR-cum & -0.02 & 95 & 0.03 & 0.45 & 0.20 & 0.08 & 0.37 & 0.32 \\
\hline QAAPR-HP & -0.02 & 95 & 0.10 & 0.23 & 0.09 & 0.05 & 0.53 & 0.33 \\
\hline QEPNtoGDP-detr & -0.02 & 95 & 0.07 & 0.61 & 0.39 & 0.12 & 0.32 & 0.33 \\
\hline QAAPNtoGDP-HP & -0.02 & 95 & 0.10 & 0.17 & 0.06 & 0.04 & 0.68 & 0.25 \\
\hline LRN-detr & -0.02 & 95 & 0.08 & 0.44 & 0.28 & 0.10 & 0.35 & 0.38 \\
\hline globM3-HP & -0.02 & 95 & 0.03 & 0.11 & 0.02 & 0.03 & 1.82 & 0.10 \\
\hline QEPNtoGDP-HP & -0.02 & 95 & 0.03 & 0.31 & 0.11 & 0.06 & 0.53 & 0.31 \\
\hline REX-cum & -0.02 & 95 & 0.04 & 0.18 & 0.07 & 0.05 & 0.69 & 0.25 \\
\hline QEPR-yoy & -0.02 & 95 & 0.03 & 0.41 & 0.16 & 0.07 & 0.44 & 0.30 \\
\hline globSR-detr & -0.02 & 95 & 0.09 & 0.05 & 0.02 & 0.04 & 1.78 & 0.13 \\
\hline SRN-HP & -0.03 & 95 & 0.06 & 0.08 & 0.02 & 0.04 & 1.81 & 0.06 \\
\hline REX-yoy & -0.03 & 95 & 0.02 & 0.19 & 0.06 & 0.05 & 0.79 & 0.16 \\
\hline M3toGDP-HP & -0.03 & 95 & 0.02 & 0.24 & 0.13 & 0.06 & 0.51 & 0.13 \\
\hline SRN-detr & -0.03 & 95 & 0.12 & 0.24 & 0.09 & 0.06 & 0.66 & 0.24 \\
\hline REX-HP & -0.03 & 95 & 0.04 & 0.22 & 0.07 & 0.05 & 0.76 & 0.25 \\
\hline spread-lev & -0.03 & 95 & 0.11 & 0.06 & 0.02 & 0.05 & 2.00 & 0.13 \\
\hline GDPR-HP & -0.03 & 95 & 0.08 & 0.32 & 0.12 & 0.07 & 0.59 & 0.12 \\
\hline LRN-HP & -0.03 & 95 & 0.04 & 0.29 & 0.14 & 0.08 & 0.56 & 0.20 \\
\hline CONStoGDP-detr & -0.03 & 95 & 0.06 & 0.11 & 0.05 & 0.06 & 1.09 & 0.12 \\
\hline CONStoGDP-HP & -0.03 & 95 & 0.05 & 0.18 & 0.04 & 0.05 & 1.47 & 0.10 \\
\hline PCNtoGDP-HP & -0.03 & 95 & 0.08 & 0.28 & 0.15 & 0.08 & 0.54 & 0.29 \\
\hline globM3-detr & -0.04 & 95 & 0.07 & 0.24 & 0.09 & 0.07 & 0.76 & 0.16 \\
\hline M1toGDP-HP & -0.04 & 95 & 0.05 & 0.22 & 0.11 & 0.07 & 0.68 & 0.19 \\
\hline -spread-lev & -0.04 & 95 & 0.06 & 0.03 & 0.00 & 0.05 & 12.29 & 0.02 \\
\hline QAAPR-detr & -0.04 & 95 & 0.06 & 0.47 & 0.19 & 0.10 & 0.50 & 0.27 \\
\hline globSR-lev & -0.04 & 95 & 0.07 & 0.05 & 0.01 & 0.05 & 7.64 & 0.04 \\
\hline QAAPNtoGDP-detr & -0.04 & 95 & 0.13 & 0.37 & 0.17 & 0.09 & 0.56 & 0.28 \\
\hline LRR-detr & -0.04 & 95 & 0.03 & 0.29 & 0.11 & 0.08 & 0.74 & 0.16 \\
\hline REX-detr & -0.05 & 95 & 0.11 & 0.26 & 0.11 & 0.09 & 0.76 & 0.18 \\
\hline SRR-detr & -0.05 & 95 & 0.05 & 0.30 & 0.10 & 0.08 & 0.83 & 0.14 \\
\hline QRPN-satoGDP-detr & -0.05 & 95 & 0.02 & 0.09 & 0.04 & 0.07 & 1.95 & 0.12 \\
\hline QRPNtoGDP-detr & -0.05 & 95 & 0.02 & 0.09 & 0.04 & 0.07 & 1.98 & 0.12 \\
\hline DCNtoGDP-HP & -0.05 & 95 & 0.11 & 0.18 & 0.06 & 0.08 & 1.29 & 0.13 \\
\hline QRPR-sa-detr & -0.05 & 95 & 0.04 & 0.14 & 0.06 & 0.08 & 1.32 & 0.18 \\
\hline QRPR-detr & -0.06 & 95 & 0.04 & 0.11 & 0.05 & 0.08 & 1.60 & 0.17 \\
\hline PCNtoGDP-detr & -0.06 & 95 & 0.11 & 0.38 & 0.21 & 0.13 & 0.62 & 0.22 \\
\hline M1toGDP-detr & -0.07 & 95 & 0.05 & 0.48 & 0.28 & 0.16 & 0.56 & 0.23 \\
\hline DCNtoGDP-detr & -0.08 & 95 & 0.17 & 0.27 & 0.15 & 0.14 & 0.94 & 0.18 \\
\hline M3toGDP-detr & -0.08 & 95 & 0.10 & 0.34 & 0.18 & 0.15 & 0.83 & 0.17 \\
\hline SRN-lev & -0.09 & 95 & 0.03 & 0.36 & 0.19 & 0.16 & 0.83 & 0.23 \\
\hline LRN-lev & -0.13 & 95 & 0.10 & 0.40 & 0.26 & 0.22 & 0.85 & 0.21 \\
\hline
\end{tabular}

Table 3: $\theta=0.2$, average results over all countries (same percentile), High-Cost Booms. 


\begin{tabular}{|c|c|c|c|c|c|c|c|c|}
\hline Indicators & usefulness & $\begin{array}{l}\text { Opt. } \\
\text { Percen. }\end{array}$ & $\begin{array}{l}\text { Coeff. } \\
\text { Variation }\end{array}$ & $\begin{array}{r}\% \text { booms } \\
\text { called }\end{array}$ & $\frac{A}{A+C}$ & $\frac{B}{B+D}$ & $\mathrm{aNtS}$ & $\frac{A}{A+B}$ \\
\hline globPC-HP & 0.13 & 70 & 0.10 & 0.95 & 0.82 & 0.32 & 0.39 & 0.30 \\
\hline globPC-detr & 0.13 & 90 & 0.39 & 0.59 & 0.55 & 0.15 & 0.28 & 0.42 \\
\hline globM1-detr & 0.12 & 90 & 0.08 & 0.61 & 0.48 & 0.12 & 0.25 & 0.41 \\
\hline QEPR-detr & 0.11 & 80 & 0.25 & 0.88 & 0.73 & 0.31 & 0.42 & 0.28 \\
\hline INV-cum & 0.11 & 65 & 0.21 & 0.97 & 0.67 & 0.27 & 0.40 & 0.29 \\
\hline CONS-cum & 0.11 & 55 & 0.33 & 0.87 & 0.64 & 0.25 & 0.39 & 0.30 \\
\hline INV-yoy & 0.11 & 70 & 0.25 & 1.00 & 0.59 & 0.22 & 0.37 & 0.31 \\
\hline QAAPR-yoy & 0.10 & 70 & 0.24 & 0.98 & 0.62 & 0.25 & 0.41 & 0.30 \\
\hline GDPR-HP & 0.10 & 80 & 0.26 & 0.92 & 0.60 & 0.24 & 0.40 & 0.28 \\
\hline CONS-yoy & 0.10 & 50 & 0.30 & 0.97 & 0.73 & 0.32 & 0.45 & 0.26 \\
\hline QAAPR-HP & 0.09 & 85 & 0.18 & 0.78 & 0.47 & 0.16 & 0.34 & 0.35 \\
\hline LRN-detr & 0.09 & 85 & 0.24 & 0.65 & 0.51 & 0.19 & 0.37 & 0.34 \\
\hline QAAPR-cum & 0.09 & 80 & 0.27 & 0.86 & 0.49 & 0.17 & 0.35 & 0.35 \\
\hline HINV-yoy & 0.09 & 75 & 0.18 & 0.81 & 0.45 & 0.15 & 0.34 & 0.32 \\
\hline QEPNtoGDP-detr & 0.09 & 90 & 0.31 & 0.71 & 0.49 & 0.18 & 0.37 & 0.31 \\
\hline INVtoGDP-HP & 0.08 & 65 & 0.23 & 0.98 & 0.70 & 0.33 & 0.47 & 0.26 \\
\hline GDPR-detr & 0.08 & 85 & 0.25 & 0.80 & 0.59 & 0.25 & 0.43 & 0.27 \\
\hline HINV-cum & 0.08 & 70 & 0.16 & 0.77 & 0.47 & 0.18 & 0.39 & 0.30 \\
\hline PCR-yoy & 0.08 & 75 & 0.33 & 0.56 & 0.39 & 0.13 & 0.33 & 0.32 \\
\hline QRPR-sa-HP & 0.08 & 75 & 0.19 & 0.82 & 0.60 & 0.27 & 0.45 & 0.27 \\
\hline QAAPR-detr & 0.07 & 70 & 0.33 & 0.95 & 0.77 & 0.39 & 0.51 & 0.24 \\
\hline INVtoGDP-detr & 0.07 & 85 & 0.29 & 0.54 & 0.41 & 0.15 & 0.37 & 0.26 \\
\hline M1-yoy & 0.07 & 75 & 0.19 & 0.81 & 0.57 & 0.25 & 0.45 & 0.27 \\
\hline M1-cum & 0.07 & 75 & 0.24 & 0.78 & 0.58 & 0.27 & 0.46 & 0.26 \\
\hline M3-cum & 0.07 & 80 & 0.32 & 0.48 & 0.32 & 0.09 & 0.30 & 0.34 \\
\hline PCR-cum & 0.07 & 70 & 0.32 & 0.57 & 0.46 & 0.19 & 0.42 & 0.26 \\
\hline M3-yoy & 0.07 & 80 & 0.28 & 0.52 & 0.31 & 0.09 & 0.30 & 0.35 \\
\hline HINVtoGDP-HP & 0.07 & 80 & 0.17 & 0.64 & 0.34 & 0.11 & 0.33 & 0.31 \\
\hline HINVtoGDP-detr & 0.07 & 90 & 0.12 & 0.51 & 0.30 & 0.09 & 0.30 & 0.34 \\
\hline QRPR-HP & 0.06 & 70 & 0.18 & 0.83 & 0.65 & 0.33 & 0.50 & 0.24 \\
\hline QAAPNtoGDP-detr & 0.06 & 70 & 0.27 & 0.82 & 0.65 & 0.33 & 0.50 & 0.24 \\
\hline M1toGDP-detr & 0.06 & 85 & 0.23 & 0.70 & 0.56 & 0.27 & 0.48 & 0.24 \\
\hline QEPR-cum & 0.06 & 80 & 0.21 & 0.84 & 0.53 & 0.25 & 0.48 & 0.25 \\
\hline SRN-detr & 0.06 & 60 & 0.29 & 0.94 & 0.68 & 0.36 & 0.52 & 0.23 \\
\hline QEPR-HP & 0.06 & 85 & 0.14 & 0.77 & 0.44 & 0.20 & 0.45 & 0.26 \\
\hline QAAPNtoGDP-HP & 0.06 & 60 & 0.31 & 0.96 & 0.75 & 0.41 & 0.54 & 0.24 \\
\hline QEPR-yoy & 0.05 & 60 & 0.22 & 1.00 & 0.76 & 0.43 & 0.56 & 0.22 \\
\hline PCNtoGDP-HP & 0.05 & 85 & 0.28 & 0.68 & 0.42 & 0.21 & 0.49 & 0.29 \\
\hline globM1-HP & 0.04 & 75 & 0.16 & 0.65 & 0.50 & 0.26 & 0.52 & 0.23 \\
\hline QEPNtoGDP-HP & 0.04 & 85 & 0.17 & 0.71 & 0.39 & 0.19 & 0.48 & 0.24 \\
\hline DCR-yoy & 0.04 & 75 & 0.38 & 0.60 & 0.33 & 0.16 & 0.48 & 0.27 \\
\hline DCR-cum & 0.04 & 75 & 0.37 & 0.57 & 0.34 & 0.17 & 0.49 & 0.25 \\
\hline shock-PC & 0.04 & 70 & 0.40 & 0.59 & 0.30 & 0.14 & 0.47 & 0.26 \\
\hline shock-GlobalM1 & 0.03 & 80 & 0.32 & 0.54 & 0.23 & 0.11 & 0.45 & 0.27 \\
\hline shock-M1 & 0.03 & 70 & 0.20 & 0.60 & 0.36 & 0.19 & 0.53 & 0.26 \\
\hline QRPR-sa-yoy & 0.03 & 75 & 0.35 & 0.58 & 0.34 & 0.18 & 0.52 & 0.22 \\
\hline QRPR-yoy & 0.03 & 70 & 0.35 & 0.64 & 0.40 & 0.22 & 0.55 & 0.20 \\
\hline QRPN-satoGDP-HP & 0.02 & 80 & 0.28 & 0.54 & 0.34 & 0.19 & 0.55 & 0.25 \\
\hline M1toGDP-HP & 0.02 & 80 & 0.33 & 0.65 & 0.40 & 0.23 & 0.58 & 0.22 \\
\hline QRPNtoGDP-HP & 0.02 & 80 & 0.29 & 0.52 & 0.32 & 0.18 & 0.57 & 0.24 \\
\hline globSR-HP & 0.02 & 35 & 0.33 & 1.00 & 0.98 & 0.63 & 0.64 & 0.21 \\
\hline SRR-detr & 0.01 & 75 & 0.26 & 0.78 & 0.54 & 0.34 & 0.62 & 0.19 \\
\hline shock-GlobalPC & 0.01 & 75 & 0.42 & 0.44 & 0.20 & 0.11 & 0.56 & 0.21 \\
\hline M3toGDP-HP & 0.01 & 95 & 0.30 & 0.24 & 0.13 & 0.06 & 0.51 & 0.13 \\
\hline LRN-HP & 0.01 & 85 & 0.41 & 0.41 & 0.28 & 0.17 & 0.60 & 0.18 \\
\hline globM3-detr & 0.01 & 80 & 0.16 & 0.59 & 0.51 & 0.32 & 0.63 & 0.20 \\
\hline QRPR-cum & 0.01 & 75 & 0.38 & 0.50 & 0.28 & 0.18 & 0.63 & 0.19 \\
\hline QRPR-sa-cum & 0.01 & 65 & 0.36 & 0.63 & 0.42 & 0.27 & 0.64 & 0.18 \\
\hline PCNtoGDP-detr & 0.01 & 95 & 0.43 & 0.38 & 0.21 & 0.13 & 0.62 & 0.22 \\
\hline REX-HP & 0.00 & 80 & 0.20 & 0.67 & 0.32 & 0.20 & 0.64 & 0.19 \\
\hline LRR-HP & 0.00 & 85 & 0.30 & 0.29 & 0.15 & 0.10 & 0.64 & 0.16 \\
\hline shock-GlobalM3 & 0.00 & 90 & 0.56 & 0.00 & 0.00 & 0.00 & & \\
\hline SRR-lev & 0.00 & 95 & 0.26 & 0.00 & 0.00 & 0.00 & & 0.00 \\
\hline REX-cum & 0.00 & 95 & 0.25 & 0.18 & 0.07 & 0.05 & 0.69 & 0.25 \\
\hline REX-yoy & 0.00 & 95 & 0.31 & 0.19 & 0.06 & 0.05 & 0.79 & 0.16 \\
\hline SRR-HP & 0.00 & 95 & 0.23 & 0.04 & 0.02 & 0.02 & 1.15 & 0.08 \\
\hline shock-M3 & 0.00 & 95 & 0.40 & 0.05 & 0.02 & 0.02 & 1.11 & 0.20 \\
\hline LRR-detr & 0.00 & 95 & 0.29 & 0.29 & 0.11 & 0.08 & 0.74 & 0.16 \\
\hline LRR-lev & -0.01 & 95 & 0.36 & 0.00 & 0.00 & 0.01 & & 0.00 \\
\hline REX-detr & -0.01 & 95 & 0.45 & 0.26 & 0.11 & 0.09 & 0.76 & 0.18 \\
\hline CPI-yoy & -0.01 & 95 & 0.39 & 0.00 & 0.00 & 0.01 & & 0.00 \\
\hline CPI-cum & -0.01 & 95 & 0.31 & 0.00 & 0.00 & 0.01 & & 0.00 \\
\hline spread-lev & -0.01 & 70 & 0.34 & 0.66 & 0.34 & 0.25 & 0.72 & 0.23 \\
\hline globM3-HP & -0.01 & 95 & 0.38 & 0.11 & 0.02 & 0.03 & 1.82 & 0.10 \\
\hline CONStoGDP-detr & -0.01 & 95 & 0.09 & 0.11 & 0.05 & 0.06 & 1.09 & 0.12 \\
\hline globSR-detr & -0.01 & 95 & 0.33 & 0.05 & 0.02 & 0.04 & 1.78 & 0.13 \\
\hline SRN-HP & -0.01 & 95 & 0.30 & 0.08 & 0.02 & 0.04 & 1.81 & 0.06 \\
\hline CONStoGDP-HP & -0.02 & 95 & 0.13 & 0.18 & 0.04 & 0.05 & 1.47 & 0.10 \\
\hline M3toGDP-detr & -0.02 & 95 & 0.26 & 0.34 & 0.18 & 0.15 & 0.83 & 0.17 \\
\hline SRN-lev & -0.02 & 95 & 0.31 & 0.36 & 0.19 & 0.16 & 0.83 & 0.23 \\
\hline DCNtoGDP-detr & -0.02 & 90 & 0.48 & 0.33 & 0.24 & 0.19 & 0.80 & 0.18 \\
\hline DCNtoGDP-HP & -0.02 & 85 & 0.33 & 0.44 & 0.23 & 0.19 & 0.81 & 0.15 \\
\hline QRPR-sa-detr & -0.02 & 95 & 0.42 & 0.14 & 0.06 & 0.08 & 1.32 & 0.18 \\
\hline -spread-lev & -0.03 & 95 & 0.28 & 0.03 & 0.00 & 0.05 & 12.29 & 0.02 \\
\hline QRPN-satoGDP-detr & -0.03 & 95 & 0.42 & 0.09 & 0.04 & 0.07 & 1.95 & 0.12 \\
\hline QRPNtoGDP-detr & -0.03 & 95 & 0.45 & 0.09 & 0.04 & 0.07 & 1.98 & 0.12 \\
\hline globSR-lev & -0.03 & 95 & 0.42 & 0.05 & 0.01 & 0.05 & 7.64 & 0.04 \\
\hline LRN-lev & -0.03 & 95 & 0.36 & 0.40 & 0.26 & 0.22 & 0.85 & 0.21 \\
\hline QRPR-detr & -0.03 & 95 & 0.46 & 0.11 & 0.05 & 0.08 & 1.60 & 0.17 \\
\hline
\end{tabular}

Table 4: $\theta=0.4$, average results over all countries (same percentile), High-Cost Booms. 


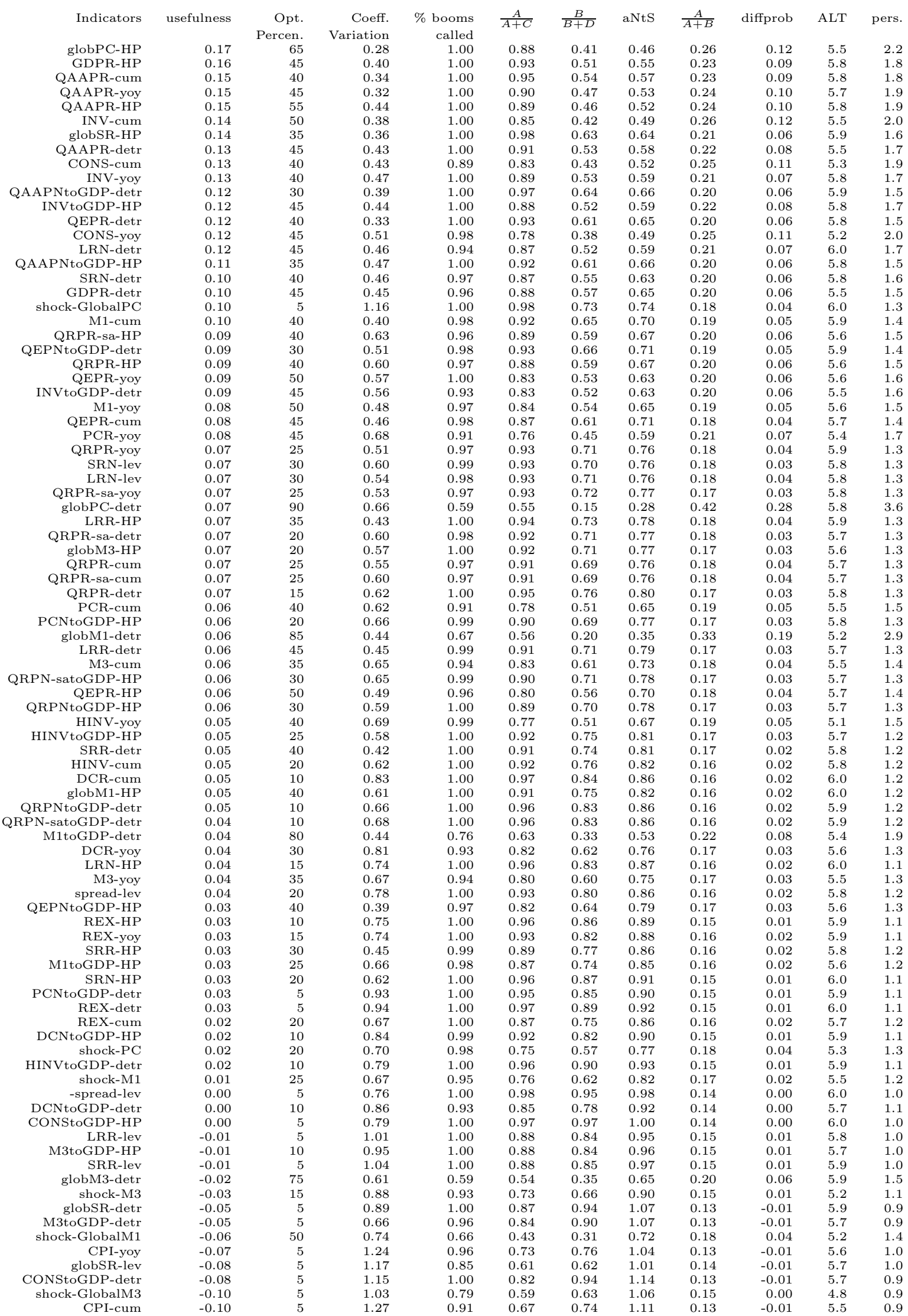

Table 5: $\theta=0.6$, average results over all countries (same percentile), High-Cost Booms. 


\begin{tabular}{|c|c|c|c|c|c|c|c|c|}
\hline Indicators & usefulness & $\begin{array}{r}\text { Opt. } \\
\text { Percen. }\end{array}$ & $\begin{array}{r}\text { Coeff. } \\
\text { Variation }\end{array}$ & $\begin{array}{r}\% \text { booms } \\
\text { called }\end{array}$ & $\frac{A}{A+C}$ & $\frac{B}{B+D}$ & aNtS & $\frac{A}{A+B}$ \\
\hline globPC-detr & 0.02 & 95 & 0.02 & 0.63 & 0.48 & 0.10 & 0.20 & 0.59 \\
\hline LRN-detr & 0.01 & 90 & 0.04 & 0.64 & 0.48 & 0.10 & 0.21 & 0.50 \\
\hline HINV-yoy & 0.01 & 90 & 0.08 & 0.30 & 0.13 & 0.02 & 0.12 & 0.29 \\
\hline SRN-detr & 0.01 & 90 & 0.14 & 0.44 & 0.29 & 0.06 & 0.21 & 0.33 \\
\hline HINV-cum & 0.01 & 95 & 0.09 & 0.09 & 0.06 & 0.01 & 0.09 & 0.21 \\
\hline INV-yoy & 0.00 & 95 & 0.06 & 0.36 & 0.11 & 0.02 & 0.20 & 0.33 \\
\hline globPC-HP & 0.00 & 95 & 0.04 & 0.22 & 0.08 & 0.02 & 0.19 & 0.51 \\
\hline CONS-cum & 0.00 & 95 & 0.09 & 0.06 & 0.03 & 0.00 & 0.13 & 0.19 \\
\hline SRR-lev & 0.00 & 85 & 0.19 & 0.10 & 0.02 & 0.00 & 0.18 & 0.30 \\
\hline CPI-yoy & 0.00 & 95 & 0.15 & 0.00 & 0.00 & 0.00 & & 0.00 \\
\hline shock-GlobalM3 & 0.00 & 90 & 0.06 & 0.00 & 0.00 & 0.00 & & 0.00 \\
\hline CPI-cum & 0.00 & 95 & 0.17 & 0.00 & 0.00 & 0.00 & & 0.00 \\
\hline PCR-yoy & 0.00 & 95 & 0.18 & 0.13 & 0.05 & 0.01 & 0.26 & 0.25 \\
\hline shock-GlobalPC & 0.00 & 95 & 0.11 & 0.27 & 0.07 & 0.02 & 0.27 & 0.29 \\
\hline HINVtoGDP-HP & 0.00 & 95 & 0.12 & 0.05 & 0.02 & 0.01 & 0.36 & 0.07 \\
\hline globM1-detr & 0.00 & 95 & 0.04 & 0.46 & 0.31 & 0.08 & 0.26 & 0.43 \\
\hline HINVtoGDP-detr & 0.00 & 95 & 0.06 & 0.18 & 0.08 & 0.02 & 0.31 & 0.23 \\
\hline CONS-yoy & 0.00 & 95 & 0.14 & 0.06 & 0.03 & 0.01 & 0.40 & 0.19 \\
\hline LRR-HP & -0.01 & 85 & 0.05 & 0.51 & 0.30 & 0.08 & 0.27 & 0.33 \\
\hline SRR-HP & -0.01 & 95 & 0.08 & 0.01 & 0.00 & 0.01 & 1.74 & 0.01 \\
\hline shock-PC & -0.01 & 95 & 0.21 & 0.02 & 0.01 & 0.01 & 0.89 & 0.02 \\
\hline PCR-cum & -0.01 & 95 & 0.15 & 0.11 & 0.04 & 0.02 & 0.45 & 0.18 \\
\hline QEPR-detr & -0.01 & 95 & 0.04 & 0.75 & 0.56 & 0.15 & 0.27 & 0.38 \\
\hline shock-GlobalM1 & -0.01 & 95 & 0.03 & 0.08 & 0.03 & 0.02 & 0.54 & 0.20 \\
\hline LRN-HP & -0.01 & 95 & 0.04 & 0.39 & 0.19 & 0.06 & 0.30 & 0.22 \\
\hline shock-M1 & -0.01 & 95 & 0.13 & 0.17 & 0.03 & 0.02 & 0.62 & 0.34 \\
\hline spread-lev & -0.01 & 95 & 0.15 & 0.06 & 0.02 & 0.02 & 0.69 & 0.08 \\
\hline shock-M3 & -0.01 & 95 & 0.11 & 0.02 & 0.01 & 0.01 & 1.79 & 0.19 \\
\hline INV-cum & -0.01 & 95 & 0.07 & 0.41 & 0.10 & 0.04 & 0.37 & 0.28 \\
\hline INVtoGDP-detr & -0.01 & 95 & 0.02 & 0.18 & 0.12 & 0.04 & 0.36 & 0.33 \\
\hline globM1-HP & -0.01 & 95 & 0.04 & 0.10 & 0.04 & 0.02 & 0.67 & 0.20 \\
\hline -spread-lev & -0.01 & 95 & 0.02 & 0.01 & 0.00 & 0.02 & 12.81 & 0.00 \\
\hline M3-yoy & -0.01 & 95 & 0.11 & 0.05 & 0.02 & 0.02 & 1.09 & 0.05 \\
\hline M1-cum & -0.01 & 95 & 0.12 & 0.19 & 0.09 & 0.04 & 0.42 & 0.18 \\
\hline M3-cum & -0.01 & 95 & 0.11 & 0.05 & 0.02 & 0.02 & 0.98 & 0.04 \\
\hline QEPR-yoy & -0.01 & 95 & 0.02 & 0.53 & 0.22 & 0.07 & 0.33 & 0.32 \\
\hline QEPR-cum & -0.01 & 95 & 0.03 & 0.59 & 0.26 & 0.08 & 0.32 & 0.34 \\
\hline globSR-HP & -0.01 & 90 & 0.06 & 0.06 & 0.02 & 0.02 & 1.40 & 0.19 \\
\hline QEPNtoGDP-detr & -0.01 & 95 & 0.00 & 0.66 & 0.52 & 0.15 & 0.29 & 0.36 \\
\hline DCR-cum & -0.02 & 95 & 0.26 & 0.02 & 0.01 & 0.02 & 1.83 & 0.02 \\
\hline CONStoGDP-HP & -0.02 & 95 & 0.08 & 0.12 & 0.03 & 0.03 & 0.99 & 0.09 \\
\hline SRN-HP & -0.02 & 95 & 0.08 & 0.01 & 0.00 & 0.02 & 5.59 & 0.01 \\
\hline REX-HP & -0.02 & 95 & 0.04 & 0.24 & 0.05 & 0.03 & 0.71 & 0.27 \\
\hline LRR-lev & -0.02 & 95 & 0.11 & 0.00 & 0.00 & 0.03 & & 0.00 \\
\hline globM3-HP & -0.02 & 95 & 0.03 & 0.17 & 0.03 & 0.03 & 1.19 & 0.17 \\
\hline INVtoGDP-HP & -0.02 & 95 & 0.10 & 0.01 & 0.00 & 0.03 & 5.54 & 0.04 \\
\hline CONStoGDP-detr & -0.02 & 95 & 0.08 & 0.06 & 0.02 & 0.03 & 1.38 & 0.19 \\
\hline DCR-yoy & -0.02 & 95 & 0.14 & 0.02 & 0.01 & 0.03 & 2.95 & 0.02 \\
\hline REX-cum & -0.02 & 95 & 0.05 & 0.09 & 0.04 & 0.04 & 0.91 & 0.11 \\
\hline globSR-detr & -0.02 & 95 & 0.14 & 0.06 & 0.02 & 0.03 & 1.40 & 0.19 \\
\hline QRPNtoGDP-HP & -0.03 & 95 & 0.06 & 0.00 & 0.00 & 0.03 & & 0.00 \\
\hline QRPR-sa-HP & -0.03 & 95 & 0.04 & 0.00 & 0.00 & 0.03 & & 0.00 \\
\hline M1-yoy & -0.03 & 95 & 0.12 & 0.18 & 0.08 & 0.06 & 0.65 & 0.15 \\
\hline QRPN-satoGDP-HP & -0.03 & 95 & 0.06 & 0.00 & 0.00 & 0.04 & & 0.00 \\
\hline REX-yoy & -0.03 & 95 & 0.02 & 0.06 & 0.02 & 0.04 & 1.81 & 0.06 \\
\hline GDPR-detr & -0.03 & 95 & 0.06 & 0.50 & 0.21 & 0.09 & 0.43 & 0.32 \\
\hline QRPR-HP & -0.03 & 95 & 0.06 & 0.06 & 0.02 & 0.05 & 1.98 & 0.09 \\
\hline M1toGDP-HP & -0.03 & 95 & 0.04 & 0.07 & 0.01 & 0.04 & 5.06 & 0.07 \\
\hline M1toGDP-detr & -0.04 & 95 & 0.05 & 0.67 & 0.32 & 0.12 & 0.39 & 0.31 \\
\hline QEPNtoGDP-HP & -0.04 & 95 & 0.02 & 0.35 & 0.13 & 0.08 & 0.60 & 0.16 \\
\hline QRPR-yoy & -0.04 & 95 & 0.05 & 0.00 & 0.00 & 0.05 & & 0.00 \\
\hline QRPR-sa-yoy & -0.04 & 95 & 0.04 & 0.00 & 0.00 & 0.05 & & 0.00 \\
\hline QEPR-HP & -0.04 & 95 & 0.02 & 0.40 & 0.20 & 0.10 & 0.49 & 0.23 \\
\hline globSR-lev & -0.04 & 95 & 0.04 & 0.06 & 0.01 & 0.05 & 6.34 & 0.06 \\
\hline SRR-detr & -0.04 & 95 & 0.06 & 0.30 & 0.10 & 0.07 & 0.72 & 0.14 \\
\hline M3toGDP-HP & -0.04 & 95 & 0.02 & 0.36 & 0.09 & 0.07 & 0.79 & 0.12 \\
\hline REX-detr & -0.04 & 95 & 0.04 & 0.25 & 0.11 & 0.08 & 0.70 & 0.20 \\
\hline QRPR-cum & -0.04 & 95 & 0.04 & 0.00 & 0.00 & 0.05 & & 0.00 \\
\hline QRPR-sa-cum & -0.04 & 95 & 0.04 & 0.00 & 0.00 & 0.05 & & 0.00 \\
\hline QAAPR-cum & -0.04 & 95 & 0.06 & 0.36 & 0.13 & 0.09 & 0.64 & 0.24 \\
\hline GDPR-HP & -0.05 & 95 & 0.08 & 0.16 & 0.03 & 0.07 & 1.99 & 0.02 \\
\hline globM3-detr & -0.05 & 95 & 0.09 & 0.08 & 0.03 & 0.07 & 2.36 & 0.05 \\
\hline PCNtoGDP-HP & -0.05 & 95 & 0.05 & 0.17 & 0.07 & 0.08 & 1.20 & 0.11 \\
\hline QAAPR-yoy & -0.05 & 90 & 0.07 & 0.65 & 0.23 & 0.13 & 0.54 & 0.29 \\
\hline QAAPR-HP & -0.06 & 90 & 0.13 & 0.52 & 0.20 & 0.12 & 0.61 & 0.28 \\
\hline QAAPNtoGDP-HP & -0.06 & 95 & 0.13 & 0.09 & 0.03 & 0.08 & 2.92 & 0.05 \\
\hline LRR-detr & -0.07 & 95 & 0.02 & 0.27 & 0.09 & 0.10 & 1.16 & 0.14 \\
\hline QAAPR-detr & -0.07 & 95 & 0.03 & 0.26 & 0.12 & 0.12 & 0.99 & 0.21 \\
\hline QAAPNtoGDP-detr & -0.07 & 95 & 0.11 & 0.23 & 0.08 & 0.11 & 1.35 & 0.18 \\
\hline QRPR-detr & -0.07 & 95 & 0.00 & 0.05 & 0.02 & 0.10 & 5.37 & 0.15 \\
\hline QRPR-sa-detr & -0.07 & 95 & 0.02 & 0.05 & 0.02 & 0.10 & 5.39 & 0.15 \\
\hline QRPN-satoGDP-detr & -0.08 & 95 & 0.02 & 0.00 & 0.00 & 0.10 & & 0.00 \\
\hline QRPNtoGDP-detr & -0.08 & 95 & 0.02 & 0.00 & 0.00 & 0.10 & & 0.00 \\
\hline PCNtoGDP-detr & -0.09 & 95 & 0.06 & 0.32 & 0.23 & 0.16 & 0.72 & 0.20 \\
\hline DCNtoGDP-HP & -0.09 & 95 & 0.06 & 0.02 & 0.01 & 0.11 & 10.12 & 0.02 \\
\hline M3toGDP-detr & -0.09 & 95 & 0.02 & 0.25 & 0.09 & 0.13 & 1.47 & 0.10 \\
\hline SRN-lev & $\begin{array}{l}-0.09 \\
-0.09\end{array}$ & 95 & 0.04 & 0.46 & 0.21 & 0.17 & 0.79 & 0.31 \\
\hline LRN-lev & -0.13 & 95 & 0.12 & 0.31 & 0.25 & 0.22 & 0.88 & 0.24 \\
\hline DCNtoGDP-detr & -0.13 & 95 & 0.23 & 0.13 & 0.05 & 0.18 & 3.27 & 0.05 \\
\hline
\end{tabular}

Table 6: $\theta=0.2$, weighted-average results over EA countries (same percentile), High-Cost Booms. 


\begin{tabular}{|c|c|c|c|c|c|c|c|c|}
\hline Indicators & usefulness & $\begin{array}{r}\text { Opt. } \\
\text { Percen. }\end{array}$ & $\begin{array}{r}\text { Coeff. } \\
\text { Variation }\end{array}$ & $\begin{array}{r}\% \text { booms } \\
\text { called }\end{array}$ & $\frac{A}{A+C}$ & $\frac{B}{B+D}$ & aNtS & $\frac{A}{A+B}$ \\
\hline globPC-detr & 0.17 & 90 & 0.38 & 0.63 & 0.63 & 0.14 & 0.23 & 0.51 \\
\hline globPC-HP & 0.14 & 70 & 0.12 & 0.94 & 0.85 & 0.34 & 0.39 & 0.31 \\
\hline QEPR-detr & 0.14 & 90 & 0.22 & 0.82 & 0.69 & 0.23 & 0.33 & 0.34 \\
\hline M1toGDP-detr & 0.14 & 85 & 0.31 & 0.84 & 0.73 & 0.26 & 0.35 & 0.32 \\
\hline LRN-detr & 0.13 & 90 & 0.25 & 0.64 & 0.48 & 0.10 & 0.21 & 0.50 \\
\hline globM1-detr & 0.12 & 85 & 0.06 & 0.74 & 0.61 & 0.20 & 0.33 & 0.35 \\
\hline QEPNtoGDP-detr & 0.12 & 95 & 0.24 & 0.66 & 0.52 & 0.15 & 0.29 & 0.36 \\
\hline INV-yoy & 0.12 & 70 & 0.17 & 1.00 & 0.61 & 0.21 & 0.35 & 0.33 \\
\hline M1-cum & 0.11 & 65 & 0.24 & 0.92 & 0.80 & 0.35 & 0.44 & 0.28 \\
\hline INV-cum & 0.10 & 70 & 0.21 & 0.99 & 0.57 & 0.21 & 0.36 & 0.32 \\
\hline QAAPR-HP & 0.10 & 60 & 0.20 & 1.00 & 0.78 & 0.35 & 0.45 & 0.28 \\
\hline INVtoGDP-HP & 0.10 & 60 & 0.18 & 1.00 & 0.80 & 0.37 & 0.46 & 0.30 \\
\hline QEPR-yoy & 0.10 & 70 & 0.20 & 0.99 & 0.77 & 0.35 & 0.46 & 0.27 \\
\hline SRN-detr & 0.09 & 80 & 0.27 & 0.56 & 0.48 & 0.16 & 0.34 & 0.28 \\
\hline QEPR-cum & 0.09 & 80 & 0.20 & 0.77 & 0.63 & 0.27 & 0.43 & 0.28 \\
\hline QAAPR-yoy & 0.09 & 45 & 0.27 & 1.00 & 0.84 & 0.41 & 0.49 & 0.27 \\
\hline M1-yoy & 0.09 & 65 & 0.16 & 0.87 & 0.72 & 0.33 & 0.46 & 0.28 \\
\hline HINV-yoy & 0.09 & 75 & 0.10 & 0.61 & 0.39 & 0.12 & 0.30 & 0.33 \\
\hline QAAPNtoGDP-HP & 0.08 & 70 & 0.40 & 0.95 & 0.66 & 0.30 & 0.46 & 0.28 \\
\hline CONS-cum & 0.08 & 55 & 0.27 & 0.73 & 0.46 & 0.18 & 0.39 & 0.30 \\
\hline CONS-yoy & 0.07 & 55 & 0.21 & 0.90 & 0.51 & 0.21 & 0.42 & 0.27 \\
\hline QAAPR-cum & 0.07 & 50 & 0.29 & 1.00 & 0.77 & 0.39 & 0.51 & 0.27 \\
\hline LRR-HP & 0.07 & 85 & 0.29 & 0.51 & 0.30 & 0.08 & 0.27 & 0.33 \\
\hline HINV-cum & 0.06 & 80 & 0.10 & 0.58 & 0.28 & 0.08 & 0.28 & 0.34 \\
\hline GDPR-HP & 0.06 & 55 & 0.31 & 1.00 & 0.80 & 0.43 & 0.54 & 0.25 \\
\hline LRN-HP & 0.06 & 90 & 0.26 & 0.42 & 0.36 & 0.14 & 0.39 & 0.19 \\
\hline QEPR-HP & 0.05 & 80 & 0.17 & 0.78 & 0.57 & 0.29 & 0.51 & 0.25 \\
\hline shock-GlobalPC & 0.04 & 70 & 0.48 & 0.65 & 0.31 & 0.14 & 0.45 & 0.27 \\
\hline shock-M1 & 0.04 & 70 & 0.26 & 0.58 & 0.36 & 0.18 & 0.50 & 0.34 \\
\hline GDPR-detr & 0.04 & 85 & 0.12 & 0.57 & 0.38 & 0.20 & 0.51 & 0.31 \\
\hline globSR-HP & 0.03 & 40 & 0.27 & 1.00 & 0.93 & 0.57 & 0.61 & 0.24 \\
\hline PCR-yoy & 0.03 & 70 & 0.33 & 0.49 & 0.32 & 0.15 & 0.49 & 0.30 \\
\hline SRR-detr & 0.03 & 85 & 0.28 & 0.72 & 0.34 & 0.17 & 0.51 & 0.26 \\
\hline QEPNtoGDP-HP & 0.03 & 80 & 0.19 & 0.77 & 0.50 & 0.28 & 0.56 & 0.24 \\
\hline REX-HP & 0.03 & 90 & 0.16 & 0.47 & 0.21 & 0.09 & 0.42 & 0.26 \\
\hline PCR-cum & 0.03 & 60 & 0.25 & 0.68 & 0.49 & 0.27 & 0.56 & 0.26 \\
\hline globM1-HP & 0.03 & 75 & 0.13 & 0.69 & 0.51 & 0.29 & 0.57 & 0.22 \\
\hline M1toGDP-HP & 0.03 & 65 & 0.26 & 0.91 & 0.71 & 0.43 & 0.61 & 0.22 \\
\hline HINVtoGDP-HP & 0.02 & 80 & 0.16 & 0.46 & 0.18 & 0.08 & 0.45 & 0.26 \\
\hline INVtoGDP-detr & 0.02 & 95 & 0.16 & 0.18 & 0.12 & 0.04 & 0.36 & 0.33 \\
\hline spread-lev & 0.02 & 65 & 0.33 & 0.92 & 0.47 & 0.28 & 0.59 & 0.25 \\
\hline QRPR-HP & 0.02 & 60 & 0.19 & 0.80 & 0.58 & 0.35 & 0.61 & 0.20 \\
\hline QAAPNtoGDP-detr & 0.02 & 70 & 0.29 & 0.81 & 0.57 & 0.35 & 0.61 & 0.20 \\
\hline globM3-detr & 0.02 & 75 & 0.10 & 0.63 & 0.55 & 0.33 & 0.61 & 0.22 \\
\hline HINVtoGDP-detr & 0.02 & 95 & 0.06 & 0.18 & 0.08 & 0.02 & 0.31 & 0.23 \\
\hline QRPR-sa-HP & 0.01 & 60 & 0.24 & 0.75 & 0.56 & 0.35 & 0.62 & 0.18 \\
\hline shock-PC & 0.01 & 65 & 0.41 & 0.33 & 0.21 & 0.12 & 0.58 & 0.24 \\
\hline SRR-lev & 0.01 & 85 & 0.26 & 0.10 & 0.02 & 0.00 & 0.18 & 0.30 \\
\hline PCNtoGDP-HP & 0.01 & 85 & 0.39 & 0.64 & 0.35 & 0.22 & 0.64 & 0.24 \\
\hline SRN-HP & 0.01 & 75 & 0.26 & 0.39 & 0.27 & 0.17 & 0.64 & 0.12 \\
\hline shock-GlobalM1 & 0.00 & 95 & 0.24 & 0.08 & 0.03 & 0.02 & 0.54 & 0.20 \\
\hline DCR-yoy & 0.00 & 40 & 0.42 & 0.94 & 0.71 & 0.47 & 0.66 & 0.21 \\
\hline REX-detr & 0.00 & 90 & 0.47 & 0.44 & 0.18 & 0.12 & 0.65 & 0.29 \\
\hline QAAPR-detr & 0.00 & 35 & 0.46 & 1.00 & 0.83 & 0.55 & 0.66 & 0.22 \\
\hline CPI-cum & 0.00 & 90 & 0.36 & 0.06 & 0.02 & 0.01 & 0.53 & 0.19 \\
\hline M3-cum & 0.00 & 35 & 0.36 & 0.95 & 0.84 & 0.56 & 0.66 & 0.21 \\
\hline CONStoGDP-detr & 0.00 & 90 & 0.12 & 0.34 & 0.13 & 0.08 & 0.65 & 0.28 \\
\hline CPI-yoy & 0.00 & 90 & 0.55 & 0.06 & 0.02 & 0.01 & 0.62 & 0.19 \\
\hline shock-GlobalM3 & 0.00 & 90 & 0.69 & 0.00 & 0.00 & 0.00 & & 0.00 \\
\hline REX-yoy & 0.00 & 90 & 0.34 & 0.31 & 0.10 & 0.07 & 0.69 & 0.22 \\
\hline globM3-HP & 0.00 & 90 & 0.38 & 0.22 & 0.12 & 0.08 & 0.69 & 0.26 \\
\hline CONStoGDP-HP & 0.00 & 90 & 0.12 & 0.33 & 0.06 & 0.04 & 0.73 & 0.23 \\
\hline M3-yoy & 0.00 & 90 & 0.31 & 0.11 & 0.05 & 0.04 & 0.76 & 0.10 \\
\hline SRR-HP & 0.00 & 95 & 0.27 & 0.01 & 0.00 & 0.01 & 1.74 & 0.01 \\
\hline REX-cum & 0.00 & 80 & 0.19 & 0.46 & 0.23 & 0.16 & 0.69 & 0.18 \\
\hline shock-M3 & -0.01 & 95 & 0.26 & 0.02 & 0.01 & 0.01 & 1.79 & 0.19 \\
\hline M3toGDP-HP & -0.01 & 95 & 0.34 & 0.36 & 0.09 & 0.07 & 0.79 & 0.12 \\
\hline PCNtoGDP-detr & -0.01 & 95 & 0.30 & 0.32 & 0.23 & 0.16 & 0.72 & 0.20 \\
\hline DCR-cum & -0.01 & 95 & 0.40 & 0.02 & 0.01 & 0.02 & 1.83 & 0.02 \\
\hline -spread-lev & -0.01 & 95 & 0.16 & 0.01 & 0.00 & 0.02 & 12.81 & 0.00 \\
\hline globSR-detr & -0.01 & 95 & 0.37 & 0.06 & 0.02 & 0.03 & 1.40 & 0.19 \\
\hline QRPNtoGDP-HP & -0.01 & 80 & 0.36 & 0.47 & 0.22 & 0.17 & 0.78 & 0.18 \\
\hline LRR-lev & -0.02 & 95 & 0.41 & 0.00 & 0.00 & 0.03 & & 0.00 \\
\hline SRN-lev & -0.02 & 95 & 0.30 & 0.46 & 0.21 & 0.17 & 0.79 & 0.31 \\
\hline QRPN-satoGDP-HP & -0.02 & 80 & 0.32 & 0.47 & 0.22 & 0.18 & 0.81 & 0.16 \\
\hline LRR-detr & -0.03 & 95 & 0.24 & 0.27 & 0.09 & 0.10 & 1.16 & 0.14 \\
\hline globSR-lev & -0.03 & 95 & 0.57 & 0.06 & 0.01 & 0.05 & 6.34 & 0.06 \\
\hline QRPR-yoy & -0.03 & 95 & 0.36 & 0.00 & 0.00 & 0.05 & & 0.00 \\
\hline QRPR-sa-yoy & -0.03 & 95 & 0.36 & 0.00 & 0.00 & 0.05 & & 0.00 \\
\hline QRPR-cum & -0.03 & 95 & 0.39 & 0.00 & 0.00 & 0.05 & & 0.00 \\
\hline QRPR-sa-cum & -0.03 & 95 & 0.33 & 0.00 & 0.00 & 0.05 & & 0.00 \\
\hline LRN-lev & -0.03 & 95 & 0.41 & 0.31 & 0.25 & 0.22 & 0.88 & 0.24 \\
\hline DCNtoGDP-detr & -0.03 & 40 & 0.39 & 0.82 & 0.72 & 0.54 & 0.74 & 0.19 \\
\hline DCNtoGDP-HP & -0.04 & 85 & 0.40 & 0.36 & 0.17 & 0.17 & 1.02 & 0.11 \\
\hline M3toGDP-detr & -0.04 & 95 & 0.35 & 0.25 & 0.09 & 0.13 & 1.47 & 0.10 \\
\hline QRPR-detr & -0.05 & 95 & 0.52 & 0.05 & 0.02 & 0.10 & 5.37 & 0.15 \\
\hline QRPR-sa-detr & -0.05 & 95 & 0.44 & 0.05 & 0.02 & 0.10 & 5.39 & 0.15 \\
\hline QRPN-satoGDP-detr & -0.06 & 95 & 0.38 & 0.00 & 0.00 & 0.10 & & 0.00 \\
\hline QRPNtoGDP-detr & -0.06 & 95 & 0.40 & 0.00 & 0.00 & 0.10 & & 0.00 \\
\hline
\end{tabular}

Table 7: $\theta=0.4$, weighted-average results over EA countries (same percentile), High-Cost Booms. 


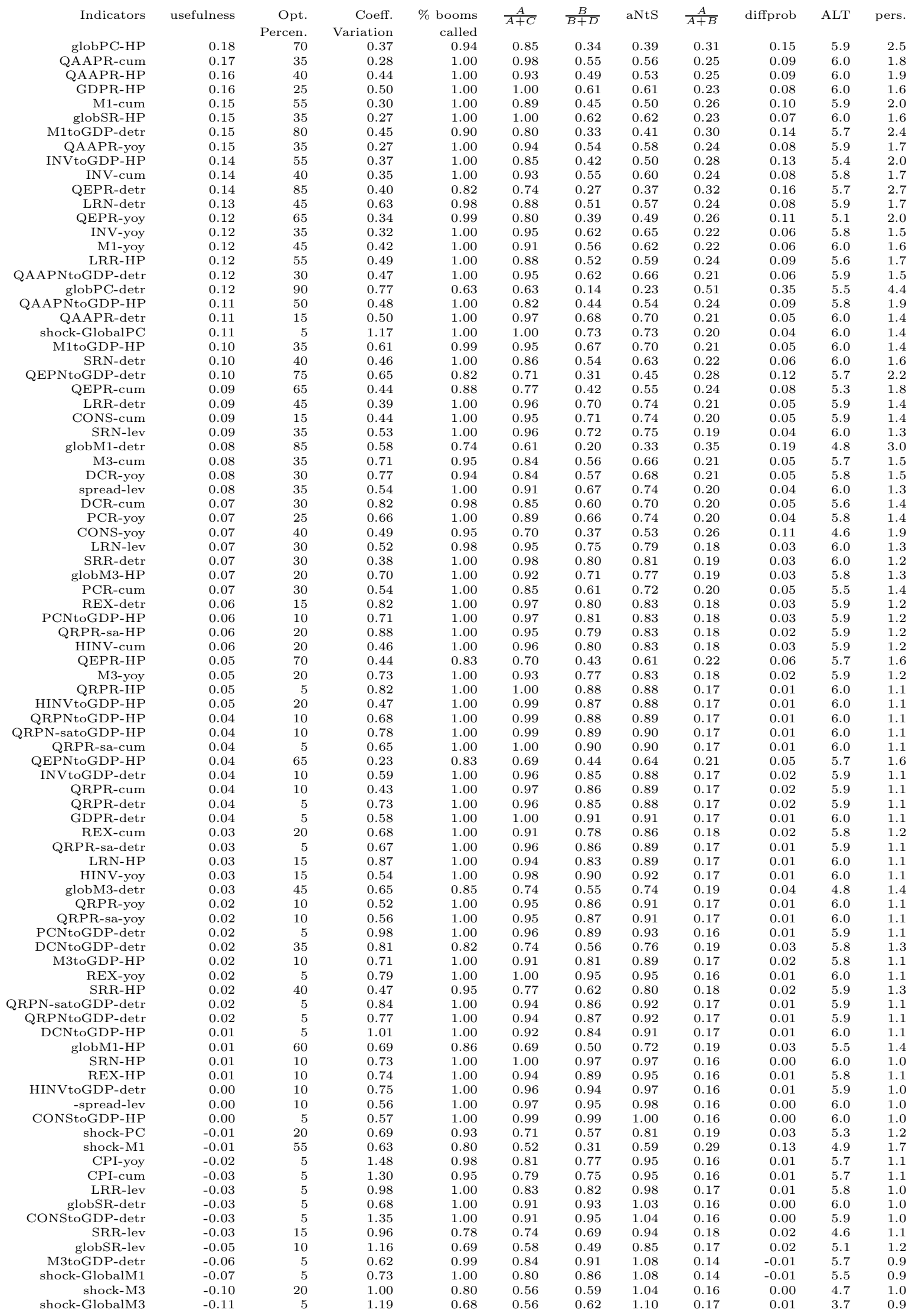

Table 8: $\theta=0.6$, weighted-average results over EA countries (same percentile), High-Cost Booms. 


\begin{tabular}{|c|c|c|c|c|c|c|c|c|}
\hline Indicators & usefulness & $\begin{array}{r}\% \text { booms } \\
\text { called }\end{array}$ & $\frac{A}{A+C}$ & $\frac{B}{B+D}$ & aNtS & $\frac{A}{A+B}$ & diffprob & ALT \\
\hline QAAPNtoGDP-HP & 0.22 & 0.98 & 0.83 & 0.18 & 0.22 & 0.41 & 0.29 & 5.4 \\
\hline QAAPR-HP & 0.21 & 1.00 & 0.91 & 0.26 & 0.28 & 0.37 & 0.26 & 5.8 \\
\hline QAAPR-yoy & 0.17 & 1.00 & 0.83 & 0.26 & 0.32 & 0.30 & 0.18 & 5.1 \\
\hline QAAPR-detr & 0.16 & 0.98 & 0.84 & 0.29 & 0.35 & 0.34 & 0.23 & 5.2 \\
\hline QAAPR-cum & 0.16 & 0.98 & 0.87 & 0.31 & 0.36 & 0.32 & 0.20 & 5.4 \\
\hline QRPR-sa-HP & 0.15 & 1.00 & 0.88 & 0.34 & 0.38 & 0.25 & 0.14 & 6.0 \\
\hline QRPN-satoGDP-HP & 0.15 & 0.75 & 0.63 & 0.18 & 0.28 & 0.27 & 0.15 & 5.9 \\
\hline QRPR-HP & 0.14 & 1.00 & 0.95 & 0.40 & 0.42 & 0.24 & 0.13 & 6.0 \\
\hline QAAPNtoGDP-detr & 0.14 & 0.83 & 0.78 & 0.28 & 0.36 & 0.38 & 0.26 & 4.7 \\
\hline QRPNtoGDP-HP & 0.14 & 0.75 & 0.62 & 0.18 & 0.28 & 0.40 & 0.30 & 5.8 \\
\hline QEPR-detr & 0.13 & 0.98 & 0.84 & 0.34 & 0.40 & 0.28 & 0.17 & 5.2 \\
\hline QRPR-yoy & 0.13 & 0.88 & 0.76 & 0.29 & 0.38 & 0.30 & 0.18 & 5.9 \\
\hline QRPR-sa-cum & 0.13 & 0.88 & 0.79 & 0.31 & 0.39 & 0.27 & 0.15 & 6.0 \\
\hline QRPR-sa-yoy & 0.13 & 1.00 & 0.87 & 0.36 & 0.42 & 0.28 & 0.17 & 5.8 \\
\hline INVtoGDP-HP & 0.13 & 0.96 & 0.80 & 0.32 & 0.40 & 0.34 & 0.23 & 5.9 \\
\hline LRR-lev & 0.13 & 0.63 & 0.59 & 0.18 & 0.31 & 0.27 & 0.17 & 5.8 \\
\hline QEPR-HP & 0.13 & 0.90 & 0.70 & 0.25 & 0.36 & 0.29 & 0.18 & 4.4 \\
\hline globPC-HP & 0.13 & 0.85 & 0.70 & 0.26 & 0.37 & 0.40 & 0.29 & 5.3 \\
\hline LRN-HP & 0.12 & 0.94 & 0.85 & 0.36 & 0.42 & 0.27 & 0.16 & 5.7 \\
\hline QRPR-cum & 0.12 & 0.88 & 0.79 & 0.32 & 0.41 & 0.21 & 0.10 & 6.0 \\
\hline QRPR-sa-detr & 0.12 & 0.88 & 0.85 & 0.36 & 0.43 & 0.23 & 0.12 & 5.9 \\
\hline QRPN-satoGDP-detr & 0.12 & 0.88 & 0.88 & 0.38 & 0.43 & 0.22 & 0.11 & 6.0 \\
\hline QRPR-detr & 0.12 & 0.88 & 0.78 & 0.32 & 0.42 & 0.23 & 0.12 & 5.7 \\
\hline QEPNtoGDP-HP & 0.12 & 0.90 & 0.61 & 0.21 & 0.35 & 0.39 & 0.28 & 3.9 \\
\hline shock-GlobalPC & 0.11 & 0.73 & 0.66 & 0.25 & 0.38 & 0.30 & 0.19 & 6.0 \\
\hline SRR-lev & 0.11 & 0.50 & 0.46 & 0.13 & 0.27 & 0.29 & 0.17 & 5.9 \\
\hline INV-cum & 0.11 & 0.83 & 0.68 & 0.27 & 0.40 & 0.23 & 0.12 & 6.0 \\
\hline QRPNtoGDP-detr & 0.11 & 0.88 & 0.84 & 0.38 & 0.46 & 0.22 & 0.10 & 6.0 \\
\hline globSR-detr & 0.10 & 0.63 & 0.59 & 0.22 & 0.38 & 0.16 & 0.05 & 6.0 \\
\hline globSR-lev & 0.10 & 0.38 & 0.42 & 0.11 & 0.26 & 0.22 & 0.11 & 6.0 \\
\hline QEPR-yoy & 0.10 & 0.94 & 0.70 & 0.29 & 0.42 & 0.31 & 0.19 & 4.6 \\
\hline CPI-cum & 0.10 & 0.50 & 0.49 & 0.16 & 0.33 & 0.33 & 0.21 & 6.0 \\
\hline globM3-HP & 0.10 & 0.63 & 0.47 & 0.15 & 0.33 & 0.20 & 0.09 & 5.4 \\
\hline SRN-lev & 0.10 & 0.63 & 0.54 & 0.20 & 0.37 & 0.30 & 0.18 & 5.7 \\
\hline QEPNtoGDP-detr & 0.09 & 0.85 & 0.80 & 0.37 & 0.47 & 0.21 & 0.10 & 5.2 \\
\hline GDPR-HP & 0.09 & 0.88 & 0.69 & 0.30 & 0.44 & 0.25 & 0.13 & 5.3 \\
\hline shock-GlobalM3 & 0.09 & 0.50 & 0.39 & 0.10 & 0.26 & 0.33 & 0.22 & 5.8 \\
\hline CPI-yoy & 0.09 & 0.38 & 0.32 & 0.07 & 0.20 & 0.36 & 0.23 & 6.0 \\
\hline PCNtoGDP-HP & 0.09 & 0.75 & 0.67 & 0.30 & 0.45 & 0.24 & 0.13 & 5.9 \\
\hline PCR-yoy & 0.08 & 0.63 & 0.49 & 0.20 & 0.40 & 0.22 & 0.12 & 4.8 \\
\hline INVtoGDP-detr & 0.08 & 1.00 & 0.93 & 0.49 & 0.52 & 0.22 & 0.10 & 5.9 \\
\hline INV-yoy & 0.08 & 0.83 & 0.54 & 0.23 & 0.42 & 0.27 & 0.16 & 5.1 \\
\hline QEPR-cum & 0.08 & 0.83 & 0.66 & 0.31 & 0.47 & 0.22 & 0.11 & 4.2 \\
\hline HINVtoGDP-detr & 0.07 & 1.00 & 0.82 & 0.42 & 0.52 & 0.25 & 0.14 & 5.8 \\
\hline LRN-lev & 0.07 & 0.58 & 0.50 & 0.21 & 0.43 & 0.21 & 0.10 & 5.6 \\
\hline M1toGDP-HP & 0.07 & 0.92 & 0.70 & 0.35 & 0.50 & 0.22 & 0.10 & 5.2 \\
\hline GDPR-detr & 0.07 & 0.88 & 0.83 & 0.44 & 0.53 & 0.19 & 0.08 & 6.0 \\
\hline LRR-HP & 0.07 & 0.52 & 0.34 & 0.12 & 0.35 & 0.25 & 0.14 & 5.0 \\
\hline globSR-HP & 0.07 & 0.75 & 0.64 & 0.31 & 0.49 & 0.18 & 0.06 & 5.7 \\
\hline DCNtoGDP-HP & 0.07 & 0.63 & 0.57 & 0.27 & 0.48 & 0.23 & 0.11 & 5.6 \\
\hline REX-detr & 0.06 & 0.67 & 0.57 & 0.27 & 0.48 & 0.19 & 0.08 & 6.0 \\
\hline spread-lev & 0.06 & 0.44 & 0.33 & 0.11 & 0.34 & 0.22 & 0.11 & 5.8 \\
\hline CONS-cum & 0.06 & 0.50 & 0.36 & 0.15 & 0.40 & 0.35 & 0.21 & 5.2 \\
\hline shock-M3 & 0.06 & 0.63 & 0.48 & 0.22 & 0.47 & 0.25 & 0.13 & 5.8 \\
\hline CONS-yoy & 0.06 & 0.50 & 0.40 & 0.17 & 0.43 & 0.35 & 0.22 & 5.5 \\
\hline PCR-cum & 0.05 & 0.58 & 0.45 & 0.21 & 0.47 & 0.24 & 0.13 & 4.4 \\
\hline M1-yoy & 0.05 & 0.56 & 0.37 & 0.16 & 0.43 & 0.21 & 0.10 & 5.2 \\
\hline HINVtoGDP-HP & 0.05 & 0.75 & 0.66 & 0.36 & 0.54 & 0.16 & 0.05 & 6.0 \\
\hline globM1-HP & 0.05 & 0.58 & 0.48 & 0.24 & 0.50 & 0.15 & 0.04 & 5.6 \\
\hline LRN-detr & 0.05 & 0.81 & 0.75 & 0.42 & 0.56 & 0.22 & 0.10 & 5.9 \\
\hline REX-cum & 0.04 & 0.58 & 0.44 & 0.22 & 0.50 & 0.16 & 0.05 & 5.3 \\
\hline HINV-cum & 0.04 & 0.75 & 0.50 & 0.27 & 0.53 & 0.16 & 0.05 & 5.9 \\
\hline DCR-yoy & 0.04 & 0.38 & 0.33 & 0.15 & 0.47 & 0.17 & 0.06 & 5.7 \\
\hline shock-PC & 0.04 & 0.46 & 0.24 & 0.10 & 0.41 & 0.30 & 0.19 & 4.7 \\
\hline M1-cum & 0.04 & 0.63 & 0.42 & 0.22 & 0.52 & 0.18 & 0.06 & 5.3 \\
\hline SRN-detr & 0.04 & 0.56 & 0.43 & 0.23 & 0.53 & 0.15 & 0.04 & 4.7 \\
\hline M1toGDP-detr & 0.03 & 0.69 & 0.60 & 0.34 & 0.57 & 0.18 & 0.07 & 5.7 \\
\hline SRR-detr & 0.03 & 0.56 & 0.48 & 0.26 & 0.55 & 0.15 & 0.04 & 5.9 \\
\hline HINV-yoy & 0.03 & 0.71 & 0.55 & 0.31 & 0.57 & 0.15 & 0.04 & 5.5 \\
\hline DCR-cum & 0.03 & 0.38 & 0.33 & 0.17 & 0.52 & 0.15 & 0.03 & 5.3 \\
\hline -spread-lev & 0.03 & 0.42 & 0.33 & 0.17 & 0.53 & 0.14 & 0.04 & 6.0 \\
\hline SRR-HP & 0.03 & 0.44 & 0.27 & 0.14 & 0.51 & 0.12 & 0.00 & 5.8 \\
\hline REX-yoy & 0.02 & 0.48 & 0.26 & 0.14 & 0.52 & 0.14 & 0.03 & 5.8 \\
\hline SRN-HP & 0.02 & 0.38 & 0.20 & 0.10 & 0.50 & 0.11 & 0.00 & 4.3 \\
\hline shock-M1 & 0.02 & 0.38 & 0.25 & 0.13 & 0.54 & 0.13 & 0.01 & 5.6 \\
\hline REX-HP & 0.02 & 0.38 & 0.28 & 0.16 & 0.56 & 0.10 & -0.02 & 5.9 \\
\hline shock-GlobalM1 & 0.02 & 0.38 & 0.25 & 0.14 & 0.55 & 0.10 & 0.00 & 5.2 \\
\hline CONStoGDP-detr & 0.02 & 0.50 & 0.39 & 0.23 & 0.59 & 0.09 & -0.02 & 5.8 \\
\hline globM3-detr & 0.01 & 0.25 & 0.25 & 0.14 & 0.57 & 0.06 & -0.06 & 6.0 \\
\hline M3-уоу & 0.01 & 0.48 & 0.31 & 0.20 & 0.62 & 0.11 & 0.00 & 4.1 \\
\hline CONStoGDP-HP & 0.00 & 0.38 & 0.27 & 0.17 & 0.64 & 0.06 & -0.05 & 5.7 \\
\hline M3-cum & 0.00 & 0.25 & 0.16 & 0.10 & 0.65 & 0.06 & -0.04 & 4.5 \\
\hline DCNtoGDP-detr & 0.00 & 0.44 & 0.41 & 0.27 & 0.66 & 0.11 & 0.00 & 6.0 \\
\hline PCNtoGDP-detr & 0.00 & 0.44 & 0.43 & 0.29 & 0.67 & 0.13 & 0.02 & 5.9 \\
\hline globPC-detr & -0.02 & 0.94 & 0.89 & 0.62 & 0.70 & 0.17 & 0.06 & 5.8 \\
\hline LRR-detr & -0.02 & 0.75 & 0.52 & 0.38 & 0.73 & 0.12 & 0.00 & 5.4 \\
\hline M3toGDP-HP & -0.04 & 0.63 & 0.42 & 0.34 & 0.81 & 0.11 & -0.01 & 4.5 \\
\hline globM1-detr & -0.04 & 0.40 & 0.20 & 0.19 & 1.00 & 0.14 & 0.03 & 3.6 \\
\hline M3toGDP-detr & -0.05 & 0.23 & 0.20 & 0.21 & 1.10 & 0.07 & -0.04 & 4.2 \\
\hline
\end{tabular}

Table 9: $\theta=0.4$, average results over all countries, Low-Cost Booms. 


\begin{tabular}{|c|c|c|c|c|c|c|c|c|}
\hline Indicators & usefulness & $\begin{array}{r}\% \text { booms } \\
\text { called }\end{array}$ & $\frac{A}{A+C}$ & $\frac{B}{B+D}$ & aNtS & $\frac{A}{A+B}$ & diffprob & ALT \\
\hline QAAPNtoGDP-HP & 0.27 & 1.00 & 0.90 & 0.14 & 0.16 & 0.50 & 0.37 & 6.0 \\
\hline QAAPR-yoy & 0.26 & 1.00 & 1.00 & 0.23 & 0.23 & 0.41 & 0.28 & 6.0 \\
\hline QAAPR-HP & 0.25 & 1.00 & 0.80 & 0.11 & 0.14 & 0.60 & 0.47 & 6.0 \\
\hline LRR-lev & 0.23 & 1.00 & 0.96 & 0.25 & 0.26 & 0.36 & 0.23 & 5.9 \\
\hline globSR-detr & 0.23 & 1.00 & 0.98 & 0.27 & 0.28 & 0.36 & 0.23 & 6.0 \\
\hline QEPNtoGDP-HP & 0.22 & 1.00 & 0.93 & 0.25 & 0.27 & 0.38 & 0.25 & 6.0 \\
\hline QAAPR-cum & 0.21 & 1.00 & 0.93 & 0.27 & 0.29 & 0.34 & 0.21 & 6.0 \\
\hline SRR-lev & 0.21 & 0.93 & 0.78 & 0.17 & 0.22 & 0.38 & 0.26 & 5.5 \\
\hline QEPR-HP & 0.20 & 1.00 & 1.00 & 0.33 & 0.33 & 0.32 & 0.18 & 6.0 \\
\hline GDPR-HP & 0.18 & 0.98 & 0.85 & 0.27 & 0.31 & 0.34 & 0.21 & 6.0 \\
\hline shock-GlobalPC & 0.18 & 1.00 & 1.00 & 0.37 & 0.37 & 0.30 & 0.17 & 6.0 \\
\hline M1-yoy & 0.18 & 0.93 & 0.58 & 0.09 & 0.16 & 0.53 & 0.40 & 5.3 \\
\hline M1-cum & 0.17 & 0.93 & 0.60 & 0.11 & 0.19 & 0.53 & 0.40 & 5.3 \\
\hline QEPR-detr & 0.17 & 1.00 & 1.00 & 0.39 & 0.39 & 0.30 & 0.17 & 6.0 \\
\hline QEPR-cum & 0.16 & 1.00 & 0.98 & 0.38 & 0.39 & 0.29 & 0.16 & 6.0 \\
\hline INVtoGDP-HP & 0.16 & 1.00 & 0.93 & 0.35 & 0.38 & 0.28 & 0.15 & 6.0 \\
\hline SRN-lev & 0.16 & 0.93 & 0.65 & 0.17 & 0.25 & 0.41 & 0.28 & 5.5 \\
\hline M1toGDP-detr & 0.15 & 0.93 & 0.60 & 0.14 & 0.24 & 0.38 & 0.25 & 5.3 \\
\hline M1toGDP-HP & 0.15 & 1.00 & 0.64 & 0.17 & 0.27 & 0.41 & 0.28 & 5.6 \\
\hline globPC-HP & 0.15 & 0.93 & 0.45 & 0.05 & 0.11 & 0.82 & 0.69 & 4.0 \\
\hline shock-GlobalM3 & 0.14 & 0.93 & 0.58 & 0.15 & 0.25 & 0.37 & 0.25 & 5.3 \\
\hline QEPR-yoy & 0.14 & 1.00 & 1.00 & 0.43 & 0.43 & 0.26 & 0.13 & 6.0 \\
\hline globSR-HP & 0.14 & 1.00 & 0.82 & 0.32 & 0.39 & 0.28 & 0.15 & 5.9 \\
\hline shock-M3 & 0.13 & 0.86 & 0.66 & 0.22 & 0.33 & 0.28 & 0.16 & 4.4 \\
\hline LRN-lev & 0.13 & 0.93 & 0.65 & 0.22 & 0.33 & 0.32 & 0.19 & 5.5 \\
\hline QRPR-sa-detr & 0.13 & 1.00 & 1.00 & 0.46 & 0.46 & 0.25 & 0.12 & 6.0 \\
\hline QAAPNtoGDP-detr & 0.12 & 0.48 & 0.46 & 0.11 & 0.23 & 0.67 & 0.54 & 2.0 \\
\hline QRPR-detr & 0.12 & 1.00 & 0.95 & 0.43 & 0.46 & 0.25 & 0.12 & 5.9 \\
\hline shock-M1 & 0.11 & 0.79 & 0.39 & 0.07 & 0.18 & 0.39 & 0.27 & 3.9 \\
\hline CONS-yoy & 0.11 & 0.79 & 0.33 & 0.03 & 0.10 & 0.49 & 0.38 & 3.1 \\
\hline QAAPR-detr & 0.11 & 1.00 & 1.00 & 0.48 & 0.48 & 0.24 & 0.11 & 6.0 \\
\hline GDPR-detr & 0.11 & 1.00 & 1.00 & 0.49 & 0.49 & 0.24 & 0.11 & 6.0 \\
\hline QRPR-cum & 0.11 & 1.00 & 0.87 & 0.40 & 0.46 & 0.25 & 0.12 & 6.0 \\
\hline QEPNtoGDP-detr & 0.11 & 1.00 & 0.99 & 0.49 & 0.49 & 0.24 & 0.11 & 6.0 \\
\hline QRPR-sa-cum & 0.10 & 1.00 & 0.87 & 0.42 & 0.48 & 0.26 & 0.13 & 6.0 \\
\hline QRPR-yoy & 0.10 & 1.00 & 0.85 & 0.40 & 0.47 & 0.28 & 0.15 & 6.0 \\
\hline CPI-yoy & 0.09 & 0.07 & 0.33 & 0.07 & 0.20 & 0.37 & 0.25 & 0.4 \\
\hline QRPR-sa-HP & 0.09 & 1.00 & 0.68 & 0.30 & 0.44 & 0.25 & 0.12 & 6.0 \\
\hline QRPR-sa-yoy & 0.09 & 1.00 & 0.85 & 0.41 & 0.49 & 0.27 & 0.14 & 6.0 \\
\hline globSR-lev & 0.09 & 0.07 & 0.33 & 0.07 & 0.22 & 0.37 & 0.24 & 0.4 \\
\hline HINVtoGDP-HP & 0.09 & 0.79 & 0.79 & 0.38 & 0.48 & 0.20 & 0.07 & 4.7 \\
\hline QRPN-satoGDP-HP & 0.09 & 0.86 & 0.60 & 0.25 & 0.42 & 0.23 & 0.11 & 5.1 \\
\hline globM3-HP & 0.08 & 0.79 & 0.33 & 0.08 & 0.25 & 0.33 & 0.20 & 3.1 \\
\hline SRR-detr & 0.08 & 1.00 & 0.79 & 0.39 & 0.50 & 0.24 & 0.11 & 6.0 \\
\hline QRPR-HP & 0.08 & 1.00 & 0.98 & 0.52 & 0.53 & 0.22 & 0.09 & 6.0 \\
\hline INV-yoy & 0.08 & 0.98 & 0.48 & 0.19 & 0.39 & 0.31 & 0.18 & 4.4 \\
\hline CONS-cum & 0.08 & 0.79 & 0.26 & 0.04 & 0.16 & 0.39 & 0.28 & 2.4 \\
\hline INV-cum & 0.08 & 0.98 & 0.95 & 0.51 & 0.53 & 0.22 & 0.09 & 6.0 \\
\hline spread-lev & 0.07 & 0.93 & 0.47 & 0.19 & 0.41 & 0.27 & 0.14 & 5.6 \\
\hline QRPN-satoGDP-detr & 0.07 & 1.00 & 1.00 & 0.55 & 0.55 & 0.22 & 0.09 & 6.0 \\
\hline QRPNtoGDP-HP & 0.07 & 0.86 & 0.73 & 0.37 & 0.50 & 0.21 & 0.09 & 5.1 \\
\hline QRPNtoGDP-detr & 0.06 & 1.00 & 0.97 & 0.54 & 0.56 & 0.22 & 0.09 & 6.0 \\
\hline CPI-cum & 0.06 & 0.07 & 0.33 & 0.12 & 0.35 & 0.28 & 0.16 & 0.4 \\
\hline HINV-cum & 0.05 & 0.86 & 0.62 & 0.33 & 0.54 & 0.20 & 0.07 & 5.1 \\
\hline HINV-yoy & 0.04 & 0.79 & 0.65 & 0.37 & 0.56 & 0.18 & 0.05 & 4.7 \\
\hline LRN-HP & 0.03 & 1.00 & 0.87 & 0.53 & 0.61 & 0.20 & 0.07 & 6.0 \\
\hline HINVtoGDP-detr & 0.03 & 1.00 & 0.61 & 0.36 & 0.60 & 0.21 & 0.08 & 5.7 \\
\hline REX-cum & 0.03 & 0.64 & 0.48 & 0.28 & 0.58 & 0.23 & 0.09 & 2.5 \\
\hline DCNtoGDP-HP & 0.02 & 0.21 & 0.21 & 0.11 & 0.51 & 0.04 & -0.09 & 1.3 \\
\hline PCR-yoy & 0.02 & 0.21 & 0.21 & 0.12 & 0.54 & 0.03 & 0.01 & 1.3 \\
\hline SRR-HP & 0.01 & 0.21 & 0.17 & 0.09 & 0.53 & 0.04 & -0.09 & 1.3 \\
\hline REX-yoy & 0.01 & 0.07 & 0.06 & 0.02 & 0.29 & 0.02 & 0.01 & 0.4 \\
\hline globM1-HP & 0.01 & 0.79 & 0.59 & 0.37 & 0.63 & 0.16 & 0.03 & 4.4 \\
\hline LRR-HP & 0.01 & 0.17 & 0.04 & 0.01 & 0.28 & 0.06 & 0.04 & 0.6 \\
\hline PCR-cum & 0.01 & 0.21 & 0.21 & 0.13 & 0.61 & 0.03 & 0.01 & 1.3 \\
\hline REX-detr & 0.01 & 0.12 & 0.09 & 0.05 & 0.56 & 0.03 & 0.01 & 1.3 \\
\hline DCR-cum & 0.00 & 0.07 & 0.07 & 0.04 & 0.59 & 0.01 & 0.00 & 0.4 \\
\hline DCR-yoy & 0.00 & 0.07 & 0.07 & 0.04 & 0.61 & 0.01 & 0.00 & 0.4 \\
\hline REX-HP & 0.00 & 0.07 & 0.05 & 0.03 & 0.60 & 0.03 & -0.10 & 0.4 \\
\hline SRN-HP & 0.00 & 0.14 & 0.07 & 0.05 & 0.66 & 0.02 & 0.00 & 0.9 \\
\hline shock-PC & 0.00 & 0.00 & 0.00 & 0.00 & & 0.00 & -0.01 & 0.0 \\
\hline M3-cum & 0.00 & 0.07 & 0.05 & 0.04 & 0.75 & 0.01 & -0.01 & 0.4 \\
\hline M3-yoy & 0.00 & 0.21 & 0.11 & 0.08 & 0.74 & 0.03 & 0.01 & 0.7 \\
\hline CONStoGDP-detr & -0.01 & 0.14 & 0.14 & 0.11 & 0.74 & 0.02 & -0.11 & 0.9 \\
\hline CONStoGDP-HP & -0.01 & 0.14 & 0.14 & 0.11 & 0.75 & 0.02 & -0.11 & 0.9 \\
\hline shock-GlobalM1 & -0.01 & 0.07 & 0.23 & 0.18 & 0.76 & 0.15 & 0.02 & 0.4 \\
\hline -spread-lev & -0.01 & 0.07 & 0.07 & 0.07 & 0.97 & 0.01 & -0.12 & 0.4 \\
\hline INVtoGDP-detr & -0.01 & 1.00 & 0.93 & 0.65 & 0.69 & 0.18 & 0.05 & 6.0 \\
\hline SRN-detr & -0.01 & 0.14 & 0.14 & 0.12 & 0.84 & 0.03 & -0.10 & 0.9 \\
\hline DCNtoGDP-detr & -0.03 & 0.21 & 0.21 & 0.19 & 0.88 & 0.03 & -0.10 & 1.3 \\
\hline LRN-detr & -0.04 & 1.00 & 0.87 & 0.64 & 0.73 & 0.17 & 0.04 & 6.0 \\
\hline LRR-detr & -0.04 & 1.00 & 0.72 & 0.54 & 0.75 & 0.16 & 0.03 & 5.6 \\
\hline PCNtoGDP-HP & -0.04 & 0.21 & 0.21 & 0.22 & 1.00 & 0.03 & -0.10 & 1.3 \\
\hline globM3-detr & -0.05 & 0.00 & 0.00 & 0.08 & & 0.00 & -0.13 & 0.0 \\
\hline M3toGDP-HP & -0.07 & 1.00 & 0.47 & 0.44 & 0.93 & 0.14 & 0.01 & 4.0 \\
\hline M3toGDP-detr & -0.08 & 0.07 & 0.07 & 0.17 & 2.41 & 0.01 & -0.12 & 0.4 \\
\hline globM1-detr & -0.08 & 0.00 & 0.00 & 0.13 & & 0.00 & -0.13 & 0.0 \\
\hline globPC-detr & -0.08 & 1.00 & 1.00 & 0.80 & 0.80 & 0.16 & 0.03 & 6.0 \\
\hline PCNtoGDP-detr & -0.10 & 0.21 & 0.21 & 0.31 & 1.44 & 0.03 & -0.10 & 1.3 \\
\hline
\end{tabular}

Table 10: $\theta=0.4$, weighted-average results over EA countries, Low-Cost Booms. 


\section{European Central Bank Working Paper Series}

For a complete list of Working Papers published by the ECB, please visit the ECB's website (http://www.ecb.europa.eu).

973 "Do China and oil exporters influence major currency configurations?" by M. Fratzscher and A. Mehl, December 2008.

974 "Institutional features of wage bargaining in 23 European countries, the US and Japan" by P. Du Caju, E. Gautier, D. Momferatou and M. Ward-Warmedinger, December 2008.

975 "Early estimates of euro area real GDP growth: a bottom up approach from the production side" by E. Hahn and F. Skudelny, December 2008.

976 "The term structure of interest rates across frequencies" by K. Assenmacher-Wesche and S. Gerlach, December 2008.

977 "Predictions of short-term rates and the expectations hypothesis of the term structure of interest rates" by M. Guidolin and D. L. Thornton, December 2008.

978 "Measuring monetary policy expectations from financial market instruments" by M. Joyce, J. Relleen and S. Sorensen, December 2008.

979 "Futures contract rates as monetary policy forecasts" by G. Ferrero and A. Nobili, December 2008.

980 "Extracting market expectations from yield curves augmented by money market interest rates: the case of Japan" by T. Nagano and N. Baba, December 2008.

98। "Why the effective price for money exceeds the policy rate in the ECB tenders?" by T. Välimäki, December 2008.

982 "Modelling short-term interest rate spreads in the euro money market" by N. Cassola and C. Morana, December 2008.

983 "What explains the spread between the euro overnight rate and the ECB's policy rate?" by T. Linzert and S. Schmidt, December 2008.

984 "The daily and policy-relevant liquidity effects" by D. L. Thornton, December 2008.

985 "Portuguese banks in the euro area market for daily funds" by L. Farinha and V. Gaspar, December 2008.

986 "The topology of the federal funds market” by M. L. Bech and E. Atalay, December 2008.

987 "Probability of informed trading on the euro overnight market rate: an update" by J. Idier and S. Nardelli, December 2008.

988 "The interday and intraday patterns of the overnight market: evidence from an electronic platform" by R. Beaupain and A. Durré, December 2008.

989 "Modelling loans to non-financial corporations in the euro area" by C. Kok Sørensen, D. Marqués lbáñez and C. Rossi, January 2009.

990 “Fiscal policy, housing and stock prices” by A. Afonso and R. M. Sousa, January 2009.

991 "The macroeconomic effects of fiscal policy" by A. Afonso and R. M. Sousa, January 2009. 
992 "FDI and productivity convergence in central and eastern Europe: an industry-level investigation" by M. Bijsterbosch and M. Kolasa, January 2009.

993 "Has emerging Asia decoupled? An analysis of production and trade linkages using the Asian international input-output table" by G. Pula and T. A. Peltonen, January 2009.

994 "Fiscal sustainability and policy implications for the euro area" by F. Balassone, J. Cunha, G. Langenus, B. Manzke, J. Pavot, D. Prammer and P. Tommasino, January 2009.

995 "Current account benchmarks for central and eastern Europe: a desperate search?" by M. Ca' Zorzi, A. Chudik and A. Dieppe, January 2009.

996 "What drives euro area break-even inflation rates?" by M. Ciccarelli and J. A. García, January 2009.

997 "Financing obstacles and growth: an analysis for euro area non-financial corporations" by C. Coluzzi, A. Ferrando and C. Martinez-Carrascal, January 2009.

998 “Infinite-dimensional VARs and factor models" by A. Chudik and M. H. Pesaran, January 2009.

999 “Risk-adjusted forecasts of oil prices" by P. Pagano and M. Pisani, January 2009.

1000 "Wealth effects in emerging market economies" by T. A. Peltonen, R. M. Sousa and I. S. Vansteenkiste, January 2009.

100I "Identifying the elasticity of substitution with biased technical change" by M. A. León-Ledesma, P. Mc Adam and A. Willman, January 2009.

1002 "Assessing portfolio credit risk changes in a sample of EU large and complex banking groups in reaction to macroeconomic shocks" by O. Castrén, T. Fitzpatrick and M. Sydow, February 2009.

1003 "Real wages over the business cycle: OECD evidence from the time and frequency domains" by J. Messina, C. Strozzi and J. Turunen, February 2009.

1004 "Characterising the inflation targeting regime in South Korea" by M. Sánchez, February 2009.

1005 "Labor market institutions and macroeconomic volatility in a panel of OECD countries" by F. Rumler and J. Scharler, February 2009.

1006 "Understanding sectoral differences in downward real wage rigidity: workforce composition, institutions, technology and competition" by P. Du Caju, C. Fuss and L. Wintr, February 2009.

1007 "Sequential bargaining in a new-Keynesian model with frictional unemployment and staggered wage negotiation" by G. de Walque, O. Pierrard, H. Sneessens and R. Wouters, February 2009.

1008 “Liquidity (risk) concepts: definitions and interactions" by K. Nikolaou, February 2009.

1009 "Optimal sticky prices under rational inattention” by B. Maćkowiak and M. Wiederholt, February 2009.

1010 "Business cycles in the euro area" by D. Giannone, M. Lenza and L. Reichlin, February 2009.

101I "The global dimension of inflation - evidence from factor-augmented Phillips curves" by S. Eickmeier and K. Moll, February 2009.

1012 "Petrodollars and imports of oil exporting countries" by R. Beck and A. Kamps, February 2009. 
1013 "Structural breaks, cointegration and the Fisher effect" by A. Beyer, A. A. Haug and B. Dewald, February 2009.

1014 “Asset prices and current account fluctuations in G7 economies” by M. Fratzscher and R. Straub, February 2009.

1015 "Inflation forecasting in the new EU Member States" by O. Arratibel, C. Kamps and N. Leiner-Killinger, February 2009.

1016 “When does lumpy factor adjustment matter for aggregate dynamics?" by S. Fahr and F. Yao, March 2009.

1017 “Optimal prediction pools” by J. Geweke and G. Amisano, March 2009.

1018 "Cross-border mergers and acquisitions: financial and institutional forces" by N. Coeurdacier, R. A. De Santis and A. Aviat, March 2009.

1019 "What drives returns to euro area housing? Evidence from a dynamic dividend-discount model" by P. Hiebert and M. Sydow, March 2009.

1020 "Opting out of the Great Inflation: German monetary policy after the break down of Bretton Woods" by A. Beyer, V. Gaspar, C. Gerberding and O. Issing, March 2009.

102I "Rigid labour compensation and flexible employment? Firm-level evidence with regard to productivity for Belgium" by C. Fuss and L. Wintr, March 2009.

1022 "Understanding inter-industry wage structures in the euro area” by V. Genre, K. Kohn and D. Momferatou, March 2009.

1023 “Bank loan announcements and borrower stock returns: does bank origin matter?" by S. Ongena and V. Roscovan, March 2009.

1024 "Funding liquidity risk: definition and measurement" by M. Drehmann and K. Nikolaou, March 2009.

1025 "Liquidity risk premia in unsecured interbank money markets" by J. Eisenschmidt and J. Tapking, March 2009.

1026 "Do house price developments spill over across euro area countries? Evidence from a global VAR" by I. Vansteenkiste and P. Hiebert, March 2009.

1027 “Long run evidence on money growth and inflation” by L. Benati, March 2009.

1028 "Large debt financing: syndicated loans versus corporate bonds" by Y. Altunbaș, A. Kara and D. Marqués- Ibáñez, March 2009.

1029 "The role of fiscal transfers for regional economic convergence in Europe" by C. Checherita, C. Nickel and P. Rother, March 2009.

1030 "Forecast evaluation of small nested model sets" by K. Hubrich and K. D. West, March 2009.

I03I "Global roles of currencies" by C. Thimann, March 2009.

1032 “Assessing long-term fiscal developments: a new approach” by A. Afonso, L. Agnello, D. Furceri and R. Sousa, March 2009.

1033 "Fiscal competition over taxes and public inputs: theory and evidence" by S. Hauptmeier, F. Mittermaier and J. Rincke, March 2009. 
1034 "The role of the United States in the global economy and its evolution over time" by S. Dées and A. Saint- Guilhem, March 2009.

1035 "The role of labor markets for euro area monetary policy" by K. Christoffel, K. Kuester and T. Linzert, March 2009.

1036 "Search in the product market and the real business cycle" by T. Y. Mathä and O. Pierrard, March 2009.

1037 "What do asset prices have to say about risk appetite and uncertainty?" by G. Bekaert, M. Hoerova and M. Scheicher, March 2009.

1038 “Are 'intrinsic inflation persistence' models structural in the sense of Lucas (1976)?” by L. Benati, March 2009.

1039 “'Real Time' early warning indicators for costly asset price boom/bust cycles: a role for global liquidity” by L. Alessi and C. Detken, March 2009. 
